\title{
Fluoride-responsive debond on demand adhesives: manipulating polymer crystallinity and hydrogen bonding to optimise adhesion strength at low bonding temperatures
}

Article

Accepted Version

Creative Commons: Attribution-Noncommercial-No Derivative Works 4.0

Babra, T. S., Wood, M., Godleman, J. S., Salimi, S., Warriner, C., Bazin, N., Siviour, C. R., Hamley, I. W., Hayes, W. and Greenland, B. W. (2019) Fluoride-responsive debond on demand adhesives: manipulating polymer crystallinity and hydrogen bonding to optimise adhesion strength at low bonding temperatures. European Polymer Journal, 119. pp. 260-271. ISSN 0014-3057 doi:

https://doi.org/10.1016/j.eurpolymj.2019.07.038 Available at https://centaur.reading.ac.uk/85532/

It is advisable to refer to the publisher's version if you intend to cite from the work. See Guidance on citing.

To link to this article DOI: http://dx.doi.org/10.1016/j.eurpolymj.2019.07.038

Publisher: Elsevier

All outputs in CentAUR are protected by Intellectual Property Rights law, 
including copyright law. Copyright and IPR is retained by the creators or other copyright holders. Terms and conditions for use of this material are defined in the End User Agreement.

\section{www.reading.ac.uk/centaur}

\section{CentAUR}

Central Archive at the University of Reading

Reading's research outputs online 


\title{
Fluoride-Responsive Debond on Demand Adhesives: Manipulating Polymer Crystallinity and Hydrogen Bonding to Optimise Adhesion Strength at Low Bonding Temperatures
}

Tahkur S. Babra, ${ }^{a}$ Matthew Wood, ${ }^{\mathrm{b}}$ Jessica S. Godleman, ${ }^{\mathrm{c}}$ Sara Salimi, ${ }^{\mathrm{c}}$ Colin Warriner, ${ }^{\mathrm{b}}$ Nicholas Bazin, ${ }^{\mathrm{b}}$ Clive R. Siviour, ${ }^{\mathrm{d}}$ Ian. W. Hamley, ${ }^{\mathrm{c}}$ Wayne Hayes ${ }^{\mathrm{c}}$ and Barnaby W. Greenland $^{\mathrm{e}^{*}}$

aDepartment of Pharmacy, University of Reading, Whiteknights, Reading, RG6 6AD (UK). ${ }^{\mathrm{b}}$ AWE Plc, Aldermaston, Reading, Berkshire, RG7 4PR (UK).

'Department of Chemistry, University of Reading, Whiteknights, Reading, RG6 6AD (UK). ${ }^{\mathrm{d}}$ Department of Engineering Science, University of Oxford, Parks Road, Oxford, OX1 3PJ (UK).

eDepartment of Chemistry, University of Sussex, Falmer, BN1 9QJ, UK.

*Email: b.w.greenland@sussex.ac.uk

\begin{abstract}
This paper reports the solvent-free synthesis of a series of six fluoride responsive debond-ondemand polyurethane (PU) adhesives that contain a silyl functionalised degradable unit (DU). To optimise the adhesion strength and debonding nature of the adhesives, the chemical composition of the PUs was varied according to the structure of the polyol or the diisocyanate component in the polymer mainchain. ${ }^{1} \mathrm{H}$ NMR spectroscopy was used to study the depolymerisation behaviour in solution state. It showed that tetra-butylammonium fluoride (TBAF) triggered the breakdown of the DU unit without fragmenting the polyol mainchain indiscriminately. On exposure to fluoride ions, the PUs underwent depolymerisation with reductions in $\mathrm{M}_{\mathrm{n}}$ ranging from $64-90 \%$ as measured by GPC analysis. The morphology and thermal properties of the PUs were characterised by differential scanning calorimetry (DSC), rheology and variable temperature (VT) SAXS/WAXS analysis. Each technique demonstrated the reversibility of the supramolecular polymer network under thermal stimuli. PUs containing poly(butadiene) soft segments were amorphous with glass transition and viscoelastic transition temperatures dependent on the nature of the soft segment and diisocyanate starting materials. The PU containing a polyester soft segment exhibited a defined melting point at $49{ }^{\circ} \mathrm{C}$. Mechanical stress-strain analysis of the series of PUs showed each exhibited greater than $70 \%$ reduction in toughness after treatment with TBAF for 30 minutes as a consequence of the
\end{abstract}


chemo-responsive degradation of the polymer mainchain. The material featuring an ester-based polyol demonstrated excellent adhesion at bonding temperatures as low as $60{ }^{\circ} \mathrm{C}$. Moreover, this material could be thermally rebonded if broken by force without loss in adhesion strength over three debond-rebond cycles. Lap shear adhesion tests showed a reduction in adhesive strength of approximately $40 \%$ (from $11.4 \mathrm{MPa}$ to $7.3 \mathrm{MPa}$ ) on exposure to fluoride ions.

\section{Introduction}

The adhesives, sealants and coatings market has grown significantly in recent decades. [1] The drive to produce novel adhesives is to reduce production costs, increase performance and broaden the range of applications for which they can be used in. The chemical structure of the adhesive is integral to the application: for example, polyurethane (PU) hot melt adhesives [28] offer strength and flexibility whereas hydrogels [9-13] can give moderate adhesion in aqueous environments. Cross-linked adhesives such as epoxy resins [6,14-20] can provide extremely strong bonds, but can be brittle, and their typical two-component composition increases fabrication complexity.

Recently, research into stimuli-responsive adhesives has received significant attention. [2124] These adhesives allow for the substrates to debond on application of a suitable external stimulus, and can enable multiple bonding and debonding cycles without loss of strength. [25] The drive for the optimisation of this class of adhesives is the increased focus on the whole lifecycle of a product. During the fabrication stage, adhesives can replace traditional assembly methods such as riveting or welding resulting in reduced manufacturing costs without loss of structural integrity of the desired product. For example, the adhesive Loctite EA 9514 exhibits stronger adhesion to aluminium than welding and thus avoids thermal damage to the aluminium components. In addition, at the end of a product's usable lifetime, efficient disassembly of a multi-component product (such as a laptop, mobile phone or vehicle) during disposal, can facilitate easy access to valuable materials, resulting in cost and efficiency savings during the recycling processes.

Stimuli-responsive adhesives, and stimuli-responsive materials can exhibit a controlled temporary loss in toughness and/or adhesion strength. This has been demonstrated in various scenarios, for example, in supramolecular materials [26] or polymers containing dynamic covalent bonds. [27] Progress in bottom-up material design has facilitated the emergence of new technologies $[28,29]$ across a broad range of disciplines including biomedical applications, 
[30-33] sensors, [34] healable [35] and damage sensing materials [36] as well as improving product recyclability. [31,37,38]

Within the field of reversible debond-on-demand adhesive materials, dynamic covalent systems have received the most attention. These systems can convert from a high to a low strength material when exposed to an external stimulus. Notable examples of such systems include polymers that contain disulfide residues that break and re-form through formation of radicals upon exposure to high intensity UV radiation; [35] Diels-Alder adducts such as those derived from furan and maleimide precursors which are responsive to high temperatures (110 $\left.{ }^{\circ} \mathrm{C}\right)[25]$ and aliphatic azo-containing polymers which weaken as a consequence of reversible cis/trans isomerisation when exposed to heat or high intensity UV light. [39,40]

Recently, supramolecular non-covalent interactions that combine to form reversible networks have been employed in stimuli responsive adhesives. [41] Thermo-responsive supramolecular adhesives utilising hydrogen bonding [28,42-47] have been demonstrated, in addition to those that harness metal/ligand interactions which were responsive to both light and heat. [28]

An additional functionality that can be built into supramolecular, debondable adhesives is the ability to undergo a permanent reduction in tensile modulus/adhesion strength. This can be achieved by a stimulus induced depolymerisation of the polymer backbone [48], which results in an irreversible reduction in molecular weight. This was recently demonstrated by Phillips and co-workers who designed an adhesive that degrades on contact with fluoride ions. [49] However, the cross-linked nature of this material meant that it could not be solvent cast or melt processed, deficiencies that could result in a loss of general utility. Our group has explored the use of fluoride ions to degrade a linear polyurethane adhesive. [48] This non-covalently crosslinked system exhibited the standard thermo-responsive debond on demand feature of a supramolecular hot-melt adhesive but with the added advantage of undergoing depolymerisation on demand resulting in permanent loss of adhesive properties (Scheme 1). 


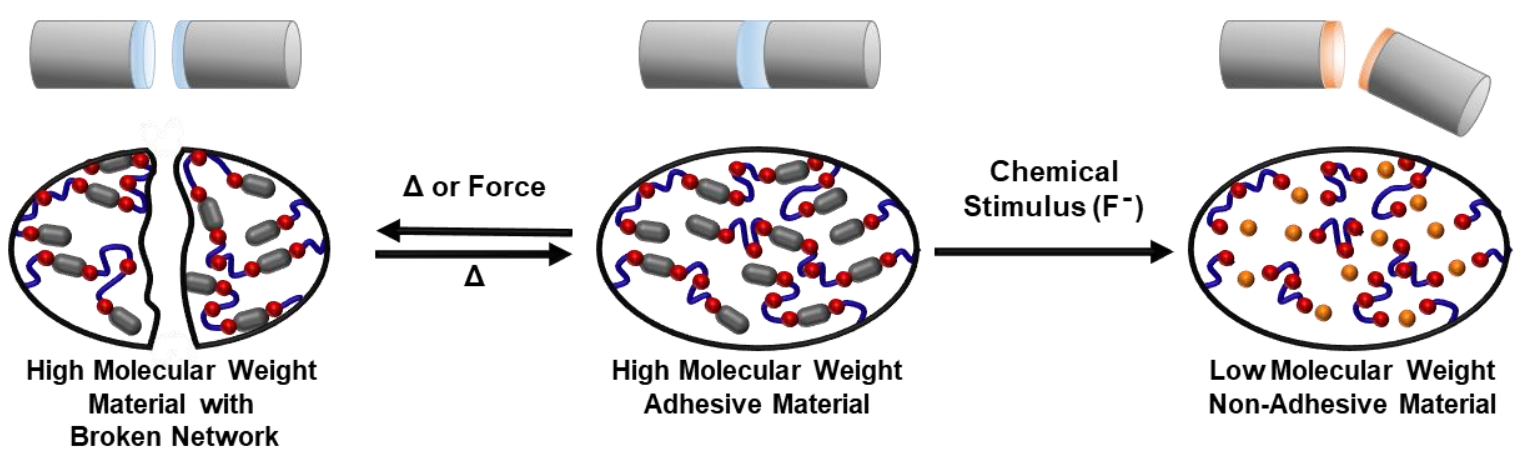

\begin{tabular}{|cccc|}
$\begin{array}{c}\text { Depolymerisable } \\
\text { Unit (DU) }\end{array}$ & $\begin{array}{c}\text { Soft Oligomer } \\
\text { Chains }\end{array}$ & $\begin{array}{c}\text { Urethane } \\
\text { Linker }\end{array}$ & $\begin{array}{c}\text { Triggered } \\
\text { DU }\end{array}$ \\
\hline
\end{tabular}

Scheme 1. Schematic showing the non-reversible depolymerisation of the polymer in response to fluoride ions (right) and the rebondable nature of the adhesive in response to elevated temperatures.

Structurally, this fluoride degradable adhesive is a phase separated polyurethane (PU). [50-53] It contained hydrogenated poly(butadiene) polyol (Krasol HLBH-P2000, 1) soft segments and hard segments containing an aromatic isocyanate linker (4,4'methylene diphenyl diisocyanate (MDI), and a fluoride degradable depolymerisation unit (Scheme 2). This initial composition resulted in a relatively high temperature to achieve maximum adhesion $\left(160{ }^{\circ} \mathrm{C}\right)$ which would be a disadvantage when bonding temperature sensitive components. Adhesion could be achieved at lower temperatures, but with much lower adhesive strength. Therefore, we sought to study the structural parameters that would facilitate a reduction in adhesion temperature without compromising adhesive performance or the ability of the material to debond on demand in response to the addition of a fluoride source.

Herein, we present the synthesis and evaluation of focused library of structurally related PU materials containing the fluoride responsive DU. Firstly, structurally distinct diisocyanates were incorporated into the PU backbone to influence phase separation between the soft and hard domains. [54-58] Secondly, the polyol component was varied with the aim of either reducing the hard-content composition or to introduce crystallinity into the adhesive structure. It was envisaged that, in common with related healable structures [35,59-62] the melting point of the crystalline regions may facilitate a dramatic reduction in tensile properties, [54] viscosity [63] and adhesion at temperatures above the melting point of the crystalline segments. $[64,65]$

\section{Experimental Section}

\subsection{Materials}

Krasol HLBH-P2000 and Krasol HLBH-P3000 was kindly supplied by Cray Valley. Stepanpol PC-205-P 30 was kindly supplied by Alfa Chemicals. 2,6-Bis(hydroxymethyl)-p-cresol, tert- 
butyldimethylsilyl chloride and imidazole were purchased from Alfa Aesar and used as received. All other chemicals were purchased from Sigma-Aldrich and used as received.

\subsection{Synthesis}

Synthesis of Degradable Unit:

The degradable unit (7) was synthesised as previously reported. [48]

Polymer synthesis:

The general procedure below was used to synthesise the polymers:

The polyol (15 mmol) was dried in a vacuum oven at $100{ }^{\circ} \mathrm{C}$ under 100 mbar vacuum for 1 hour. The diisocyanate (2.0 equivalents) was added to the polyol (12 mmol, 1.0 equivalent) and stirred at $80 \mathrm{rpm}$ with an overhead stirrer, at $80{ }^{\circ} \mathrm{C}$ for 3 hours to form an isocyanate terminated prepolymer. The reaction temperature was raised to $105^{\circ} \mathrm{C}$ and the degradable unit (1 equivalent) was added and stirred for 1 hour. The crude polymer was dissolved in chloroform $(200 \mathrm{~mL})$ and precipitated slowly into methanol $(1.8 \mathrm{~L})$. The precipitate was filtered and washed with methanol $(2 \times 200 \mathrm{~mL})$, dried under reduced pressure to afford the adhesive polymer. See the supplementary information (SI) for full characterisation of the polymers produced via this method.

Polymer Film Casting and Sample preparation for mechanical assessment:

Uniform films (between 200 and $500 \mu \mathrm{m}$ thick) suitable for mechanical testing were cast from THF $(0.2 \mathrm{~g} / \mathrm{mL})$ in a PTFE mould $(15 \times 15 \mathrm{~cm})$. The solvent was allowed to evaporate slowly at room temperature overnight, before being placed in a vacuum oven at $50{ }^{\circ} \mathrm{C}(800 \mathrm{mbar})$ for a further 18 hours to remove remaining solvent. DSC analysis showed that solvent was not present in the resultant cast films.

\subsection{Characterisation Techniques}

${ }^{1} \mathrm{H}$ NMR and ${ }^{13} \mathrm{C}$ NMR spectra were recorded on either a Bruker Nanobay 400 or a Bruker DPX 400 spectrometer operating at $400 \mathrm{MHz}$ for ${ }^{1} \mathrm{H}$ nuclei or $100 \mathrm{MHz}$ for ${ }^{13} \mathrm{C}$ nuclei, respectively. The samples for NMR spectroscopic analysis were prepared in $\mathrm{CDCl}_{3}$, and dissolution was aided with slight heating. The data was processed using MestReNova Version 6.0.2-5475. Chemical shifts $(\delta)$ are reported in ppm relative to tetramethylsilane $(\delta=0.00 \mathrm{ppm})$ and the central signal for $\mathrm{CDCl}_{3}(\delta=77.0 \mathrm{ppm})$ for ${ }^{1} \mathrm{H}$ and ${ }^{13} \mathrm{C}$ NMR spectra, respectively. ${ }^{1} \mathrm{H}$ NMR coupling constants $(J)$ are expressed in Hertz $(\mathrm{Hz})$. Infrared spectroscopic analysis was 
carried out on a PerkinElmer 100 FT-IR spectrometer equipped with a diamond ATR sampling attachment, and samples were analysed in neat form. The infrared spectroscopic data were processed using Microsoft Excel 365. GPC was conducted using an Agilent Technologies 1260 Infinity system equipped with two Agilent PLgel $5 \mu \mathrm{m}$ MIXED-D $300 \times 7.5 \mathrm{~mm}$ columns in series eluting with analytical grade THF $(2 \mathrm{mg} / \mathrm{mL})$ with butylated hydroxytoluene (BHT). Samples were dissolved in the same solvent at $(2 \mathrm{mg} / \mathrm{mL})$ and filtered through a syringe filter $(0.2 \mu \mathrm{m})$. Data were processed using standard Agilent GPC/SEC software in comparison to polystyrene standards.

Differential scanning calorimetric analysis used a TA Instruments DSC Q2000 with samples exposed to three cycles from $200{ }^{\circ} \mathrm{C}$ to $-80{ }^{\circ} \mathrm{C}$ to $200{ }^{\circ} \mathrm{C}$ at $5{ }^{\circ} \mathrm{C} / \mathrm{min}$ unless stated otherwise; with an initial cycle from $20^{\circ} \mathrm{C}$ to $110^{\circ} \mathrm{C}$ to $20^{\circ} \mathrm{C}$ at $10{ }^{\circ} \mathrm{C} / \mathrm{min}$. The typical sample mass was 5-6 mg, and the data was processed using TA Universal Analysis Version 4.7A and Microsoft Excel 365. DSC thermograms are shown from $-60{ }^{\circ} \mathrm{C}$ to $90{ }^{\circ} \mathrm{C}$ as no thermal changes were detected outside these temperatures (see SI, Fig. S17 - S21 for full thermograms). Thermogravimetric analysis employed a TGA Q50 instrument by heating the solid samples (ca. $20 \mathrm{mg}$ ) from ambient temperature to $+300{ }^{\circ} \mathrm{C}$ at a ramp rate of $+10{ }^{\circ} \mathrm{C} \mathrm{min}^{-1}$. Data were processed using TA Universal Analysis Version 4.7A. Rheological measurements were performed using an Anton Paar Physica MCR 301 rheometer with a parallel plate oscillatory shear geometry. For polymer film samples, circular samples of $25 \mathrm{~mm}$ diameter $(0.35 \mathrm{~mm}$ average thickness) were cut from the polymer film using a steel punch cutter. For the polymers that were very viscous liquids rather than peelable films, the materials were cooled to $10{ }^{\circ} \mathrm{C}$, and a small ball of $10 \mathrm{~mm}$ diameter was flattened into a $25 \mathrm{~mm}$ disc. During single frequency temperature sweep, samples were placed into the rheometer and equilibrated at a temperature above the point of polymer flow, and then thermally cycled at a rate of $2{ }^{\circ} \mathrm{C} / \mathrm{min}$, first increasing in temperature, then decreasing. This cycle was repeated twice to assess repeatability and any changes in properties. The frequency of oscillation was set to $5 \mathrm{~Hz}$, and the shear strain amplitude to $0.1 \%$. The data was processed using Microsoft Excel 365 and MATLAB R2017.

SAXS and WAXS analysis was carried out at the Alba Synchrotron on the Non-Crystalline Diffraction Beamline (BL11-NCD). Samples of approximately $8 \mathrm{~mm}$ diameter circles were cut from the film and wrapped in aluminium foil. The sample was placed into a Linkam stage, connected to a liquid nitrogen cooling station. The beamline was equipped with an ADSC Quantum 210r CCD detector (SAXS) and Rayonix LX255-HS detector (WAXS). The data was processed using Microsoft Excel 365 and MATLAB R2017. 
Tensile stress-strain experiments were carried out in accordance with ASTM D638-10 standards using an AML X5-500 single column universal tester, equipped with a $5 \mathrm{kN}$ load cell and wedge grips. Specimens with dimensions of $4.0 \times 0.5 \mathrm{~cm}$ were cut from the film. The samples were analysed at a strain rate of $100 \mathrm{~mm} / \mathrm{min}$.

Lap shear adhesion samples were carried out in accordance with ASTM D1002 standards using an AML X5-500 single column universal tester, equipped with a $5 \mathrm{kN}$ load cell and wedge grips. The aluminium coupons were cleaned for 20 minutes in methyl ethyl ketone and dried overnight in a desiccator. The coupons were then etched using the following procedure: iron (III) sulfate (75 g) was dissolved in deionised water $(500 \mathrm{~mL})$, to which concentrated sulfuric acid $(100 \mathrm{~mL})$ was added slowly while maintaining the temperature below $65^{\circ} \mathrm{C}$. The etching bath was placed in a water bath at $65^{\circ} \mathrm{C}$, and the coupons submerged in the etching solution for 12 minutes. Upon completion, the coupons were washed with deionised water at room temperature, followed by deionised water at $70{ }^{\circ} \mathrm{C}$ and repeating between the two temperatures three times. The coupons were placed in an oven at $70{ }^{\circ} \mathrm{C}$ for 2 hours before being used to create the lap shear samples. Samples were adhered at $140{ }^{\circ} \mathrm{C}$ for 18 hours with a $1 \mathrm{~kg}$ weight used as a compression source. Samples were subjected to a strain rate of $1.0 \mathrm{~mm} / \mathrm{min}$.

Butt tensile adhesion samples were carried in accordance with BS EN 158702009 and carried out on an Instron 5500R Universal Mechanical Testing Machine equipped with a $10 \mathrm{kN}$ load cell and serrated wedge grips for cylinders. Steel cylinders with a $16 \mathrm{~mm}$ diameter were grit blasted with Guyson fumed alumina mesh size 180/220 and cleaned sequentially with compressed air, then acetone before being stored in a desiccator prior to use. The samples were placed in a vice grip with a spacer between each substrate and compressed under a spring tension of $100 \mathrm{~N}$ before being placed in an oven at specific temperatures for 18 hours. Samples were subject to a strain rate of $1.3 \mathrm{~mm} / \mathrm{min}$.

\section{Results}

\subsection{Synthesis and Characterisation}

A focussed library of potential adhesives were synthesised (Scheme 2) to provide a structure/property analysis which would enable a rational improvement in the thermal and mechanical properties PU 8 that we have reported previously. [48] Two series of polymers were produced: Series $1(\mathbf{8}, 9$ and 10) which contained varying diisocyanate linkers and Series $2(8,11$ and 12) which contained different polyols. The polymers were synthesised by a onepot, two step solvent-free method in excellent isolated yield $(<88 \%)$. [48] Briefly, a pre- 
polymer was prepared from the polyol and diisocyanate linker, prior to the addition of the degradable unit 7. The polyols and diisocyanate linkers used are detailed in Scheme 2 and the constituents of each PU adhesive are detailed in Table 1.
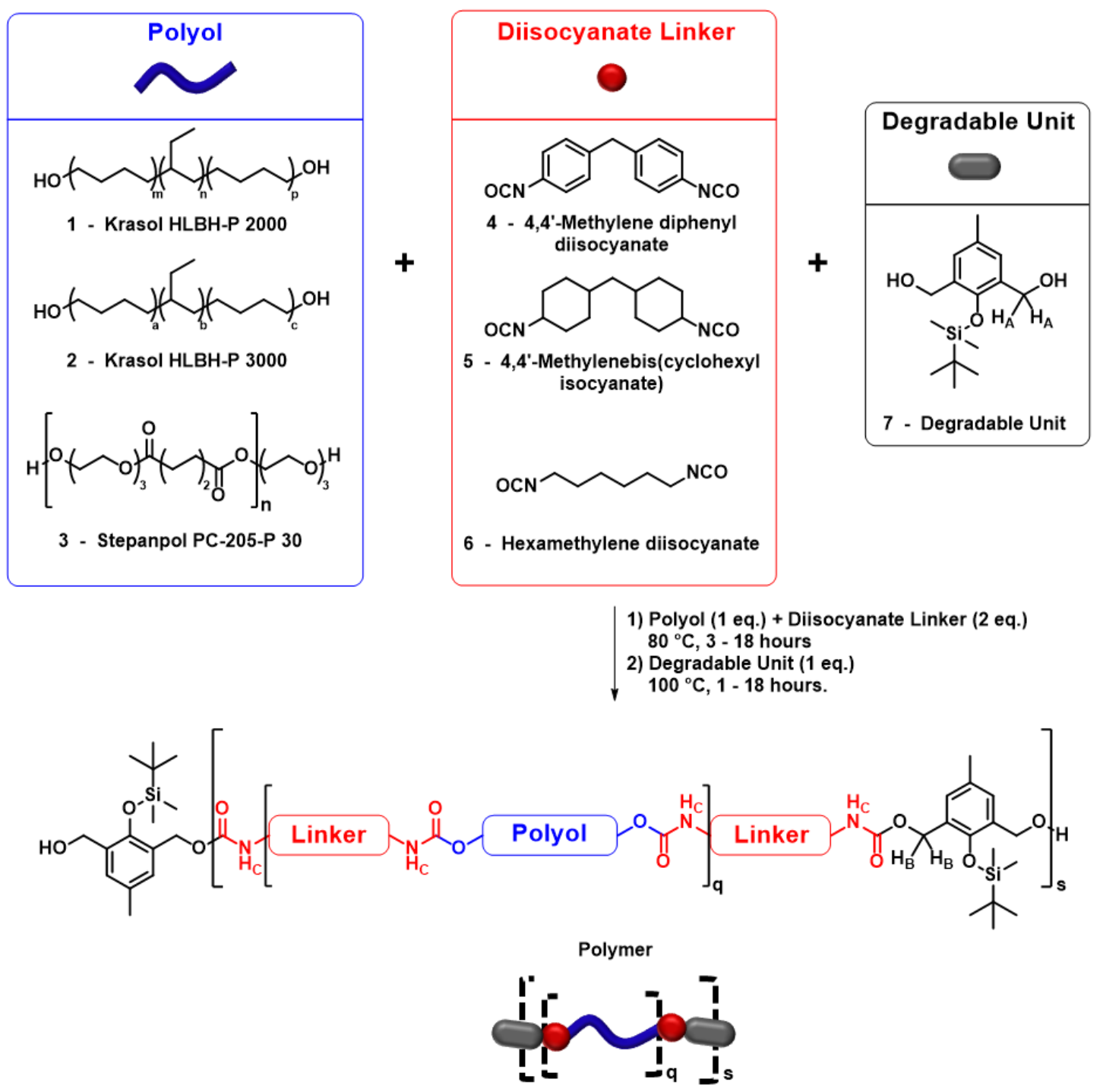

Scheme 2. General synthesis of the polymers containing the degradable unit with varying polyols and diisocyanates (Protons labelled $H_{A}, H_{B}$ and $H_{c}$ give rise to characteristic signals in the ${ }^{1} H N M R$ spectrum of the monomers and polymers as discussed below) 


\begin{tabular}{|c|c|c|c|c|c|c|}
\hline Polyol & & $\begin{array}{c}\text { Diisocyanate } \\
\text { Linker }\end{array}$ & & $\begin{array}{c}\text { Degradable } \\
\text { Unit }\end{array}$ & & $\begin{array}{c}\text { Degradable } \\
\text { adhesive }\end{array}$ \\
\hline $\begin{array}{c}1 \\
\left(M_{n} 3.4 \text { kDa, } \boxplus \text { 1.1) }\right.\end{array}$ & + & 4 & + & 7 & $\rightarrow$ & $\begin{array}{c}\mathbf{8} \\
(97 \%)\end{array}$ \\
\hline $\begin{array}{c}1 \\
\left(M_{n} 3.4 \text { kDa, } \boxplus \text { 1.1) }\right.\end{array}$ & + & 5 & + & 7 & $\rightarrow$ & $\begin{array}{c}9 \\
(88 \%)\end{array}$ \\
\hline $\begin{array}{c}1 \\
\left(M_{n} 3.4 \mathrm{kDa}, \oplus 1.1\right)\end{array}$ & + & 6 & + & 7 & $\rightarrow$ & $\begin{array}{c}10 \\
(87 \%)\end{array}$ \\
\hline $\begin{array}{c}2 \\
\left(M_{n} 4.6 \mathrm{kDa}, \boxplus 1.1\right)\end{array}$ & + & 4 & + & 7 & $\rightarrow$ & $\begin{array}{c}11 \\
(99 \%)\end{array}$ \\
\hline $\begin{array}{c}3 \\
\left(M_{n} 6.8 \mathrm{kDa}, \boldsymbol{\oplus} 1.8\right)\end{array}$ & + & 4 & + & 7 & $\rightarrow$ & $\begin{array}{c}12 \\
(92 \%)\end{array}$ \\
\hline
\end{tabular}

Table 1. Chemical composition of the polymers containing different polyols or diisocyanates. Yields shown in brackets.

The polymers were characterised by ${ }^{1} \mathrm{H}$ NMR spectroscopy (See SI for full spectra). All of the polymers showed a downfield shift in the resonance frequency of the methylene protons of the degradable unit $7\left(\mathrm{H}_{\mathrm{A}}\right.$, Scheme 2$)$ from $4.6 \mathrm{ppm}$ to $5.1-5.2 \mathrm{ppm}$ when incorporated in the polymer backbone $\left(\mathrm{H}_{\mathrm{B}}\right)$. A urethane $\left(\mathrm{N}-\mathrm{H}_{\mathrm{C}}\right)$ resonance was observed between 3.2 - $3.4 \mathrm{ppm}$ in the spectra of the aliphatic isocyanate containing polymers 9 and 10; or between $6.5-6.7$ ppm for the aromatic isocyanate containing polymers $\mathbf{8 , 1 1}$, and $\mathbf{1 2}$ (exemplified for $\mathbf{1 2}$ in Fig. 2). Infrared spectroscopic analysis of the polymers showed a characteristic absorbance bands at approximately $1700 \mathrm{~cm}^{-1}$ and $3300 \mathrm{~cm}^{-1}$ for $\mathrm{C}=\mathrm{O}$ and $\mathrm{N}-\mathrm{H}$ stretches, respectively, and absorbances at approximately $2200 \mathrm{~cm}^{-1}$ indicative of residual isocyanate were not observed in any of the products.

${ }^{1} \mathrm{H}$ NMR spectroscopy was employed to study the degradation of the polymers on addition of fluoride ions. We have previously found that a both a fluoride source and a nucleophile such as $\mathrm{H}_{2} \mathrm{O}$ is required to complete the degradation reaction [48]. Therefore, in this work tetrabutylammonium fluoride trihydrate $\left(\mathrm{TBAF} .3 \mathrm{H}_{2} \mathrm{O}\right)$ was added to solution of polymer in deuterated chloroform in equal molar quantities to the polymer. All five polymers showed complete degradation of the DU in less than 1 minute as evidenced by the loss of the methylene proton $\left(\mathrm{H}_{\mathrm{B}}\right)$ resonances $c a .5 .0 \mathrm{ppm}$ and urethane proton $\left(\mathrm{H}_{\mathrm{C}}\right)$ resonances in the ${ }^{1} \mathrm{H}$ NMR spectra of the degraded materials. This effect is exemplified for the polymer $\mathbf{1 2}$ in Fig. 1 (see SI Figures S1 - S4 for remaining degradation data). In addition, the polyester backbone of polymer 12 was not affected by the addition of TBAF as evidenced constant values for the methylene resonance at 4.1 and $2.3 \mathrm{ppm}$ in the spectra of the pristine and degraded PUs (Fig. 2). This confirms that degradation occurred exclusively at the DU as designed (Scheme 1). 


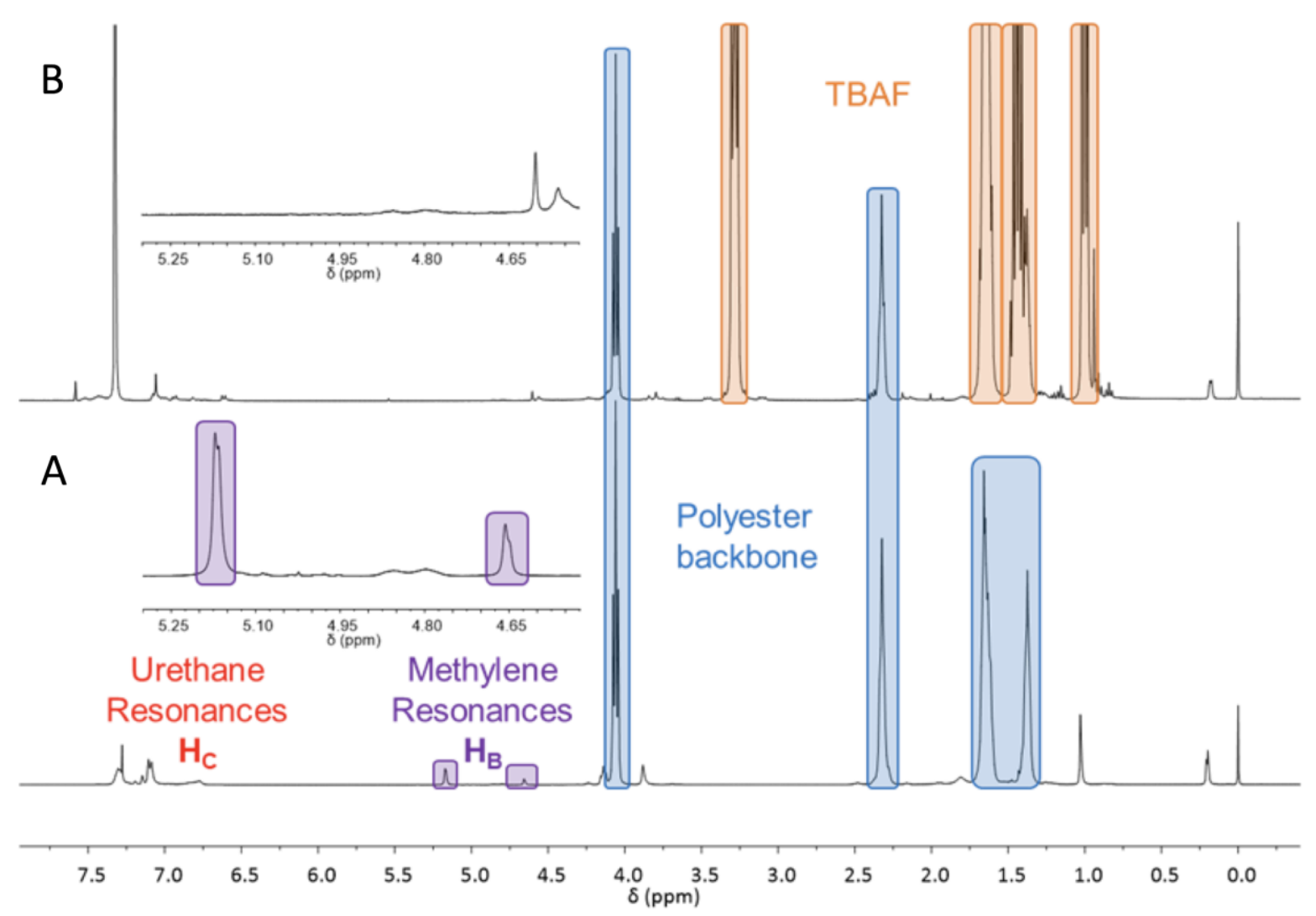

Fig. 1. ${ }^{1} \mathrm{H}$ NMR spectra showing (A) before and (B) after addition of TBAF.3 $\mathrm{H}_{2} \mathrm{O}$ to polymer 12. $\left(\mathrm{CDCl}_{3}, 400 \mathrm{MHz}\right)$

The molecular weights of the two series of polymers before and after degradation with TBAF were also analysed by gel permeation chromatography (GPC). The GPC eluograms are shown in Fig. 2, with molecular weight data detailed in Table 2. Each polymer showed a significant reduction in molecular weight after degradation (at least by $64 \%$ ).
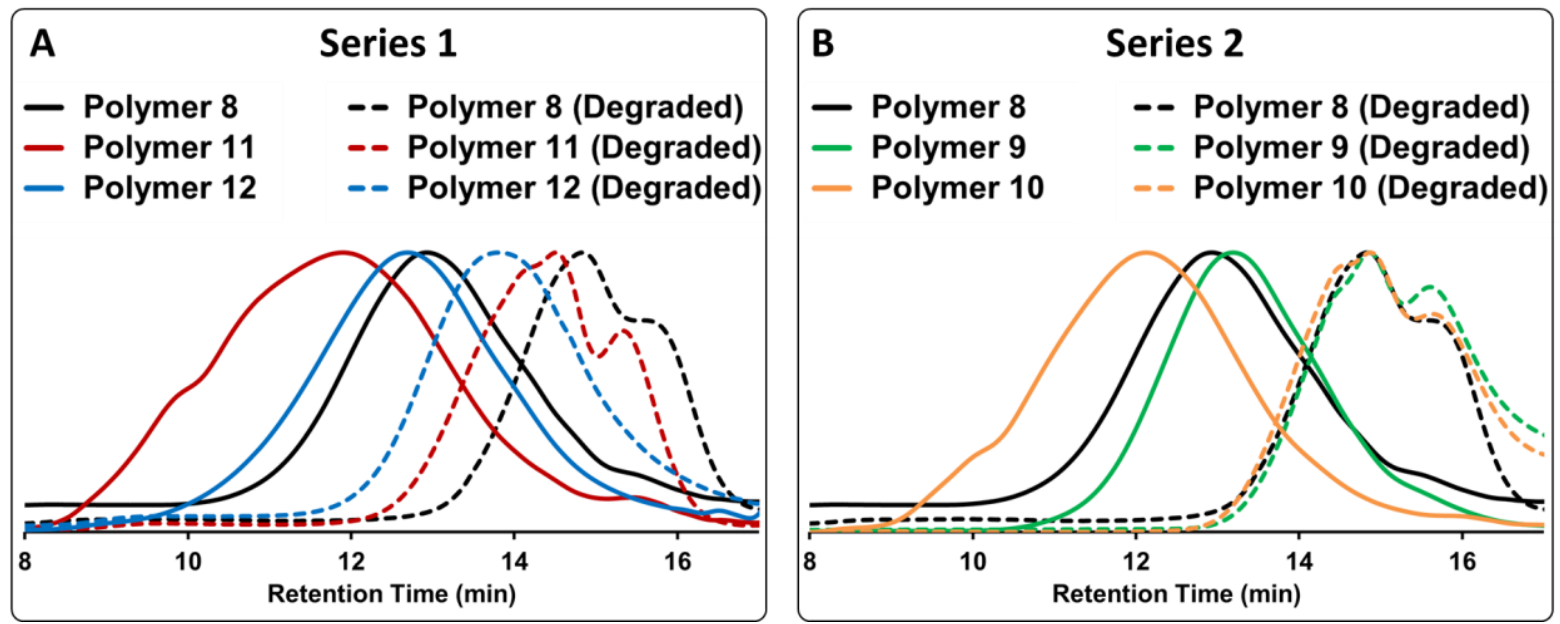

Fig. 2. GPC eluograms of $(A)$ series one which vary by diisocyanate structure and $(B)$ series two, which vary by polyol structure. (THF, PS standards). 


\begin{tabular}{ccccccc}
\hline Polymer & $\begin{array}{c}\mathbf{M}_{\mathbf{n}} \\
(\mathbf{D a})\end{array}$ & $\begin{array}{c}\mathbf{M}_{\mathbf{w}} \\
(\mathbf{D a})\end{array}$ & $\boldsymbol{\oplus}$ & $\begin{array}{c}\mathbf{M}_{\mathbf{n}} \\
(\mathbf{D a})\end{array}$ & $\begin{array}{c}\mathbf{M}_{\mathbf{w}} \\
(\mathbf{D a})\end{array}$ & $\boldsymbol{\oplus}$ \\
\hline $\mathbf{8}$ & 26100 & 71480 & 2.74 & 6210 & 10300 & 1.65 \\
$\mathbf{9}$ & 20400 & 51800 & 2.54 & 4000 & 8300 & 2.08 \\
$\mathbf{1 0}$ & 56000 & 254000 & 4.54 & 5400 & 10000 & 1.85 \\
$\mathbf{1 1}$ & 77180 & 445000 & 5.77 & 9740 & 17600 & 1.81 \\
& & & & & & \\
$\mathbf{1 2}$ & 35000 & 118000 & 3.37 & $(2400$ & 27100 & 2.19 \\
\hline
\end{tabular}

Table 2. GP molecular weight and dispersity data for the polymers before and after degradation. See SI, Fig. S5 - S9 for the eluograms.

Inspection of the molecular weight data for series 1 (polymers 8, 9 and 10, Fig. 3a) in which the key variable was the diisocyanate linker, show that for each material, the degraded products exhibit very similar eluograms. Each eluogram possesses two peak maxima, corresponding to $\mathrm{M}_{\mathrm{n}} \sim 10.7 \mathrm{kDa}$ and $\sim 3.0 \mathrm{kDa}$. This would be expected form the nature of the synthesis, where only polyols separated by DU units would be cleaved, leaving polyols separated by a single MDI residue unaffected by the fluoride ions (Scheme 3). This results in the observation of degraded products containing between one and three polyols separated by MDI units (i.e. $\mathrm{q}=$ 1 to 3 in Scheme 2 and 3).

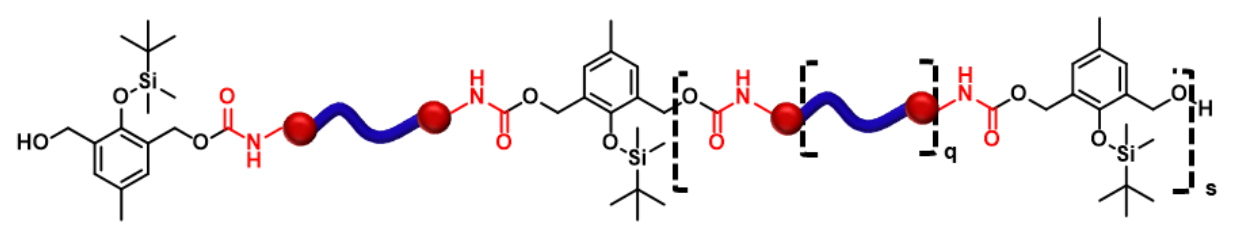<smiles>Cc1cc(C)c(OCc2c(C)cc(CO)c(CO)c2CO)c(CO)c1O</smiles>

Scheme 3. Schematic showing the degradation of the polymer backbone by addition of $T B A F .3 \mathrm{H}_{2} \mathrm{O}$ producing a smaller $M_{w}$ unit which is not affected by the fluoride ions. 
In conclusion and in agreement with the ${ }^{1} \mathrm{H}$ NMR spectroscopic data discussed above (see Fig. 1) it is apparent that fluoride ions do not cause the breakdown of the polyols in the backbone of the PUs, but are indeed selective for cleavage of the DU. With the polymers characterised and solution state degradation properties analysed, attention moved to determining how altering the diisocyanate or the polyol affected the thermal properties of the PUs, a key parameter in the design of a thermoresponsive adhesive.

\subsection{Thermal Properties and Morphology of the Polymers}

The thermal properties of polymers were determined initially using Differential Scanning Calorimetry (DSC). Melting temperatures $\left(T_{m}\right)$ were not detected for polymers 8 - 11 (Fig. 3a) which confirms the amorphous nature of the PUs. The glass transition temperatures $\left(T_{g}\right)$ of PUs which contained the hydrogenated polybutadienes $(\mathbf{8}-\mathbf{1 1})$ were remarkably similar $(-45 \pm$ $3{ }^{\circ} \mathrm{C}$, see Fig. $3 \mathrm{~b}$ ), showing little variance when compared to those of the starting polyols (1, $T_{g}-46^{\circ} \mathrm{C}$ and $2, T_{g}-48{ }^{\circ} \mathrm{C}$ ) suggesting a phase separated morphology. The ester-containing polymer 12 exhibited a distinctive $T_{m}$ at $49{ }^{\circ} \mathrm{C}$, similar to the starting polyol $\mathbf{3}\left(T_{m}=54{ }^{\circ} \mathrm{C}\right)$ and recrystallisation temperature, $T_{c}$ at $19{ }^{\circ} \mathrm{C}$ at this cooling rate $\left(5{ }^{\circ} \mathrm{C} / \mathrm{min}\right)$. Further investigation into the thermal properties of $\mathbf{1 2}$ showed that whilst $T_{m}$ remained essentially constant $\left(49+/-0.5^{\circ} \mathrm{C}\right)$ at all heating / cooling rates measured, $T_{c}$ decreases from 27.1 to 7.7 ${ }^{\circ} \mathrm{C}$ as the ramp rate increase from 2 to $20{ }^{\circ} \mathrm{C} / \mathrm{min}$ (see SI Fig. S23). Changes in the $\mathrm{T}_{\mathrm{c}}$ of this magnitude relating to the thermal history of the sample are characteristic of cold crystallisation as observed for polyesters. [66]

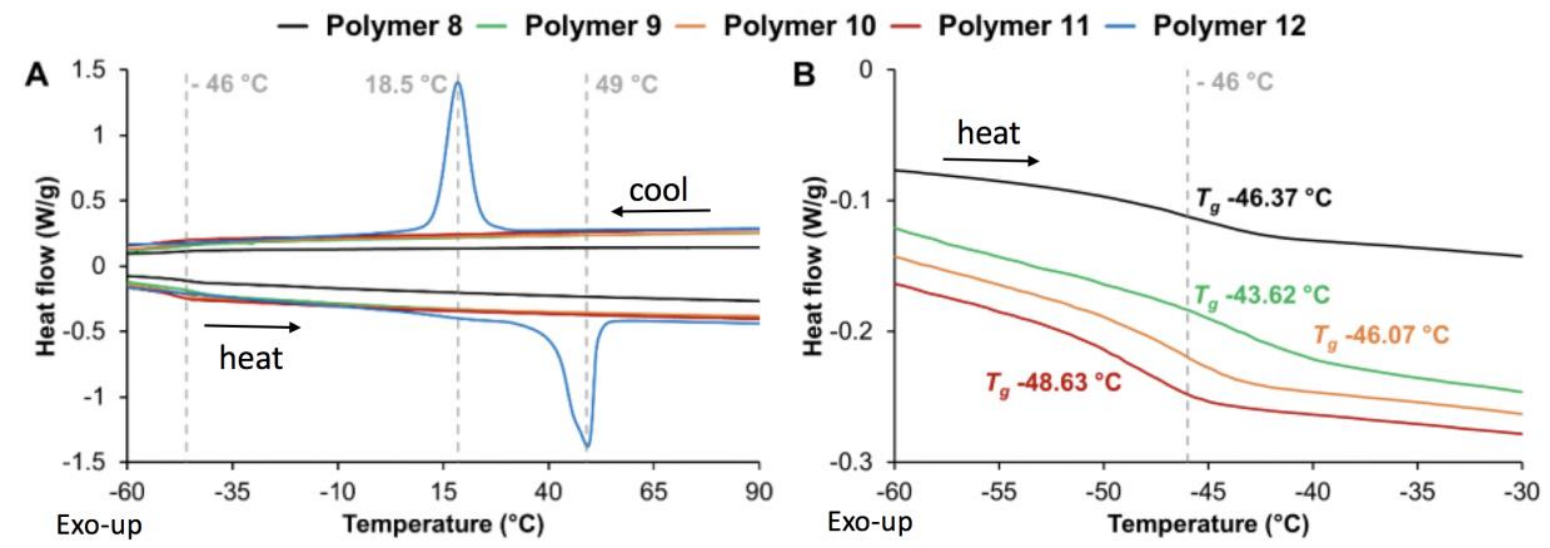

Fig. 3. DSC thermograms of the polymers from the second heat-cool cycle highlighting (A) the melting $\left(T_{m}\right)$ and recrystallisation $\left(T_{c}\right)$ temperature of polymer 12 and $(B)$ the glass transition temperatures $\left(T_{g}\right)$ of polymers $8,9,10$ and 11 (heating/cooling rate $5{ }^{\circ} \mathrm{C} / \mathrm{min}$ ).

Rheological analysis was carried out to determine the viscoelastic transition temperature, an important factor in determining the lowest temperature at which the material can be melt 
processed.[67] After an initial heat-cool temperature ramp to ensure contact between the plates, three heat-cool cycles were carried out to determine the thermal reversibility of the supramolecular polymer network (see SI, Fig. S10 - S14) with the second heat cycle shown in Fig. 4.

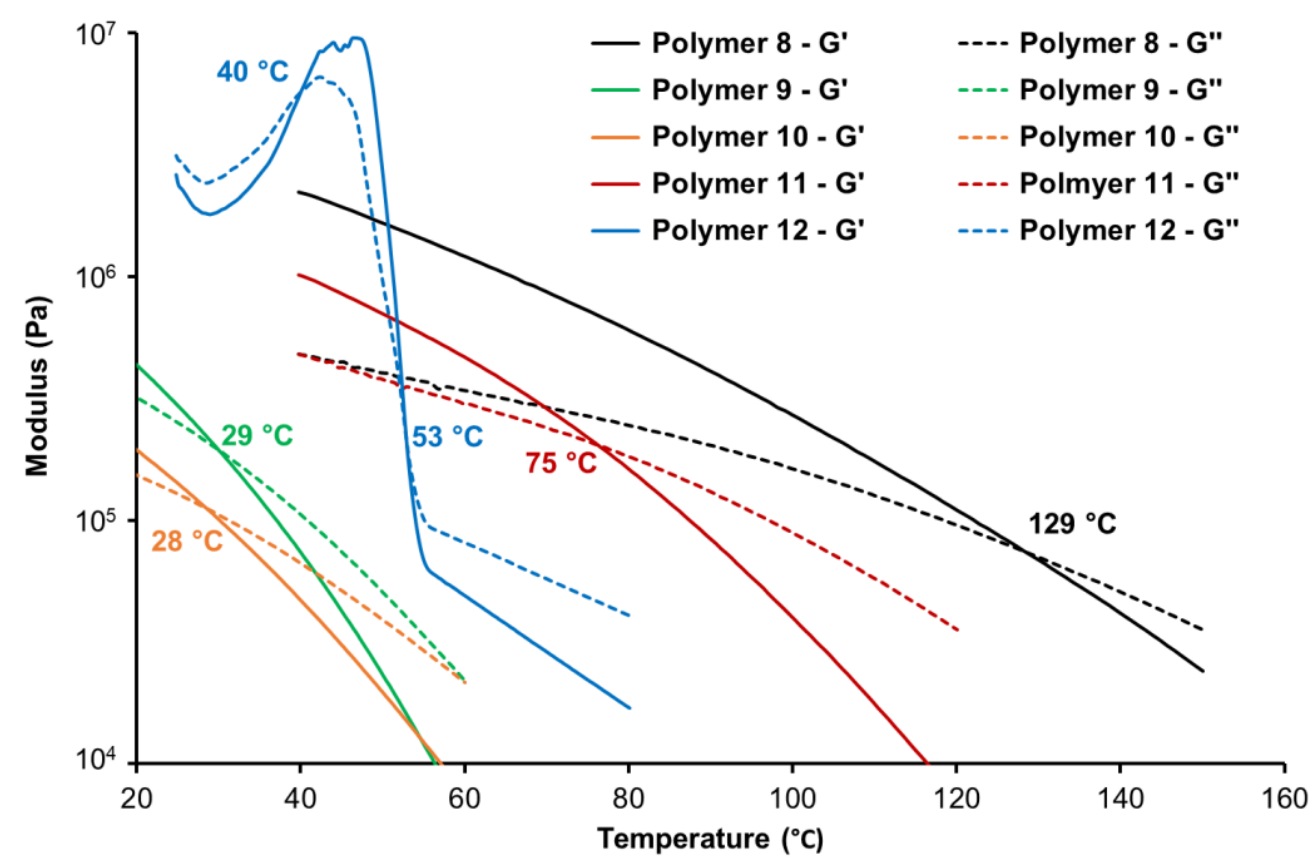

Fig. 4. Rheological analysis of polyurethanes $8-12$. Values indicate the viscoelastic transition temperature (heating rate: $2{ }^{\circ} \mathrm{C} / \mathrm{min}$, frequency: $5 \mathrm{~Hz}$, amplitude $0.1 \%$ ).

The viscoelastic transition for both polymers 9 and $\mathbf{1 0}$ was recorded to be $28{ }^{\circ} \mathrm{C}$, significantly lower than the flow temperature of polymer $8\left(125^{\circ} \mathrm{C}\right)$. This shows that exchange of the aromatic for aliphatic diisocyanate groups weakens the supramolecular interactions within the polymer network. This trend was evident from the physical appearance of polymers $\mathbf{9}$ and $\mathbf{1 0}$ at room temperature, which are very viscous liquids; not self-supporting films as observed for polymers 8, 11 and 12. Polymer 11 exhibited a reduction in the flow temperature at $75^{\circ} \mathrm{C}$ when compared to $\mathbf{8}$, which is a result of it containing a longer polybutadiene polyol (2) which provide larger soft segments within the polymer network.

The rheological analysis of polymer 12 (Fig. 4) exhibits two crossover points in storage and loss modulus $\left(40{ }^{\circ} \mathrm{C}\right.$ and $53{ }^{\circ} \mathrm{C}$ ). This higher temperature range is similar to the melt region determined by DSC analysis (Fig. 3a). Complete loss of modulus occurs just above $50{ }^{\circ} \mathrm{C}$, showing that the polymer has melted. Polymer 12 exhibited variations in rheological properties through each of the three heat-cool cycles (see SI, Fig. S14). This may be expected from the DSC studies (Figs 3 and S23) where it was observed the crystallisation temperature is dependent on the thermal history of polymer 12. In this case even though the heating/cooling 
rates where the same over the three cycles, the change in processing history of the material from the solvent cast product ( $1^{\text {st }}$ run) to a material that has undergone a heating/cooling cycle during rheological analysis ( $2^{\text {nd }}$ run) can be seen to affect the rheological properties of the material. Similar processing dependent mechanical behaviour was observed by Tang and coworkers in a structurally related hydrogen bonded telechelic supramolecular polymer. [52]

To gain an insight into the effect that the chemical structure has on the morphology of the system, variable temperature (VT) small angle X-ray scattering (SAXS) and wide angle X-ray scattering (WAXS) were carried out on thin film samples of each of the polymers (Fig. 5).
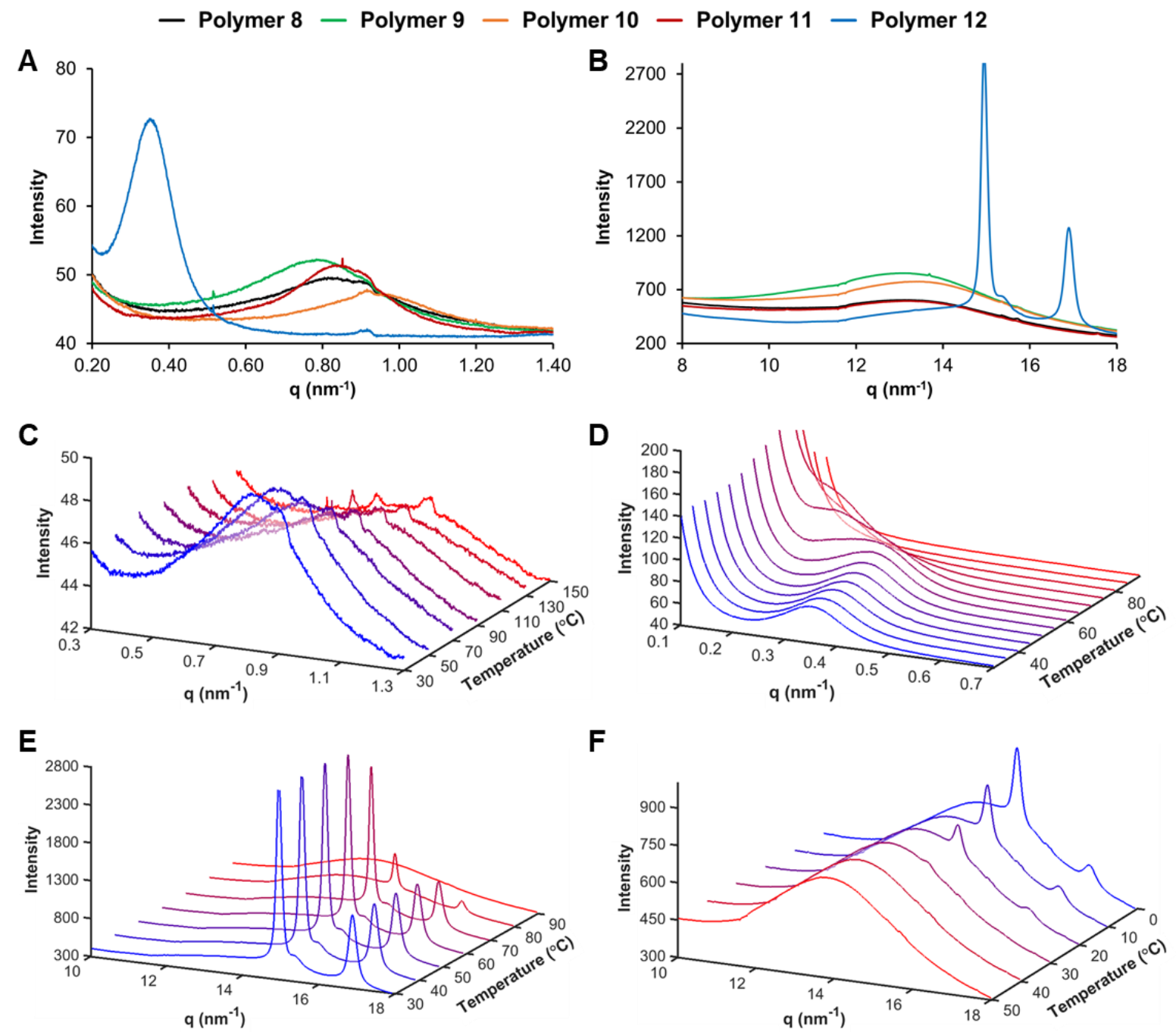

Fig. 5. (A) SAXS and (B) WAXS analysis of polymers 8 - 12; 3D diffraction data of $(C) V T$-SAXS of polymer 8 during a heat ramp; (D) VT-SAXS of polymer 12 during a heat ramp; VT-WAXS of polymer 12 during $(E)$ heating ramp and $(F)$ cooling ramp. Heating/cooling ramps were carried out at $10^{\circ} \mathrm{C} / \mathrm{min}$. See SI, Fig. S15 for additional $2 \mathrm{D}$ VT-diffraction data.

The SAXS diffraction data for polymers 8 - 12 are presented in Fig. 5a. Polymers 8 - 10 which contain the same polyol soft segment, but varying isocyanates, all show a broad Bragg peak 
with a maximum at approximately $0.85 \mathrm{~nm}^{-1}$. This corresponds to a d-spacing of $7.39 \mathrm{~nm}$, which is similar to that previously reported for PU materials containing poly(butadiene) polyols and is characteristic of a microphase separated morphology. [50,51] Polymer 11 shows a slightly larger d-spacing at $7.85 \mathrm{~nm}$ as a result of the higher molecular weight polyol (2) used as the soft segment in the backbone. The broad nature of the diffraction patterns for 8-11 is characteristic of an amorphous structure. [50,51] In contrast, polymer 12, featuring the crystalline poly(ester) 3 , exhibited a sharp diffraction peak at $0.35 \mathrm{~nm}^{-1}$ which correlated to a larger d-spacing value of $17.95 \mathrm{~nm}$.

WAXS analysis (Fig. 5b) of polymers 8 - 11 showed a broad diffraction peak at approximately $13 \mathrm{~nm}^{-1}$, relating to a spacing of $4.83 \AA$ and correspond to the hydrogen bonded urethane residues. [68,69] In contrast, analysis of polymer 12 revealed two sharp diffraction bands. The first, observed at $15.0 \mathrm{~nm}^{-1}$ suggests assembly via the hydrogen bonding moieties (4.19 $\AA$ ) and the second band at $16.9 \mathrm{~nm}^{-1}$ indicates $\pi$ - $\pi$-stacking interactions $(3.72 \AA$ ) between the aromatic components in the hard segments of the PU. [53] Alternatively, the diffraction peak may correspond to Bragg reflexions from an orthorhombic crystalline lattice, however, there are an insufficient number of peaks to distinguish these two possibilities.

VT-SAXS analysis was carried out on polymer 8 (Fig. 5c) to probe the evolution of polymer morphology as a function of temperature. During the heating ramp, two peaks at $\mathrm{q}=0.75 \mathrm{~nm}^{-1}$ and $\mathrm{q}=0.92 \mathrm{~nm}^{-1}$ became resolved as the material reached its viscoelastic transition temperature $\left(129^{\circ} \mathrm{C}\right.$, Fig. 4). The development of these peaks suggests a phase separation process when the polymer starts to flow at high temperature. VT-SAXS analysis of the remaining amorphous polymers $(\mathbf{9}-\mathbf{1 1})$ were all similar in nature and presented an $8-12 \%$ decrease in intensity of the scattering signal at approximately $0.80 \mathrm{~nm}^{-1}$, which may be expected as a consequence of their similar chemical structure. VT-SAXS on polymer 12 (Fig. 5d) shows a sharp peak at $30{ }^{\circ} \mathrm{C}\left(\mathrm{q}=0.35 \mathrm{~nm}^{-1}\right)$ that starts to shift to a lower $q$ value as the temperature is elevated to $55^{\circ} \mathrm{C}\left(\mathrm{q}=0.20 \mathrm{~nm}^{-1}\right)$, before decreasing in intensity thereafter as the polyester crystalline segments melted.

The VT-WAXS data for polymer 12 (Figs. 5e and 5f) showed similar thermal transitions as observed during SAXS analysis described above. Specifically a progressive decrease in intensity of the two sharp peaks $\left(\mathrm{q}=15.0\right.$ and $\left.16.9 \mathrm{~nm}^{-1}\right)$ in the WAXS data occurs at $60{ }^{\circ} \mathrm{C}$, followed by a shift to a broad diffraction pattern a lower $q$ value $\left(\mathrm{q} \sim 13.8 \mathrm{~nm}^{-1}\right)$ indicative of a weakening in hydrogen bonding with increasing temperature.[51] The loss in intensity at 
$60{ }^{\circ} \mathrm{C}$ is a result of the polymer melting, followed by the collapse of the supramolecular interactions at a higher temperature. The sharp signals are recovered during a cooling ramp (Fig. 5e) at $20^{\circ} \mathrm{C}$ when the polymer recrystallises. These data are in agreement with both the DSC results (Fig. 3) and trends observed during rheological analysis (Fig. 4).

The thermal analysis has thus far shown that exchanging of the aromatic groups in the diisocyanate for aliphatic groups (series 1) reduces the flow temperature of the amorphous polymer network as a result of a reduction in the degree of phase separation and strength of the supramolecular interactions. Changing the amorphous polyol to a crystalline polyol introduces a melting temperature to the series of adhesives while retaining the supramolecular hydrogen bonding interactions within the polymer network.

\subsection{Mechanical Testing}

For mechanical stress-strain testing of the pristine and degraded materials, the polymers $\mathbf{8 , 1 1}$ and 12 were cast from THF into homogenous films $(15 \times 15 \mathrm{~cm})$. The viscous nature of 9 and 10 at room temperature prohibited the formation of peelable, self-supporting films and therefore could not be analysed using this technique. Ten samples $(4.0 \times 0.5 \mathrm{~cm})$ were cut from each of the films of polymers $\mathbf{8}, \mathbf{1 1}$ and $\mathbf{1 2}$. Five samples of each were directly subject to stressstrain analysis, and the remaining five samples of each were exposed to a TBAF solution (30 mins) then dried at $40{ }^{\circ} \mathrm{C}$ for 30 minutes. Representative stress-strain graphs of the pristine and degraded materials are shown in Fig. 9a (see SI, Fig. S23-S25 for all raw data). The ultimate tensile strength (Fig. 6b), toughness (Fig. 6c) and tensile modulus (Fig. 6d) were calculated from the mean values recorded from five specimens. 

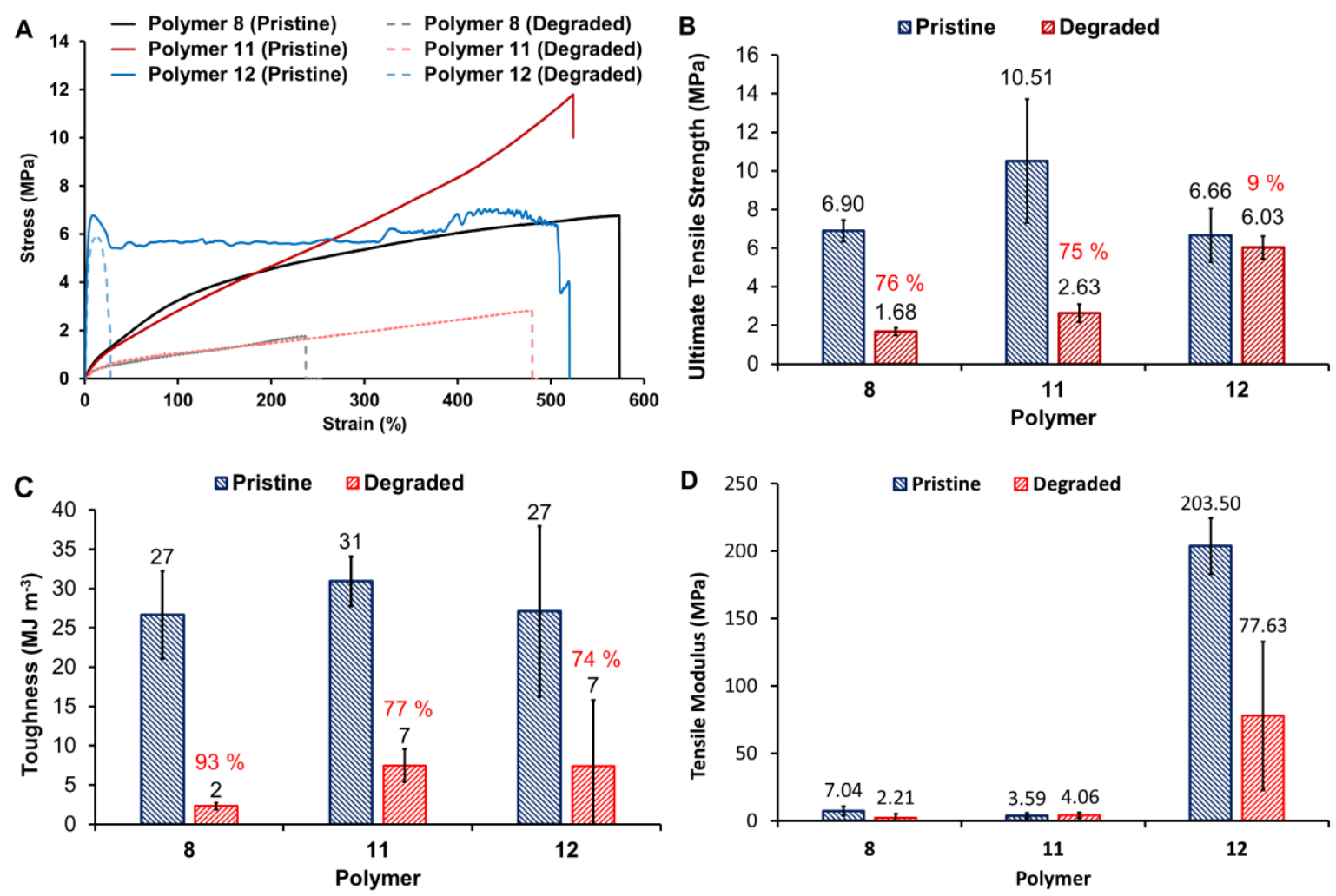

Fig. 6. Representative stress-strain curves (A) of polymers 8, 11 and 12 before and after degradation. The ultimate tensile strength (B), toughness $(C)$ and Young's Modulus of polymer 8, 11 and 12, calculated from the stress-strain curves. Errors are calculated from the standard deviation $(n=5)$.

The stress- strain response of polymer $\mathbf{8}$ (Fig. 6A) has an initial slope which is constant up to approximately $100 \%$ strain and exhibits a tensile modulus of 7.0 MPa. This is followed by a lower tensile modulus region between 100 and approximately $575 \%$ strain prior to failure just above $6 \mathrm{MPa}$. In comparison, polymer 11 contains a higher molecular weight polyol and exhibits a lower initial tensile modulus (3.6 MPa) but higher ultimate tensile strength (10 $\mathrm{MPa})$. The ester-containing polymer 12 exhibits a markedly different response to strain, with an initial tensile modulus of $203.5 \mathrm{MPa}$ at low strain $(<25 \%)$ which is 2 orders of magnitude greater than either $\mathbf{8}$ or 11. This shows the dramatic effect that the crystalline regions have on the stiffness of the material. The stress then remains relatively constant up to breaking at a strain of approximately $500 \%$.

After exposure to fluoride ions amorphous polymers $\mathbf{8}$ and $\mathbf{1 1}$ show a dramatic loss ( $\mathrm{ca} .75 \%)$ of UTS, especially in comparison to $\mathbf{1 2}$ (9\% reduction in UTS after degradation, Fig. 6b). This confirms that the UTS of the amorphous polymers is defined by the hydrogen bonding components, which are lost on degradation, whereas, the interaction in the crystalline regions dominate at low strain in both the pristine and degraded samples of $\mathbf{1 2}$ (Scheme 4). All the 
polymers showed significant loss in toughness (>74\%, Fig. 6C) after degradation, as a consequence of their reduced molecular weights (Fig. 2) and loss of hydrogen bonding interactions (Scheme 3). This chemo-response property confirms that these materials have the properties required for debond-on-demand adhesive applications.

Polymers 8 - 11
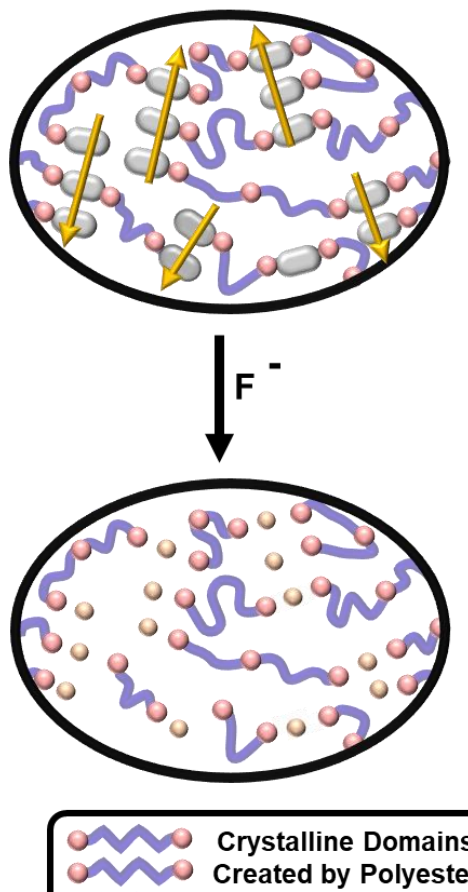
backbone
Polymer 12

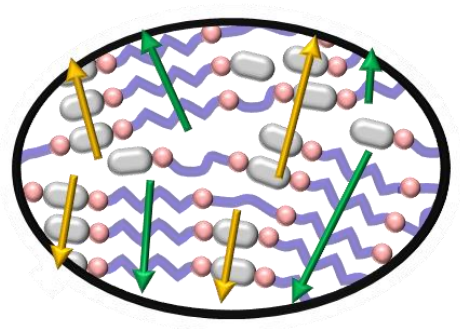

$F^{-}$

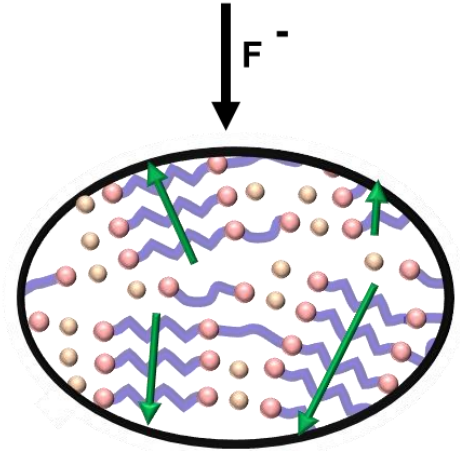

Amorphous Domains Created by Supramolecular Interactions

Force Exerted on Amorphous Network

Scheme 4. Schematic showing the proposed differences in the transfer of force between amorphous polymers 8-11 and the crystalline polymer 12 before and after degradation.

\subsection{Adhesion Testing}

Although polymers $\mathbf{9}$ and $\mathbf{1 0}$ did not form self-supporting films, it was possible to carry out adhesion tests. Butt-tensile adhesion tests were carried out on samples bonded at 25 and $60{ }^{\circ} \mathrm{C}$; whereas samples for lap shear testing were bonded at $140{ }^{\circ} \mathrm{C}$. In each case, the force required to break the adhesive bond was recorded for 5 identical samples (see SI, for raw data). Butttensile adhesion tests on the viscous polymers $\mathbf{9}$ and $\mathbf{1 0}$ showed that they were $85 \%$ and $98 \%$ weaker in adhesive strength, respectively, in comparison to polymer 8 when adhered at $60{ }^{\circ} \mathrm{C}$ (the lowest temperature that polymer $\mathbf{8}$ would adhere at). These data, therefore, show that the 
loss of the phase separation within the polymer network as a consequence of exchanging the aromatic MDI unit for aliphatic units greatly decreases the adhesive strength of the material.

Polymers 8, 11 and 12 were also analysed using lap shear and butt-tensile adhesion tests. Lap shear adhesion tests were carried out before and after treatment with fluoride ions. Butt-tensile adhesion tests were employed to investigate the influence of bonding temperature on adhesion strength. Moreover, samples were thermally re-bonded after fracture to study the reversibility of the polymeric adhesive.

Lap shear adhesion samples were carried out according to ASTM D1002, and compressed with a $1 \mathrm{~kg}$ weight at a $140{ }^{\circ} \mathrm{C}$ for 18 hours. The adhered samples were pulled and the force at break was recorded and converted into the lap shear modulus which takes into account the surface area of adhered material (Fig. 7). Samples were degraded by submerging the material in an aqueous solution of TBAF $(0.025 \mathrm{M})$.

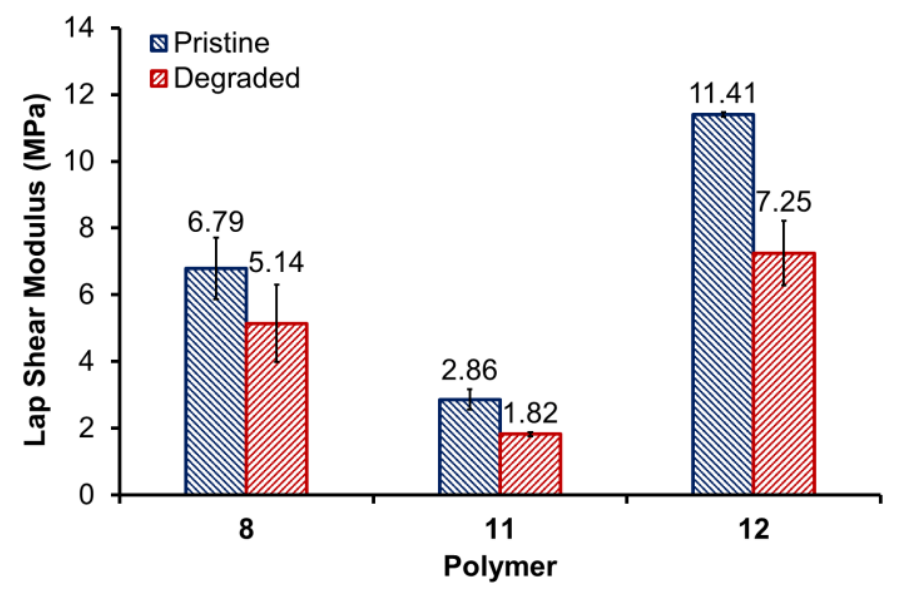

Fig. 7. The force at break recorded from the lap shear samples of polymer 8,11 and 12; before and after degradation. Errors were calculated from the standard deviation of five samples. Errors were calculated from the standard deviation $(n=5)$

All three materials showed a weakening in adhesive strength of approximately $30 \%$ after degradation, showing that the degradation units were triggered by treatment with TBAF when incorporated into a range of chemical structures. Polymer $\mathbf{1 1}$ which had a marginally stronger UTS and toughness than polymer 8 (Fig. 6), showed a much weaker lap shear modulus during adhesion tests (Fig. 7, 70\% less). Polymer 12 shows the reverse of this trend, with a similar ultimate tensile strength and toughness to polymer $\mathbf{8}$, but nearly twice as strong adhesion force as measured during the lap shear tests.

As a demonstration of the dramatic effect that the introduction of a melting point can have on the bonding strength of the polymers at lower adhesion temperatures, the amorphous adhesive 8 and crystalline adhesive 12 were both adhered for 0.5 and $18 \mathrm{~h}$ at just $60{ }^{\circ} \mathrm{C}$ (Fig. 8a). At this 
bonding temperature, polymer 8 is well above its $\mathrm{T}_{\mathrm{g}}\left(-47^{\circ} \mathrm{C}\right)$, but is still significantly below its viscoelastic transition $\left(129^{\circ} \mathrm{C}\right)$. In contrast, this bonding temperature is above the $\mathrm{T}_{\mathrm{m}}$ of $\mathbf{1 2}$, resulting in significant flow of the material which aids bonding. Thus, polymer $\mathbf{8}$ exhibits a force at break of just $0.08 \mathrm{kN}$ after 30 minutes bonding at $60{ }^{\circ} \mathrm{C}$ when compared to polymer 12 which form forms a significantly stronger bond $(0.9 \mathrm{kN})$ under the same bonding conditions. In each case, longer adhesion times at $60{ }^{\circ} \mathrm{C}$ results in stronger bonds.

Finally, thermal debonding-rebonding experiments were carried out on polymer 12 to investigate the thermal reversibility of the adhesive (Fig. 8b). Butt-tensile adhesion tests were conducted on samples of polymer 12 which had been bonded at $60{ }^{\circ} \mathrm{C}$ for 18 hours, the substrates were pulled apart before re-adhering under the same thermal conditions $\left(60^{\circ} \mathrm{C}\right)$. The debond-rebond cycle was repeated four times, and the force to break the specimen was recorded. These results demonstrate that polymer 12 containing the polyester 3 backbone and 4,4'-MDI diisocyanate linker $\mathbf{4}$ is thermally rebondable over three debond-rebond cycles without measurable loss of adhesive strength.

A

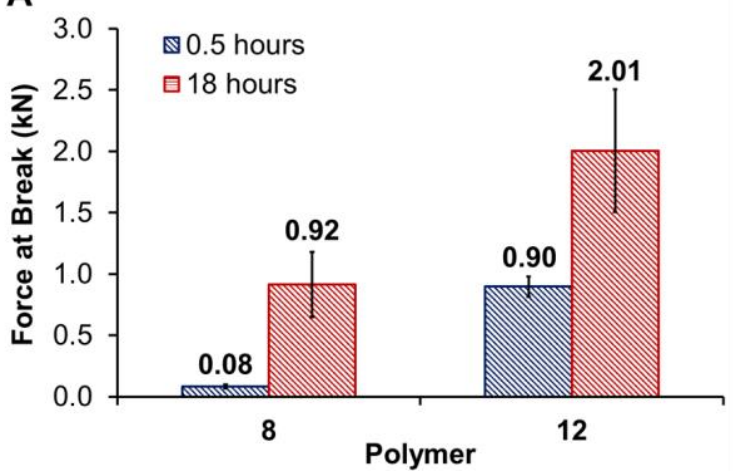

B

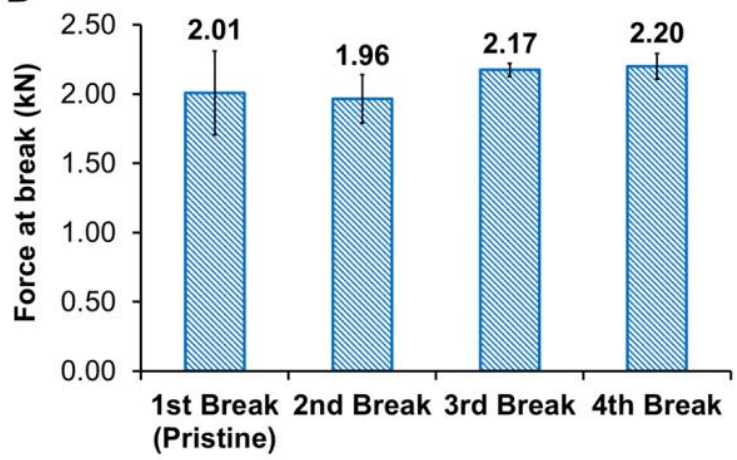

Fig. 8. (A) The force required to break the adhesives from the butt-tensile adhesion test, with adhesions carried out at $60^{\circ} \mathrm{C}$ for 0.5 and 18 hours. (B) Debonding-rebonding studies of polymer 12 when adhered at $60^{\circ} \mathrm{C}$ for 18 hours. Errors were calculated from the standard deviation $(n=4)$.

\section{Conclusions}

In this study, two series of polymers have been synthesised to try to optimise the bonding temperature of a thermally rebondable polyurethane-based adhesive whilst retaining chemoresponsive depolymerisation which facilitates debond-on-demand behaviour. The series of polymers varied by either the structure of the diisocyanate on the nature of the polyol soft segment of the PU. All the polymers could be access via a one-pot, two step synthesis in excellent isolated yield (>88\%) and $\mathrm{M}_{\mathrm{n}}$ values in the range 20 to $77 \mathrm{kDa}$. All of the polymers 
exhibited a significant reduction in $\mathrm{M}_{\mathrm{n}}$ values (at least by $64 \%$ ) on contact with fluoride ions and $\mathrm{H}_{2} \mathrm{O}$ as a consequence of the designed depolymerisation facilitated by the degradation unit in the polymer backbone. DSC and rheological analysis showed that changing the diisocyanate linker influenced the viscoelastic transition temperature of the amorphous samples. Changing the polybutadiene polyol to a polyester resulted in a novel adhesive that exhibited a defined melting point at $49{ }^{\circ} \mathrm{C}$. Small- and wide-angle X-ray diffraction analysis revealed supramolecular interactions for all of the polymers, with variable temperature experiments showing the reversibility of these interactions. Polyurethanes containing varying polyols and the aromatic diisocyanate MDI all exhibited good mechanical properties (toughness $>27 \mathrm{MJ}$ $\mathrm{m}^{-3}$ ), which was reduced by approximately $75 \%$ after degradation on contact with fluoride ions. Adhesion testes showed that polymer 12 containing the polyester $\mathbf{3}$ showed adhesive strengths at near $3.5 \mathrm{kN}$ after bonding at $140{ }^{\circ} \mathrm{C}$ during lap shear adhesion tests and at approximately $2.0 \mathrm{kN}$ at $60{ }^{\circ} \mathrm{C}$ from butt-tensile adhesion tests. This value is nearly twice as high as for polymer $\mathbf{8}$ measured when bonding at the same temperature.

The use of TBAF. $3 \mathrm{H}_{2} \mathrm{O}$ to facilitate debonding may present issues in a real-world setting, where both reagents must penetrate the adhesive to facilitate depolymerisation, although we have shown previously that the DU is not sensitive to other halide ions [48], which decreases the possibility of unintended degradation and debonding. This study does show the importance of introducing crystallinity into a degradable adhesive in order to produce materials that bond strongly at easily accessible temperatures $\left(<100{ }^{\circ} \mathrm{C}\right)$. This is valuable in order to broaden the use of these materials in bonding substrates which are thermally unstable at high temperatures.

\section{Acknowledgements}

The authors would like to thank AWE Plc and the ESPRC for co-funding a studentship for TSB; and Domino Printing Sciences for co-funding a studentship for JG. We thank the EPSRC for Platform grant EP/L020599/1. We are grateful to the University of Reading for access to instrumentation in the Chemical Analysis Facility in addition to Cray Valley for the supply of Krasol materials and Alfa Chemicals for the supply of Stepanpol® PC-205P-30. The authors would like to thank Dr Oliver Balmford for his input to the presentation of VT-SAXS and VTWAXS data. The authors would also like to thank Dr Marzena Tkaczyk in the Department of Engineering Science at the University of Oxford for assistance in the use of the rheometeric 
facilities. We are grateful to Alba Synchrotron for use of the beamline BL11-NCD, and Dr Juan Carlos Martínez for assistance in the use of the beamline facilities.

\section{Appendix A: Supplementary data.}

The Supplementary Data is available free of charge on the "website" at DOI "\#\#\#\#".

Characterisation of all polymers including ${ }^{1} \mathrm{H}$ and ${ }^{13} \mathrm{C}$ NMR spectroscopy, IR spectroscopy, DSC and GPC analysis; rheological analysis of all polymers; degradation of polymers followed by ${ }^{1} \mathrm{H}$ NMR spectroscopy; lap shear and butt-tensile adhesion testing of polymers $\mathbf{9}$ and 10; DSC thermograms of all three cycles; Stress-strain curves of polymers 8, 11 and 12 and ${ }^{1} \mathrm{H}$ and ${ }^{13} \mathrm{C}$ NMR spectra for characterisation.

Data Availability: Raw data can be obtained from the authors on request.

\section{References:}

[1] F. Awaja, M. Gilbert, G. Kelly, B. Fox, P.J. Pigram, Adhesion of Polymers, Prog. Polym. Sci. 34 (2009) 948-968.

[2] F. Chabert, F. Tournilhac, N. Sajot, S. Tencé-Girault, L. Leibler, Supramolecular polymer for enhancement of adhesion and processability of hot melt polyamides, Int. J. Adhes. Adhes. 30 (2010) 696-705.

[3] J.A. Pomposo, J. Rodrıguez, H. Grande, Polypyrrole-based conducting hot melt adhesives for EMI shielding applications, Synth. Met. 104 (1999) 107-111.

[4] C. Galan, C.A. Sierra, J.M. Gomez Fatou, J.A. Delgado, A hot-melt pressure-sensitive adhesive based on styrene-butadiene-styrene rubber. The effect of adhesive composition on the properties, J. Appl. Polym. Sci. 62 (1996) 1263-1275.

[5] M. Fernandez, M. Landa, M.E. Munoz, A. Santamaria, Thermal and Viscoelastic Features of New Nanocomposites Based on a Hot-Melt Adhesive Polyurethane and Multi-Walled Carbon Nanotubes, Macromol. Mater. Eng. 295 (2010) 1031-1041.

[6] X. Luo, K.E. Lauber, P.T. Mather, A thermally responsive, rigid, and reversible adhesive, Polymer 51 (2010) 1169-1175.

[7] A. Bakken, N. Boyle, B. Archambault, A. Hagen, N. Kostry, K. Fischer, R. Taleyarkhan, Thermal and ionizing radiation induced degradation and resulting formulation and performance of tailored poly(lactic acid) based hot melt adhesives, Int. J. Adhes. Adhes. 71 (2016) 66-73. 
[8] J. Canales, M.E. Muñoz, M. Fernández, A. Santamaría, Rheology, electrical conductivity and crystallinity of a polyurethane/graphene composite: Implications for its use as a hot-melt adhesive, Compos. Part A 84 (2016) 9-16.

[9] C.W. Peak, J.J. Wilker, G. Schmidt, A review on tough and sticky hydrogels, Colloid Polym. Sci. 291 (2013) 2031-2047.

[10] G. Sudre, L. Olanier, Y. Tran, D. Hourdet, C. Creton, Reversible adhesion between a hydrogel and a polymer brush, Soft Matter 8 (2012) 8184-8193.

[11] C. Ghobril, M.W. Grinstaff, The chemistry and engineering of polymeric hydrogel adhesives for wound closure: a tutorial, Chem. Soc. Rev. 44 (2015) 1820-1835.

[12] B.M. Shin, J. Kim, D.J. Chung, Synthesis of $\mathrm{pH}-$ responsive and adhesive superabsorbent hydrogel through bulk polymerization, Macromol. Res. 21 (2013) 582-587.

[13] E.M. White, J.E. Seppala, P.M. Rushworth, B.W. Ritchie, S. Sharma, J. Locklin, Switching the Adhesive State of Catecholic Hydrogels using Phototitration, Macromolecules 46 (2013) 8882-8887.

[14] J.H. Aubert, Thermally removable epoxy adhesives incorporating thermally reversible diels-alder adducts, J. Adhes. 79 (2003) 609-616.

[15] S.N. Ghosh, S. Maiti, An epoxy-terminated structural adhesive. II. Curing, adhesive strength, and flammability characteristics, J. Appl. Polym. Sci. 63 (1997) 683-691.

[16] K. Luo, T. Xie, J. Rzayev, Synthesis of thermally degradable epoxy adhesives, J. Polym. Sci. Part A Polym. Chem. 51 (2013) 4992-4997.

[17] Q. Zhang, M. Molenda, T.M. Reineke, Epoxy Resin Thermosets Derived from Trehalose and $\beta$-Cyclodextrin, Macromolecules 49 (2016) 8397-8406.

[18] U. Lafont, H. Van Zeijl, S. Van Der Zwaag, Influence of Cross-linkers on the Cohesive and Adhesive Self-Healing Ability of Polysulfide-Based Thermosets, ACS Appl. Mater. Interfaces 4 (2012) 6280-6288.

[19] Z. Czech, Synthesis and cross-linking of acrylic PSA systems, J. Adhes. Sci. Technol. 21 (2007) 625-635.

[20] H. Chung, R.H. Grubbs, Rapidly Cross-Linkable DOPA Containing Terpolymer Adhesives and PEG-Based Cross-Linkers for Biomedical Applications, Macromolecules 45, (2012) 9666-9673.

[21] K.M. Herbert, S. Schrettl, S.J. Rowan, C. Weder, 50th Anniversary Perspective: Solid-State Multistimuli, Multiresponsive Polymeric Materials, Macromolecules 50 (2017) 8845-8870.

[22] M. Wei, Y. Gao, X. Li, M.J. Serpe, Stimuli-responsive polymers and their applications, Polym. Chem. 8 (2017) 127-143. 
[23] M. A. Stuart, W.T.S. Huck, J. Genzer, M. Müller, C. Ober, M. Stamm, G.B. Sukhorukov, I. Szleifer, V. V Tsukruk, M. Urban, F. Winnik, S. Zauscher, I. Luzinov, S. Minko, Emerging applications of stimuli-responsive polymer materials, Nat. Mater. 9 (2010) 101-113.

[24] A.J.R. Amaral, G. Pasparakis, Stimuli responsive self-healing polymers: gels, elastomers and membranes, Polym. Chem. (2017) 6464-6484.

[25] J.H. Aubert, Thermally removable epoxy adhesives incorporating thermally reversible diels-alder adducts, J. Adhes. 79 (2003) 609-616.

[26] C. Heinzmann, C. Weder, L.M. de Espinosa, Supramolecular polymer adhesives: advanced materials inspired by nature, Chem. Soc. Rev. 342 (2015) 342-358.

[27] R.J. Wojtecki, M. A. Meador, S.J. Rowan, Using the dynamic bond to access macroscopically responsive structurally dynamic polymers, Nat. Mater. 10 (2011) 1427.

[28] C. Heinzmann, S. Coulibaly, A. Roulin, G.L. Fiore, C. Weder, Light-Induced Bonding and Debonding with Supramolecular Adhesives, ACS Appl. Mater. Interfaces 6 (2014) 4713-9.

[29] S.T. Phillips, W. Seo, J.S. Robbins, M. Olah, K. Schmid, A.M. DiLauro, SignalResponsive Polymer Used For, E.g. Films, Comprises Polymer and End-Cap, Where Cleavage of End-Cap by Specific Chemical or Physical Signal Depolymerizes Polymer, WO2012005806 A2, 2012.

[30] P.J.M. Bouten, M. Zonjee, J. Bender, S.T.K. Yauw, H. Van Goor, J.C.M. Van Hest, R. Hoogenboom, The chemistry of tissue adhesive materials, Prog. Polym. Sci. 39 (2014) 1375-1405.

[31] V. Delplace, J. Nicolas, Degradable vinyl polymers for biomedical applications, Nat. Chem. 7 (2015) 771-784.

[32] Y. Shi, P. Zhou, R. Freitag, S. Agarwal, Enzymatically Degradable Polyester-Based Adhesives, ACS Biomater. Sci. Eng. 1 (2015) 971-977.

[33] S. Ho, A.M. Young, Synthesis, polymerisation and degradation of poly(lactide-copropylene glycol) dimethacrylate adhesives, Eur. Polym. J. 42 (2006) 1775-1785.

[34] H. Mohapatra, H. Kim, S.T. Phillips, Stimuli-Responsive Polymer Film that Autonomously Translates a Molecular Detection Event into a Macroscopic Change in Its Optical Properties via a Continuous, Thiol-Mediated Self-Propagating Reaction, J. Am. Chem. Soc. 137 (2015) 12498-12501.

[35] B.T. Michal, E.J. Spencer, S.J. Rowan, Stimuli-Responsive Reversible Two-Level Adhesion from a Structurally Dynamic Shape-Memory Polymer, ACS Appl. Mater. Interfaces 8 (2016) 11041-11049. 
[36] P. Pissis, G. Georgousis, C. Pandis, P. Georgiopoulos, A. Kyritsis, E. Kontou, M. Micusik, K. Czanikova, M. Omastova, Strain and Damage Sensing in Polymer Composites and Nanocomposites with Conducting Fillers, Procedia Eng. 114 (2015), 590-597.

[37] Z. Guo, Y. Zuo, S. Feng, Thermally self-healing silicone-based networks with potential application in recycling adhesives, RSC Adv. 6 (2016) 73140-73147.

[38] E. Chabert, J. Vial, J.-P. Cauchois, M. Mihaluta, F. Tournilhac, Multiple welding of long fiber epoxy vitrimer composites, Soft Matter 12 (2016) 4838-4845.

[39] S. Ito, H. Akiyama, M. Mori, M. Yoshida, H. Kihara, Azobenzene-Containing Triblock Copolymer Adhesive Based on Light-Induced Solid-Liquid Phase Transition: Application to Bonding for Various Substrates, Macromol. Chem. Phys. 1900105 (2019) 1-6

[40] S. Ito, H. Akiyama, R. Sekizawa, M. Mori, M. Yoshida, H. Kihara, Light-Induced Reworkable Adhesives Based on ABA-type Triblock Copolymers with Azopolymer Termini, ACS Appl. Mater. Interfaces. 10 (2018) 32649-32658

[41] C. Heinzmann, C. Weder, L.M. de Espinosa, Supramolecular polymer adhesives: advanced materials inspired by nature, Chem. Soc. Rev. 342 (2015) 342-358.

[42] A. Faghihnejad, K.E. Feldman, J. Yu, M. V. Tirrell, J.N. Israelachvili, C.J. Hawker, E.J. Kramer, H. Zeng, Adhesion and Surface Interactions of a Self-Healing Polymer with Multiple Hydrogen-Bonding Groups, Adv. Funct. Mater. 24 (2014) 2322-2333.

[43] K.A. Houton, G.M. Burslem, A.J. Wilson, Development of solvent-free synthesis of hydrogen-bonded supramolecular polyurethanes, Chem. Sci. 6 (2015) 2382-2388.

[44] C. Heinzmann, U. Salz, N. Moszner, G.L. Fiore, C. Weder, Supramolecular CrossLinks in Poly(alkyl methacrylate) Copolymers and Their Impact on the Mechanical and Reversible Adhesive Properties, ACS Appl. Mater. Interfaces 7 (2015) 1339513404.

[45] K. Yamauchi, J.R. Lizotte, T.E. Long, Thermoreversible Poly(alkyl acrylates) Consisting of Self-Complementary Multiple Hydrogen Bonding, Macromolecules 36 (2003) 1083-1088.

[46] S. Cheng, M. Zhang, N. Dixit, R.B. Moore, T.E. Long, Nucleobase Self-Assembly in Supramolecular Adhesives, Macromolecules 45 (2012) 805-812.

[47] K. Yamauchi, A. Kanomata, Thermoreversible Polyesters Consisting of Multiple Hydrogen Bonding (MHB), Macromolecules 37 (2004) 3519-3522.

[48] T.S. Babra, A. Trivedi, C.N. Warriner, N. Bazin, D. Castiglione, C. Sivour, W. Hayes, B.W. Greenland, Fluoride degradable and thermally debondable polyurethane based adhesive, Polym. Chem. 8 (2017) 7207-7216. 
[49] H. Kim, H. Mohapatra, S.T. Phillips, Rapid, On-Command Debonding of StimuliResponsive Cross-Linked Adhesives by Continuous, Sequential Quinone Methide Elimination Reactions, Angew. Chem. Int. Ed. 54 (2015) 13063-13067.

[50] A. Feula, X. Tang, I. Giannakopoulos, A. Chippindale, I. Hamley, F. Greco, C.P. Buckley, C.R. Siviour, W. Hayes, An adhesive elastomeric supramolecular polyurethane healable at body temperature, Chem. Sci. 7 (2016) 4291-4300.

[51] A. Feula, A. Pethybridge, I. Giannakopoulos, X. Tang, A. Chippindale, C.R. Siviour, C.P. Buckley, I.W. Hamley, W. Hayes, A Thermoreversible Supramolecular Polyurethane with Excellent Healing Ability at $45^{\circ} \mathrm{C}$, Macromolecules 48 (2015) 6132-6141.

[52] X. Tang, A. Feula, B.C. Baker, K. Melia, D. Hermida Merino, I.W. Hamley, C.P. Buckley, W. Hayes, C.R. Siviour, A dynamic supramolecular polyurethane network whose mechanical properties are kinetically controlled, Polymer 133 (2017) 143-150.

[53] D.H. Merino, A. Feula, K. Melia, A.T. Slark, I. Giannakopoulos, C.R. Siviour, C.P. Buckley, B.W. Greenland, D. Liu, Y. Gan, P.J. Harris, A.M. Chippindale, I.W. Hamley, W. Hayes, A systematic study of the effect of the hard end-group composition on the microphase separation, thermal and mechanical properties of supramolecular polyurethanes, Polymer 107 (2016) 368-378.

[54] S. Piril Ertem, E. Yilgor, C. Kosak, G.L. Wilkes, M. Zhang, I. Yilgor, Effect of soft segment molecular weight on tensile properties of poly(propylene oxide) based polyurethaneureas, Polymer 53 (2012) 4614-4622.

[55] E. Yilgör, M. Isik, C.K. Söz, I. Yilgör, Synthesis and structure-property behavior of polycaprolactone-polydimethylsiloxane-polycaprolactone triblock copolymers, Polymer 83 (2016) 138-153.

[56] O. Oguz, S.A. Koutsoumpis, E. Simsek, E. Yilgor, I. Yilgor, P. Pissis, Y.Z. Menceloglu, Effect of soft segment molecular weight on the glass transition, crystallinity, molecular mobility and segmental dynamics of poly(ethylene oxide) based poly(urethane-urea) copolymers, RSC Adv. 7 (2017) 40745-40754.

[57] E. Yildirim, M. Yurtsever, E. Yilgör, I. Yilgör, G.L. Wilkes, Temperature-dependent changes in the hydrogen bonded hard segment network and microphase morphology in a model polyurethane: Experimental and simulation studies, J. Polym. Sci. Part B Polym. Phys. 56 (2018) 182-192.

[58] O.C. Onder, E. Yilgor, I. Yilgor, Preparation of monolithic polycaprolactone foams with controlled morphology, Polymer 136 (2018) 166-178.

[59] P. Cordier, F. Tournilhac, C. Soulié-Ziakovic, L. Leibler, Self-healing and thermoreversible rubber from supramolecular assembly, Nature 451 (2008) 977-980.

[60] M. Yan, J. Tang, H.-L. Xie, B. Ni, H.-L. Zhang, E.-Q. Chen, Self-healing and phase behavior of liquid crystalline elastomer based on a block copolymer constituted of a 
side-chain liquid crystalline polymer and a hydrogen bonding block, J. Mater. Chem. C 3 (2015) 8526-8534.

[61] Y. Yanagisawa, Y. Nan, K. Okuro, T. Aida, Mechanically robust, readily repairable polymers via tailored noncovalent cross-linking, Science 359 (2018) 72-76.

[62] X. Qi, D. Zhang, Z. Ma, W. Cao, Y. Hou, J. Zhu, Y. Gan, M. Yang, An Epidermislike Hierarchical Smart Coating with a Hardness of Tooth Enamel, ACS Nano 12 (2018) 1062-1073.

[63] R. Agnaou, M. Capelot, S. Tencé-Girault, F. Tournilhac, L. Leibler, Supramolecular Thermoplastic with 0.5 Pa.s Melt Viscosity, J. Am. Chem. Soc, 136, (2014), 1126811271.

[64] X. Luo, R. Ou, D.E. Eberly, A. Singhal, W. Viratyaporn, P.T. Mather, A Thermoplastic/Thermoset Blend Exhibiting Thermal Mending and Reversible Adhesion, ACS Appl. Mater. Interfaces 1 (2009) 612-620.

[65] X. Luo, P.T. Mather, Shape Memory Assisted Self-Healing Coating, ACS Macro Lett. 2 (2013) 152-156.

[66] M. C. Righetti, Crystallization of Polymers Investigated by temperature-modulated DSC, Materials, 10 (2017), 1-22

[67] G. Marin, P. Vandermaesen, J. Komornicki, Rheological Properties of Hot-Melt Adhesives: A Model for Describing the Effects of Resin Content, J. Adhes. 35 (1991) 23-37.

[68] K. Melia, B.W. Greenland, D. Hermida-Merino, L.R. Hart, I.W. Hamley, H.M. Colquhoun, A.T. Slark, W. Hayes, Self-assembling unsymmetrical bis-ureas, React. Funct. Polym. 124 (2018) 156-161.

[69] P.J. Woodward, D. Hermida Merino, B.W. Greenland, I.W. Hamley, Z. Light, A.T. Slark, W. Hayes, Hydrogen Bonded Supramolecular Elastomers: Correlating Hydrogen Bonding Strength with Morphology and Rheology, Macromolecules 43 (2010) 2512-2517.

[70] G. Habenicht, Applied Adhesive Bonding: A Practical Guide for Flawless Results, Wiley-VCH Verlag GmbH \& Co KGaA, Weinheim, 2009. 


\section{Supporting Information}

Fluoride Responsive Debond on Demand Adhesives: Manipulating Polymer Crystallinity and Hydrogen Bonding to Optimise Adhesion Strength at Low Bonding Temperatures

Tahkur S. Babra, ${ }^{\text {a }}$ Matthew Wood, ${ }^{\mathrm{b}}$ Jessica S. Godleman, ${ }^{\mathrm{c}}$ Sara Salimi, ${ }^{\mathrm{c}}$ Colin Warriner, ${ }^{\mathrm{b}}$ Nicholas Bazin, ${ }^{\mathrm{b}}$ Clive Sivour, ${ }^{\mathrm{d}}$ Ian. W. Hamley, ${ }^{\mathrm{c}}$ Wayne Hayes ${ }^{\mathrm{c}}$ and Barnaby W. Greenland. ${ }^{\mathrm{e}}$

aDepartment of Pharmacy, University of Reading, Whiteknights, Reading, RG6 6AD (UK).

${ }^{\mathrm{b}}$ AWE Plc, Aldermaston, Reading, Berkshire, RG7 4PR (UK).

'Department of Chemistry, University of Reading, Whiteknights, Reading, RG6 6AD (UK).

dDepartment of Engineering Science, University of Oxford, Parks Road, Oxford, OX1 3PJ (UK).

${ }^{e}$ Department of Chemistry, University of Sussex, Falmer, BN1 9QJ, UK. Email:

b.w.greenland@sussex.ac.uk

\section{Description}

Polymer Characterisation

${ }^{1} \mathrm{H}$ NMR degradation studies of polymers

Molecular weight data before and after solution state degradation studies

Raw rheological data

Full VT-scattering data

Lap sheer degradation data

Full DSC thermograms

Raw stress strain data for pristine and degraded polymers

Adhesion temperature dependent butt tensile data

${ }^{1} \mathrm{H}$ and ${ }^{13} \mathrm{C}$ NMR spectra for polymers

\section{Page(s)}

$\mathrm{S} 2-\mathrm{S} 3$

S4 - S5

S6 - S8

S9 - S11

S12

S13

S14-S16

S17-S18

S20 - S24 
Characterisation:

Synthesis of the polymers $\mathbf{8}-\mathbf{1 2}$ were carried out using the general procedure:

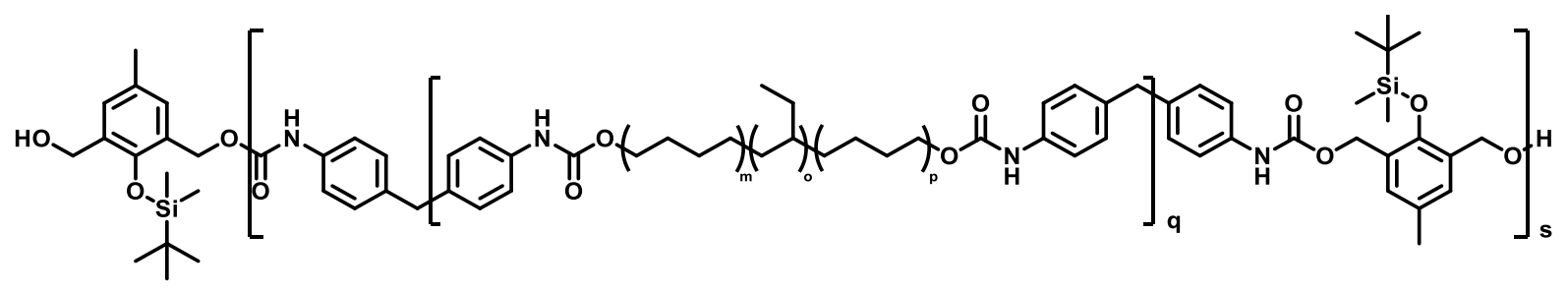

Polymer 8 (40.1 g, 97 \%). $v_{\max }$ (thin film, $\mathrm{cm}^{-1}$ ) 3317, 2961, 2919, 2873, 2854, 2159, 1736, 1708, 1599, $1533,1461,1414,1379,1304,1219,1066 . \delta_{\mathrm{H}}\left(400 \mathrm{MHz}, \mathrm{CDCl}_{3}, \mathrm{ppm}\right)(\mathrm{n}=$ number of chain extension) $7.38-7.20\left(\mathrm{~m}, 8 \mathrm{H}_{\mathrm{n}}\right), 7.21-7.02\left(\mathrm{~m}, 8 \mathrm{H}_{\mathrm{n}}+2 \mathrm{H}_{\mathrm{n}}\right), 6.55\left(\mathrm{~m}, 4 \mathrm{H}_{\mathrm{n}}\right), 5.17\left(\mathrm{~s}, 4 \mathrm{H}_{\mathrm{n}}\right), 4.82-4.59\left(\mathrm{~m}, 0.3 \mathrm{H}_{\mathrm{n}}\right)$, $4.23-4.07\left(\mathrm{~m}, 4 \mathrm{H}_{\mathrm{n}}\right), 3.88\left(\mathrm{~s}, 4 \mathrm{H}_{\mathrm{n}}\right), 2.30\left(\mathrm{~m}, 3 \mathrm{H}_{\mathrm{n}}\right), 1.93-0.71\left(\mathrm{~m}, 350 \mathrm{H}_{\mathrm{n}}\right), 0.21\left(\mathrm{~s}, 6 \mathrm{H}_{\mathrm{n}}\right) . \delta_{\mathrm{C}}(100 \mathrm{MHz}$, $\left.\mathrm{CDCl}_{3}, \mathrm{ppm}\right) 153.7,153.5,149.16,136.3,136.2,136.1,135.9,131.4,130.8,129.4,126.9,118.9,62.5$, 40.6, 38., 38.7, 38.4, 38.1, 37.9, 37.3, 36.1, 34.9, 33.5, 33.3, 30.7, 30.5, 30.2, 29.9, 29.8, 29.3, 26.8, $26.6,26.5,26.1,25.9,25.9,20.6,19.5,18.7,11.4,10.9,10.7,10.66,10.6,9.4,0.0,-0.9,-3.7$. GPC (THF/BHT $250 \mathrm{ppm}) \mathrm{M}_{\mathrm{w}} 71400, \mathrm{M}_{\mathrm{n}} 26100, Ð 2.73$. DSC $T_{g}=-45.5^{\circ} \mathrm{C}$.

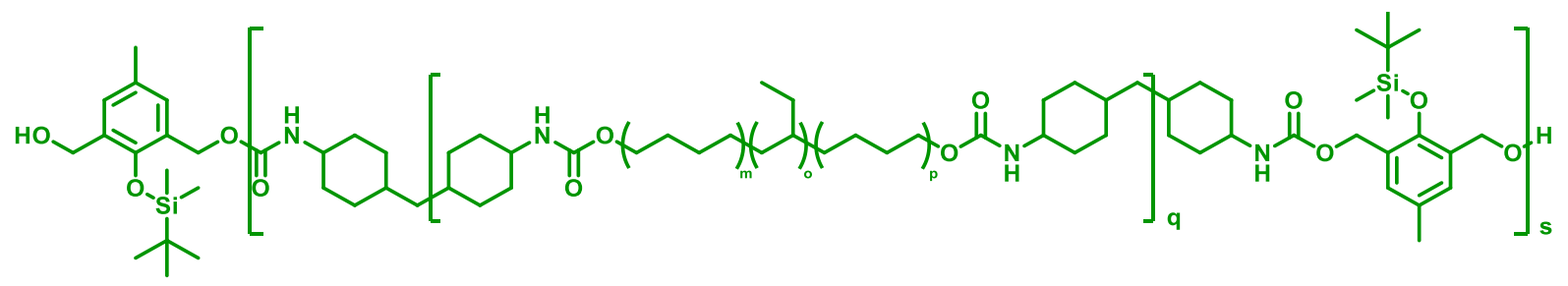

Polymer 9 (36.5 g, 88 \%). $v_{\max }$ (thin film, $\left.\mathrm{cm}^{-1}\right)$ 3333, 2958, 2919, 2854, 2266, 1698, 1536, 1461, 136, $1223,1088,897,778 . \delta_{\mathrm{H}}\left(400 \mathrm{MHz}, \mathrm{CDCl}_{3}, \mathrm{ppm}\right)(\mathrm{n}=$ number of chain extension $) 7.14-7.04(\mathrm{~m}$, $\left.2 \mathrm{H}_{\mathrm{n}}\right), 5.06\left(\mathrm{~s}, 4 \mathrm{H}_{\mathrm{n}}\right), 4.95-4.20\left(\mathrm{~m}, 4 \mathrm{H}_{\mathrm{n}}\right), 4.17-3.90\left(\mathrm{~m}, 4 \mathrm{H}_{\mathrm{n}}\right), 3.88-3.66\left(\mathrm{~m}, 2 \mathrm{H}_{\mathrm{n}}\right), 3.52-3.26(\mathrm{~m}$, $\left.3 \mathrm{H}_{\mathrm{n}}\right), 2.08-0.50\left(\mathrm{~m}, 446 \mathrm{H}_{\mathrm{n}}\right), 0.19\left(\mathrm{~s}, 6 \mathrm{H}_{\mathrm{n}}\right) . \delta_{\mathrm{C}}\left(100 \mathrm{MHz}, \mathrm{CDCl}_{3}, \mathrm{ppm}\right), 39.1,38.9,38.5,38.4,37.9$, 37.6, 36.1, 36.0, 33.4, 33.2, 32.0, 30.7, 30.2, 30.1, 29.8, 28.1, 26.8, 26.6, 26.4, 26.2, 26.1, 26.0, 25.9, 20.6, 18.7, 10.9, 10.7, 0.0, -3.7. GPC (THF/BHT $250 \mathrm{ppm}) \mathrm{M}_{\mathrm{w}} 51800, \mathrm{M}_{\mathrm{n}} 20400, Ð 2.54$. DSC $T_{g}=-$ $48.2^{\circ} \mathrm{C}$.

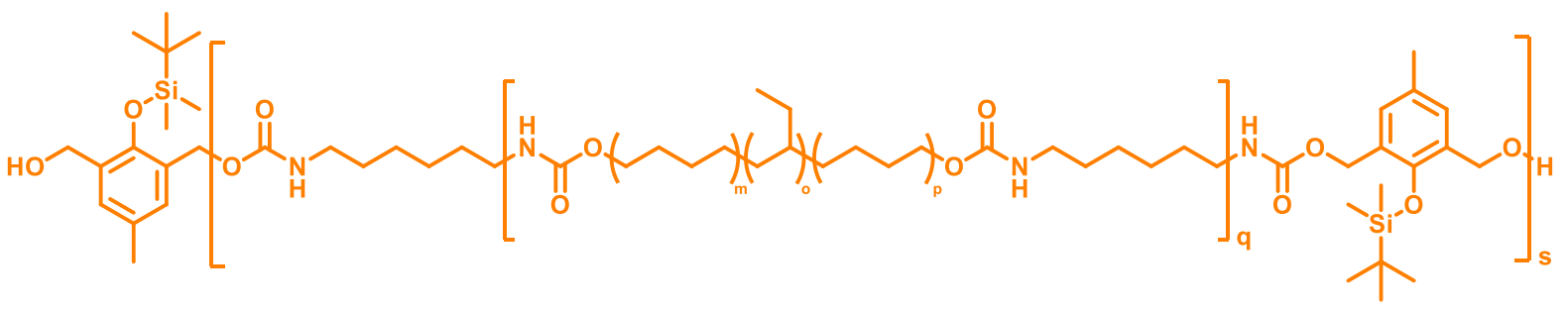

S2 
Polymer 10 (33.8 g, 87 \%). $v_{\max }\left(\right.$ thin film, $\left.\mathrm{cm}^{-1}\right)$ 3336, 2956, 2919, 2851, 2873, 1705, 1539, 1464, $1376,1242,1153,1070,900,838,778,725 . \delta_{\mathrm{H}}\left(400 \mathrm{MHz}, \mathrm{CDCl}_{3}, \mathrm{ppm}\right)(\mathrm{n}=$ number of chain extension) $7.12-7.06\left(\mathrm{~m}, 2 \mathrm{H}_{\mathrm{n}}\right), 5.07\left(\mathrm{~s}, 4 \mathrm{H}_{\mathrm{n}}\right), 4.92-4.57\left(\mathrm{~m}, 4 \mathrm{H}_{\mathrm{n}}\right), 4.14-3.94\left(\mathrm{~m}, 4 \mathrm{H}_{\mathrm{n}}\right), 3.31-2.97$ $\left(\mathrm{m}, 10 \mathrm{H}_{\mathrm{n}}\right), 2.30-2.23\left(\mathrm{~m}, 3 \mathrm{H}_{\mathrm{n}}\right), 2.04-1.82\left(\mathrm{~m}, 4 \mathrm{H}_{\mathrm{n}}\right) 1.71-0.53\left(\mathrm{~m}, 413 \mathrm{H}_{\mathrm{n}}\right), 0.19\left(\mathrm{~s}, 6 \mathrm{H}_{\mathrm{n}}\right) . \delta_{\mathrm{C}}(100$ $\mathrm{MHz}, \mathrm{CDCl}_{3}$, ppm), 62.1, 40.9, 38.9, 38.5, 38.3, 37.9, 37.6, 36.1, 33.4, 33.2, 30.7, 30.2, 29.8, 26.8, 26.6, 26.3, 26.0, 25.8, 20.6, 18.7, 10.9, 10.6, 0.0, -3.7. GPC (THF/BHT $250 \mathrm{ppm}) \mathrm{M}_{\mathrm{w}} 254000, \mathrm{M}_{\mathrm{n}}$ 56000, Đ4.54. DSC $T_{g}=-46.3^{\circ} \mathrm{C}$.

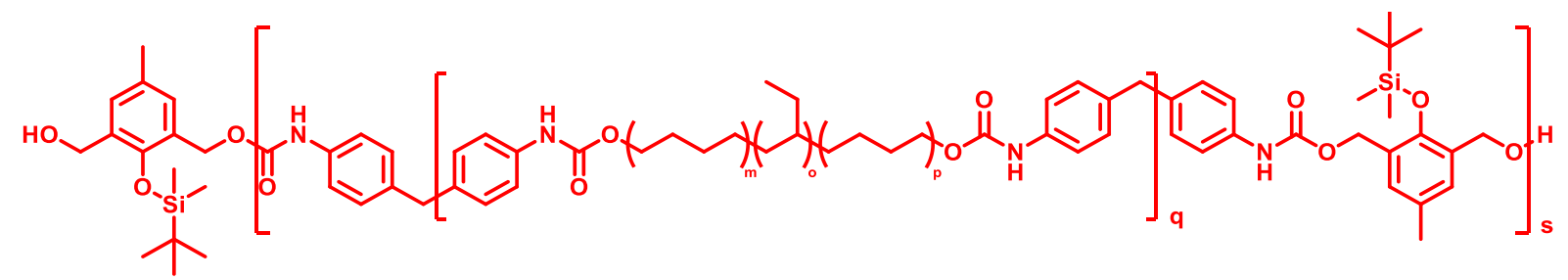

Polymer 11 (37.3 g, 99 \%). $v_{\max }$ (thin film, $\mathrm{cm}^{-1}$ ) 2234, 2958, 2920, 2873, 2854, 2169, 2003, 1733, $1708,1598,1526,1457,1414,1380,1311,1070,772 . \delta_{\mathrm{H}}\left(400 \mathrm{MHz}, \mathrm{CDCl}_{3}, \mathrm{ppm}\right)(\mathrm{n}=$ number of chain extension) $7.38-7.20\left(\mathrm{~m}, 8 \mathrm{H}_{\mathrm{n}}\right), 7.20-6.97\left(\mathrm{~m}, 8 \mathrm{H}_{\mathrm{n}}+2 \mathrm{H}_{\mathrm{n}}\right), 6.71-6.39\left(\mathrm{~m}, 4 \mathrm{H}_{\mathrm{n}}\right), 5.17\left(\mathrm{~s}, 4 \mathrm{H}_{\mathrm{n}}\right), 4.94$ $-4.79\left(\mathrm{~m}, 0.2 \mathrm{H}_{\mathrm{n}}\right), 4.23-4.06\left(\mathrm{~m}, 4 \mathrm{H}_{\mathrm{n}}\right), 3.88\left(\mathrm{~s}, 4 \mathrm{H}_{\mathrm{n}}\right), 2.28\left(\mathrm{~m}, 3 \mathrm{H}_{\mathrm{n}}\right), 2.06-0.54\left(\mathrm{~m}, 530 \mathrm{H}_{\mathrm{n}}\right), 0.21(\mathrm{~s}$, $\left.6 \mathrm{H}_{\mathrm{n}}\right) . \delta_{\mathrm{C}}\left(100 \mathrm{MHz}, \mathrm{CDCl}_{3}, \mathrm{ppm}\right) 153.7,153.4,136.2,135.8,131.4,130.8,129.4,126.9,118.9,62.5$, 40.5, 38.9, 38.4, 37.8, 36.0, 34.9, 33.6, 33.2, 30.7, 30.2, 29.7, 26.7, 26.1, 25.9, 20.5, 18.6, 10.9, 10.7, 10.6, 10.0, 0.0, -3.7. GPC (THF/BHT $250 \mathrm{ppm}) \mathrm{M}_{\mathrm{w}} 445000, \mathrm{M}_{\mathrm{n}} 77180, Ð 5.77$. DSC $T_{g}=-47.9^{\circ} \mathrm{C}$.

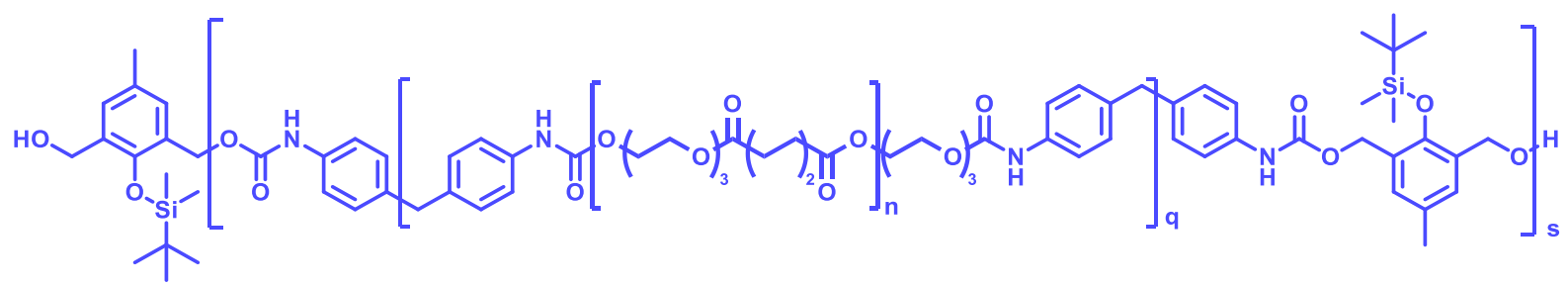

Polymer 12 (55.6 g, 92 \%). $v_{\max }$ (thin film, $\mathrm{cm}^{-1}$ ) 3349, 2954, 2935, 2898, 2864, 2178, 2003, 1727, $1596,1530,1464,1370,1260,1219,1164,1073,1044,969,910,735 . \delta_{\mathrm{H}}\left(400 \mathrm{MHz}, \mathrm{CDCl}_{3}, \mathrm{ppm}\right)(\mathrm{n}=$ number of chain extension) $7.36-7.22\left(\mathrm{~m}, 8 \mathrm{H}_{\mathrm{n}}\right), 7.16-7.03\left(\mathrm{~m}, 8 \mathrm{H}_{\mathrm{n}}+2 \mathrm{H}_{\mathrm{n}}\right), 6.92-6.68\left(\mathrm{~m}, 2 \mathrm{H}_{\mathrm{n}}\right)$, $5.19-5.14\left(\mathrm{~m}, 3 \mathrm{H}_{\mathrm{n}}\right), 4.68-4.62\left(\mathrm{~m}, 1 \mathrm{H}_{\mathrm{n}}\right), 4.17-4.11\left(\mathrm{~m}, 4 \mathrm{H}_{\mathrm{n}}\right), 4.10-4.02\left(\mathrm{~m}, 66 \mathrm{H}_{\mathrm{n}}\right), 3.90-3.85(\mathrm{~m}$, $\left.4 \mathrm{H}_{\mathrm{n}}\right), 2.39-2.25\left(\mathrm{~m}, 70 \mathrm{H}_{\mathrm{n}}\right), 1.86-1.75\left(\mathrm{~m}, 4 \mathrm{H}_{\mathrm{n}}\right), 1.73-1.56\left(\mathrm{~m}, 140 \mathrm{H}_{\mathrm{n}}\right), 1.45-1.31\left(\mathrm{~m}, 70 \mathrm{H}_{\mathrm{n}}\right), 1.03$ $\left(\mathrm{s}, 9 \mathrm{H}_{\mathrm{n}}\right), 0.26-0.14\left(\mathrm{~m}, 6 \mathrm{H}_{\mathrm{n}}\right) . \delta_{\mathrm{C}}\left(100 \mathrm{MHz}, \mathrm{CDCl}_{3}, \mathrm{ppm}\right) 173.4,129.4,118.8,64.3,40.5,33.9,28.8$, 28.5, 26.0, 25.6, 24.4, 18.7, 0.0, -3.7.GPC (THF/BHT 250 ppm) $\mathrm{M}_{\mathrm{w}} 118000, \mathrm{M}_{\mathrm{n}} 35000, Ð 3.37$. DSC $T_{g}=1.0{ }^{\circ} \mathrm{C}, T_{m}=48.4{ }^{\circ} \mathrm{C}$. 


\section{$\underline{{ }^{1} H \text { NMR spectroscopy: Degradation Study }}$}

Polymer 9

B
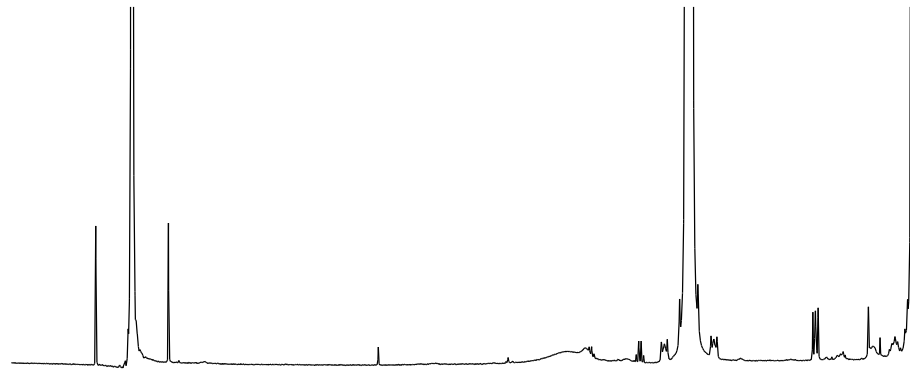

A
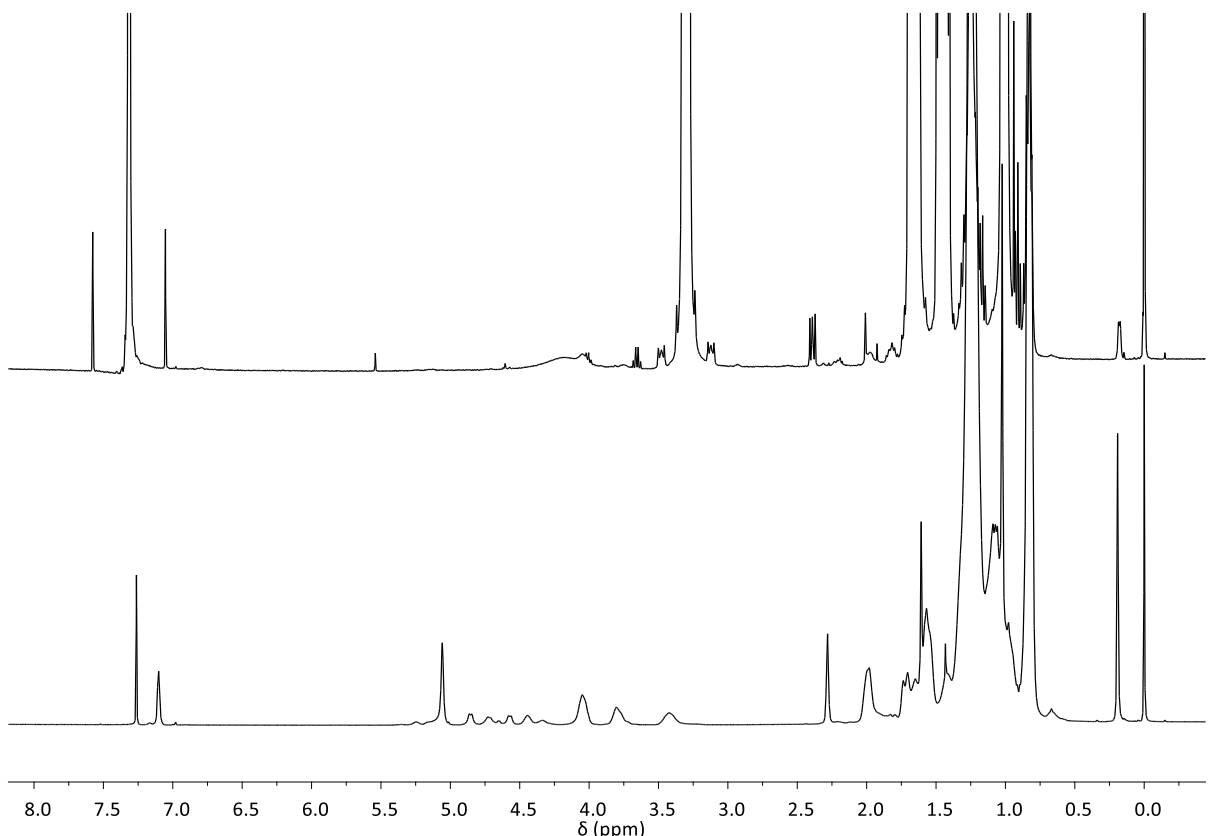

Fig. S1. ${ }^{1} \mathrm{H} N M R$ spectra showing $(A)$ before and $(B)$ after degradation of polymer $9 .\left(C D C l_{3}, 400\right.$ $\mathrm{MHz})$

\section{Polymer 10}

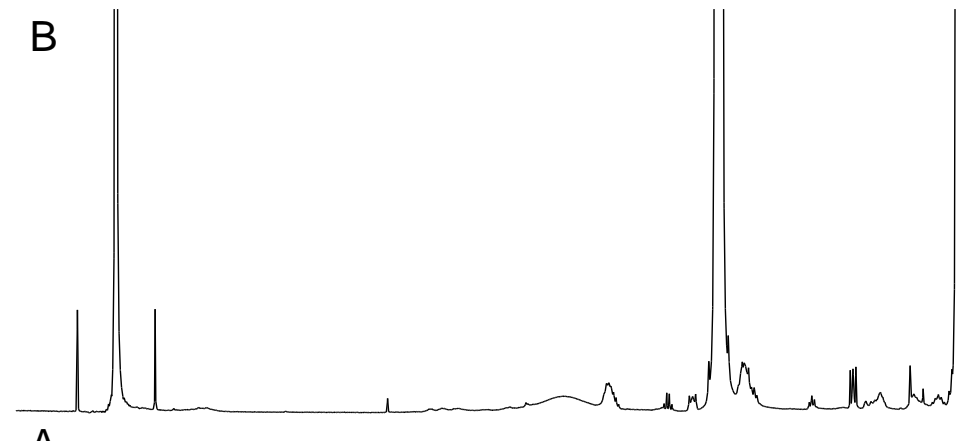

A
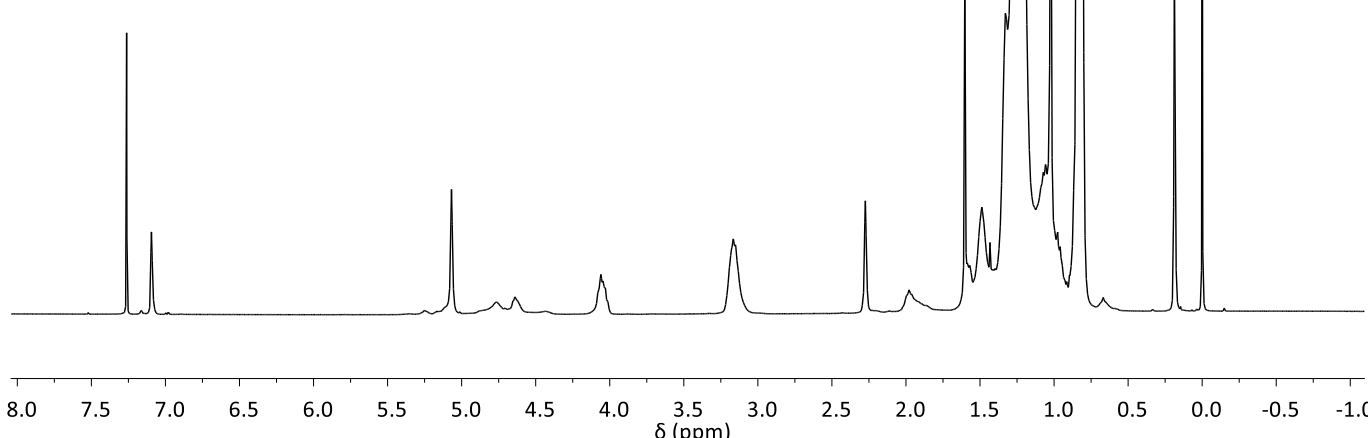

Fig. S2. ${ }^{1} H$ NMR spectra showing (A) before and (B) after degradation of polymer $10 .\left(C_{D C l}, 400\right.$ $\mathrm{MHz})$ 


\section{Polymer 11}

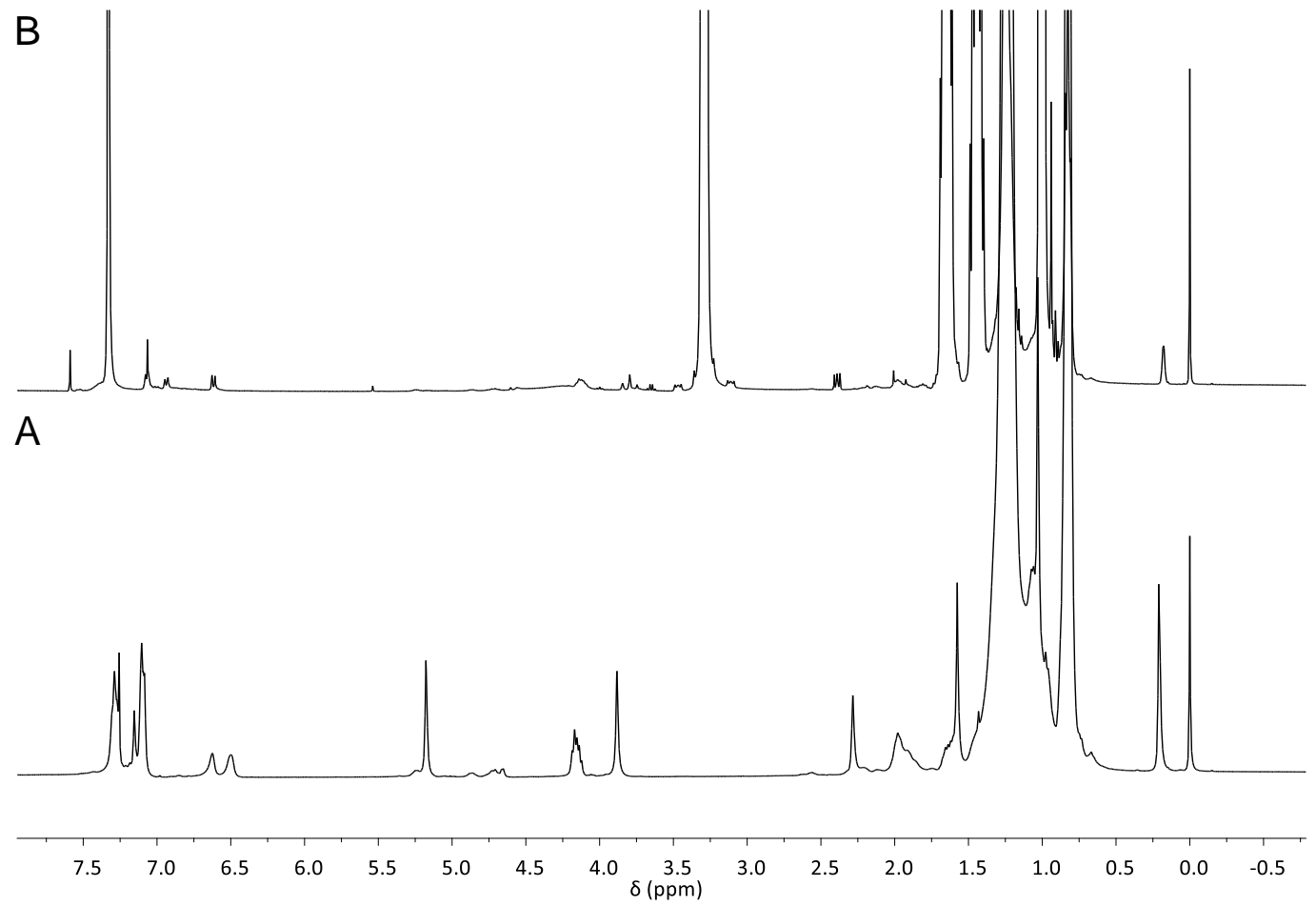

Fig. S3. ${ }^{1} \mathrm{H} N M R$ spectra showing (A) before and (B) after degradation of polymer 11 . $\left(\mathrm{CDCl}_{3}, 400\right.$ $\mathrm{MHz}$

\section{Polymer 12}

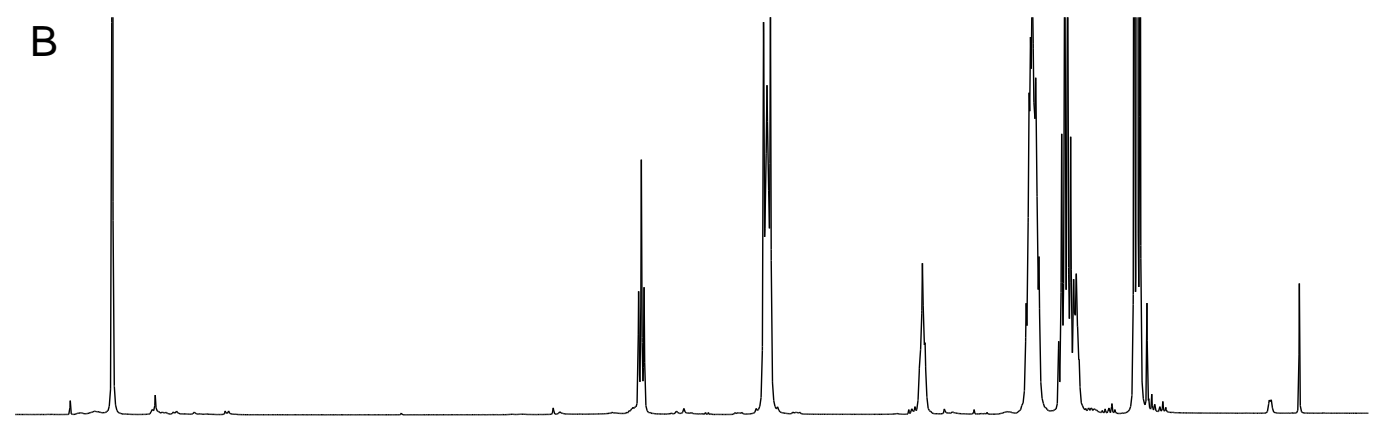

A

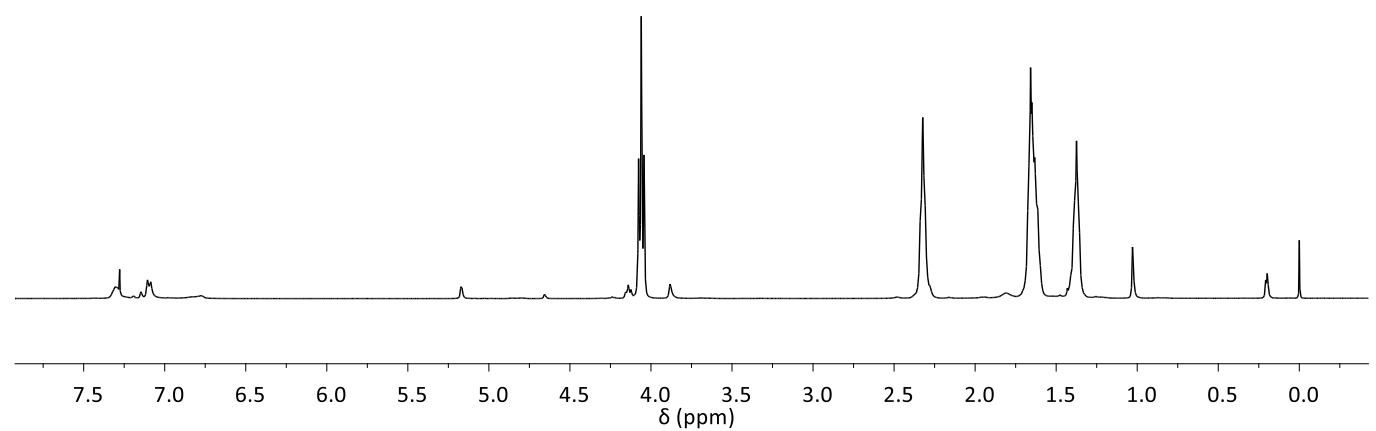

Fig. S4. ${ }^{1} H$ NMR spectra showing (A) before and (B) after degradation of polymer $12 .\left(C^{2} C l_{3}, 400\right.$ $\mathrm{MHz}$ ) 


\section{$\underline{\text { GPC Peak Maxima Calculations }}$}

Polymer 8

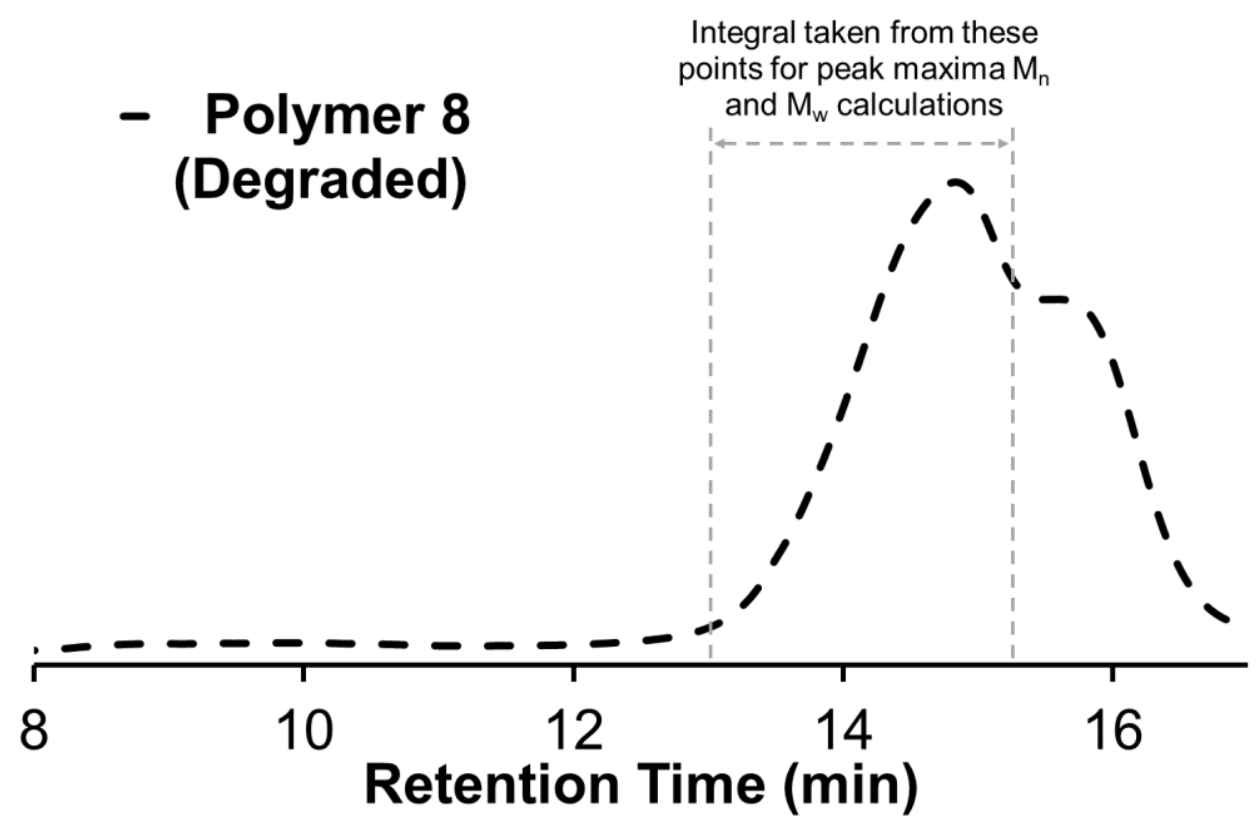

Fig. S5. GPC eluogram of Polymer 8 after degradation, showing the region used to determine the molecular weight of the peak maxima. (THF, PS standard).

Polymer 9

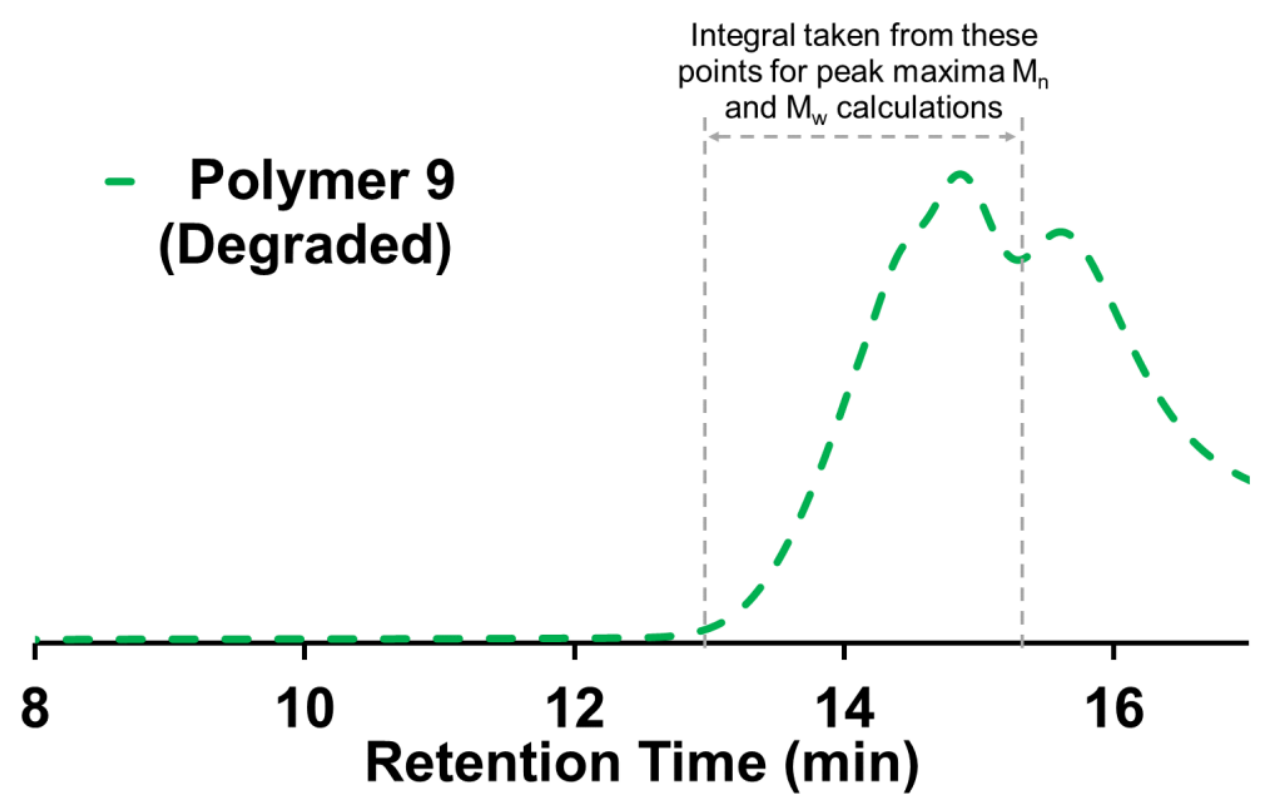

Fig. S6. GPC eluogram of Polymer 9 after degradation, showing the region used to determine the molecular weight of the peak maxima. (THF, PS standard). 
Polymer 10

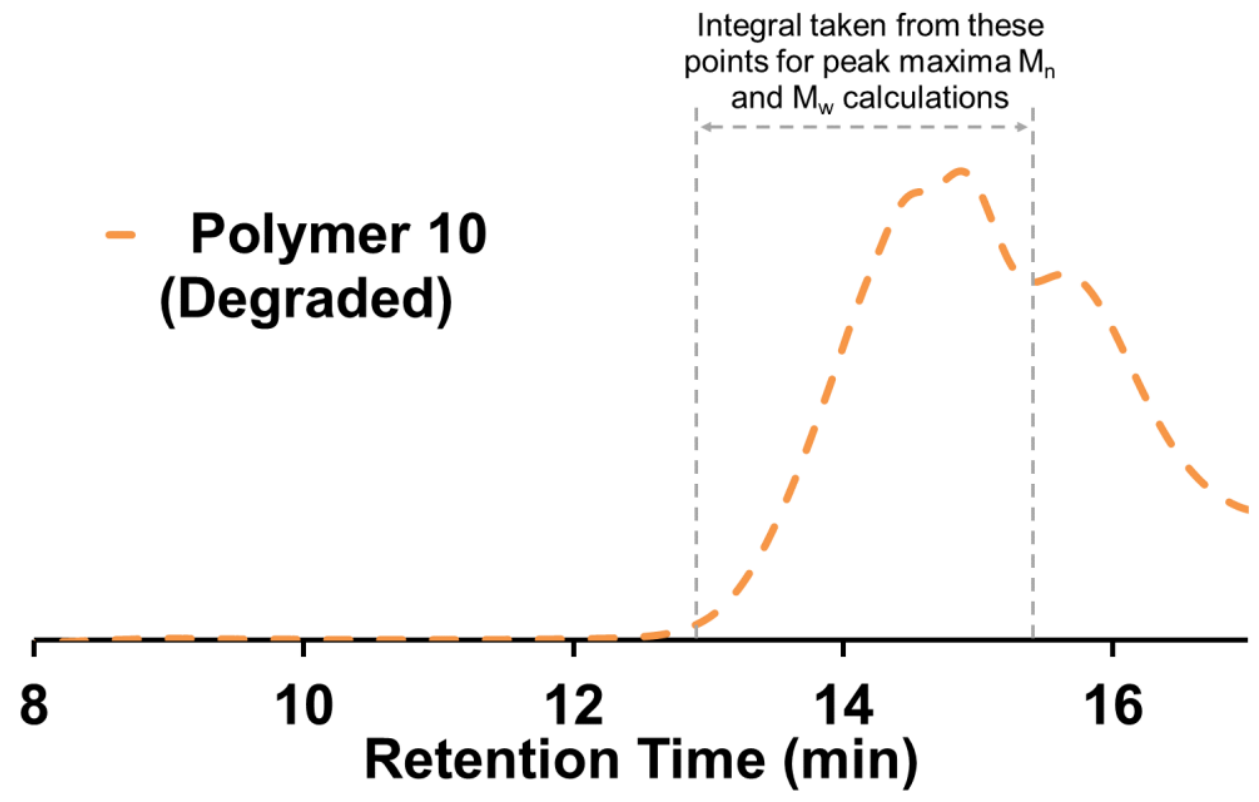

Fig. S7. GPC eluogram of Polymer 10 after degradation, showing the region used to determine the molecular weight of the peak maxima. (THF, PS standard).

Polymer 11

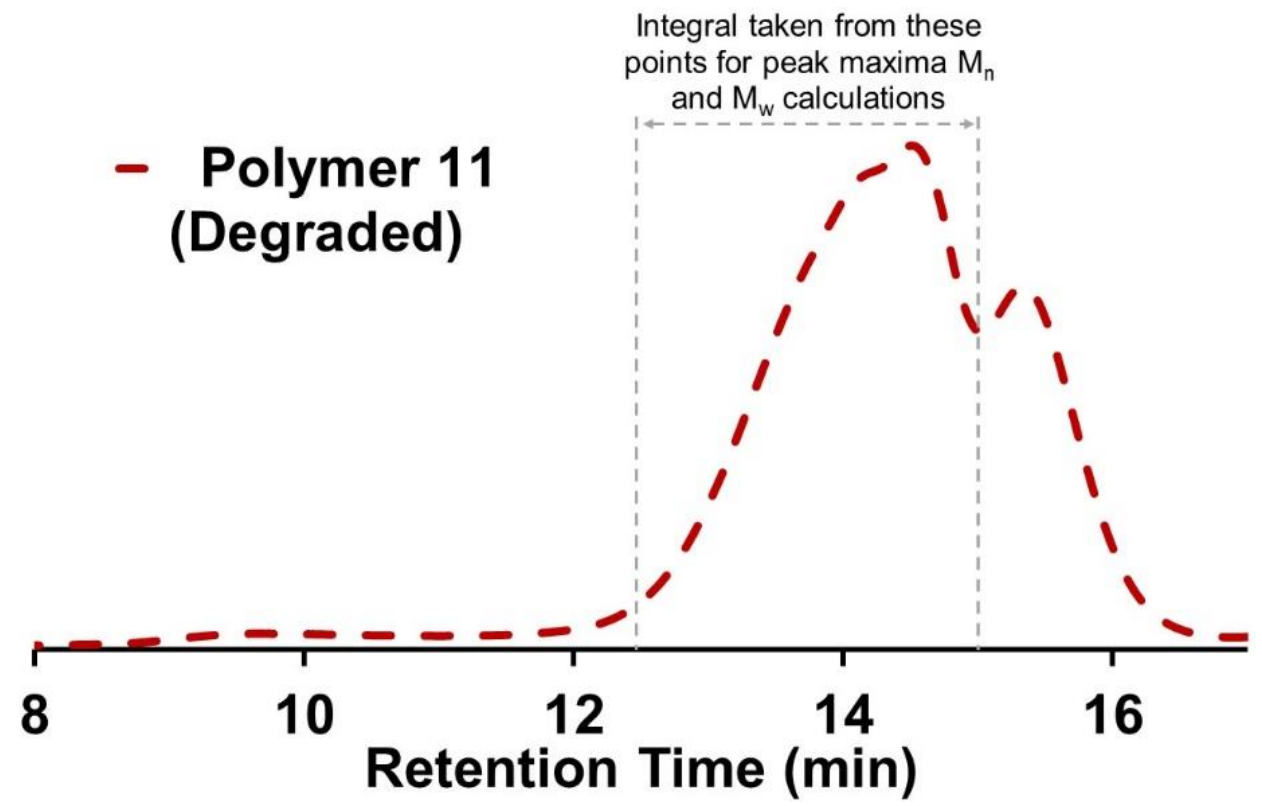

Fig. S8. GPC eluogram of Polymer 11 after degradation, showing the region used to determine the molecular weight of the peak maxima. (THF, PS standard). 
Polymer 12

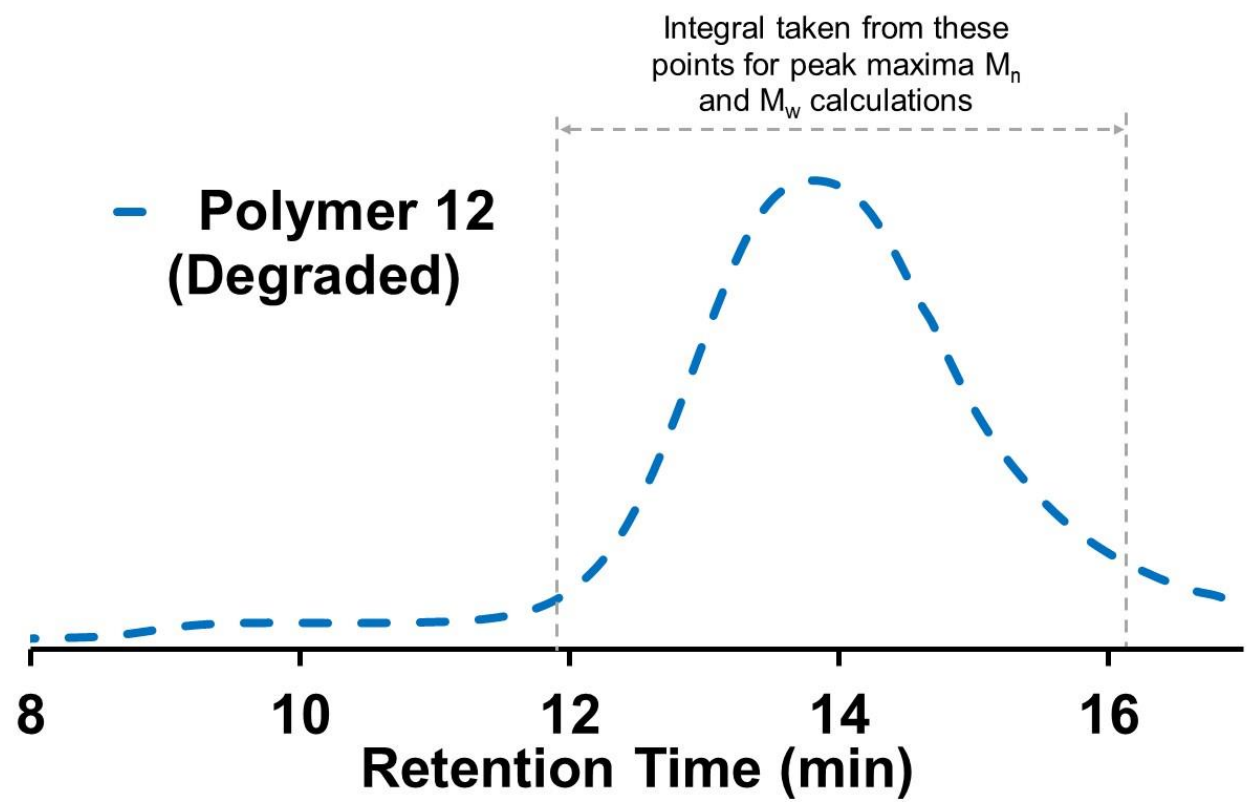

Fig. S9. GPC eluogram of Polymer 12 after degradation, showing the region used to determine the molecular weight of the peak maxima. (THF, PS standard). 


\section{Rheological Analysis Full Dataset}

Temperature ramps used for rheometry analysis:

$\begin{array}{lll}\text { Polymer } 8 & - & 40{ }^{\circ} \mathrm{C}-140{ }^{\circ} \mathrm{C} \\ \text { Polymer 9 } & - & 10{ }^{\circ} \mathrm{C}-60{ }^{\circ} \mathrm{C} \\ \text { Polymer } 10 & - & 10{ }^{\circ} \mathrm{C}-50{ }^{\circ} \mathrm{C} \\ \text { Polymer } 11 & - & 40{ }^{\circ} \mathrm{C}-100{ }^{\circ} \mathrm{C} \\ \text { Polymer } 12 & - & 25^{\circ} \mathrm{C}-80{ }^{\circ} \mathrm{C}\end{array}$

\section{Polymer 8}

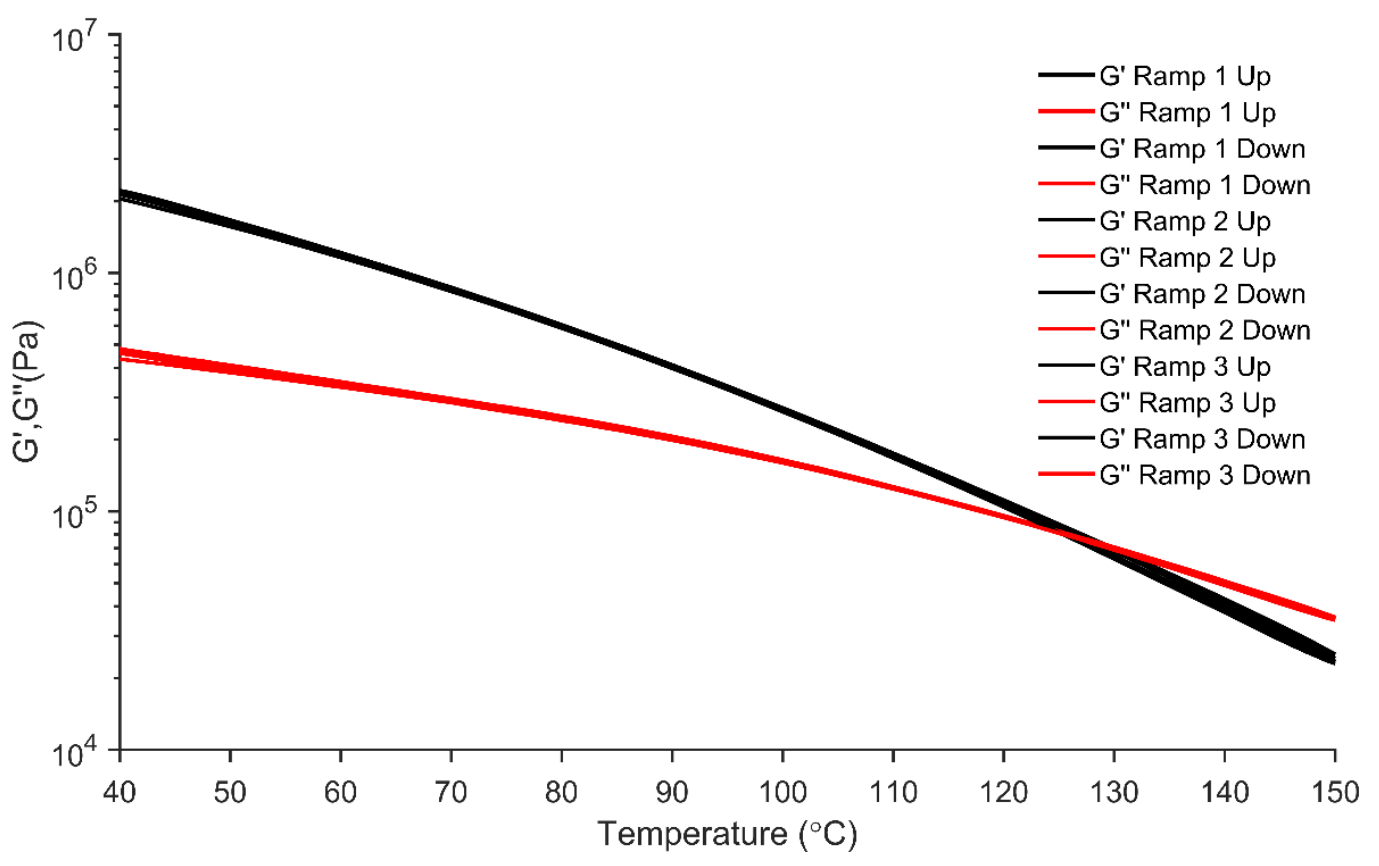

Fig. S10. Rheological Data from three heat-cool cycles for Polymer 8. 


\section{Polymer 9}

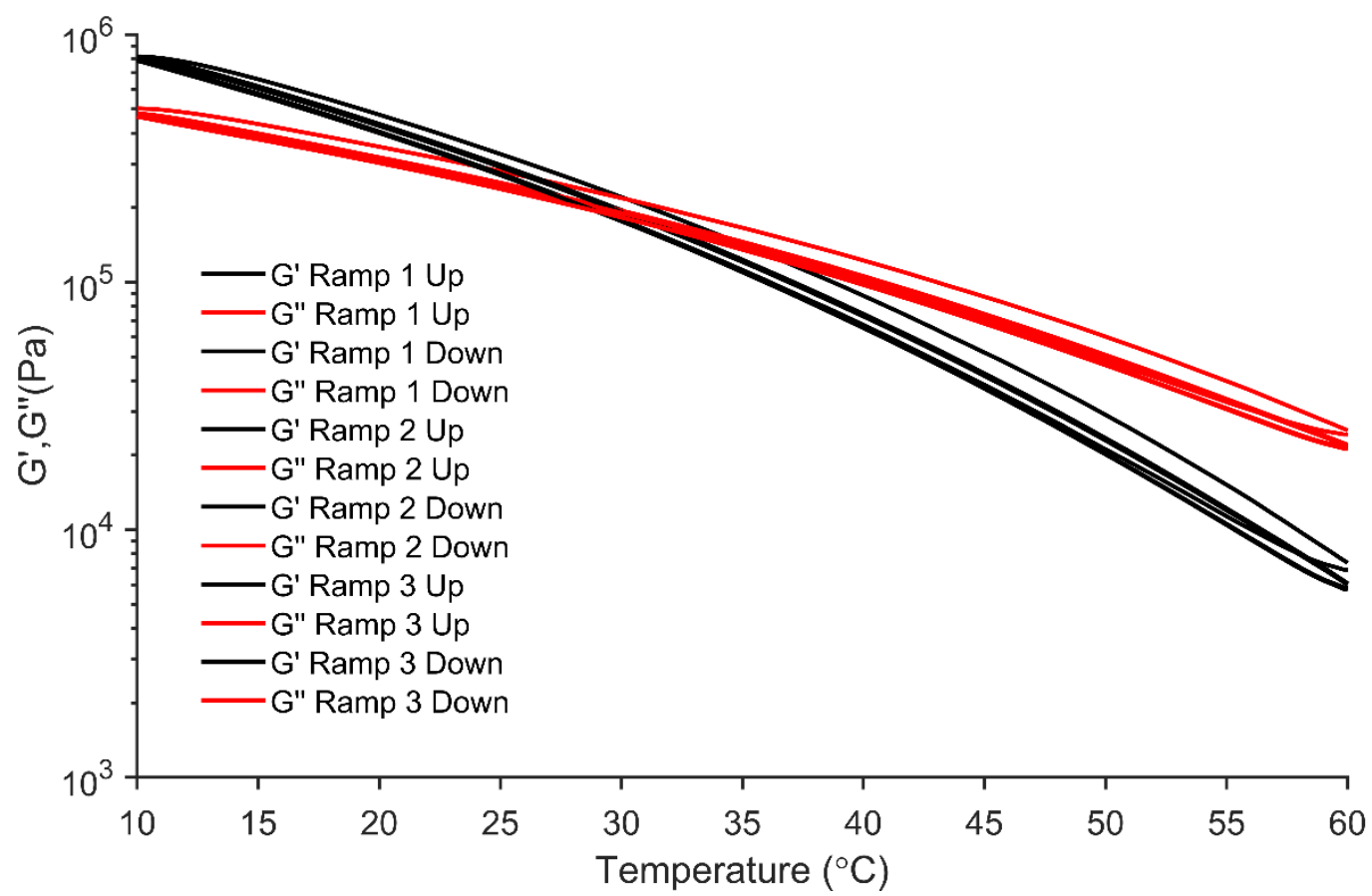

Fig. S11. Rheological Data from three heat-cool cycles for Polymer 9.

\section{Polymer 10}

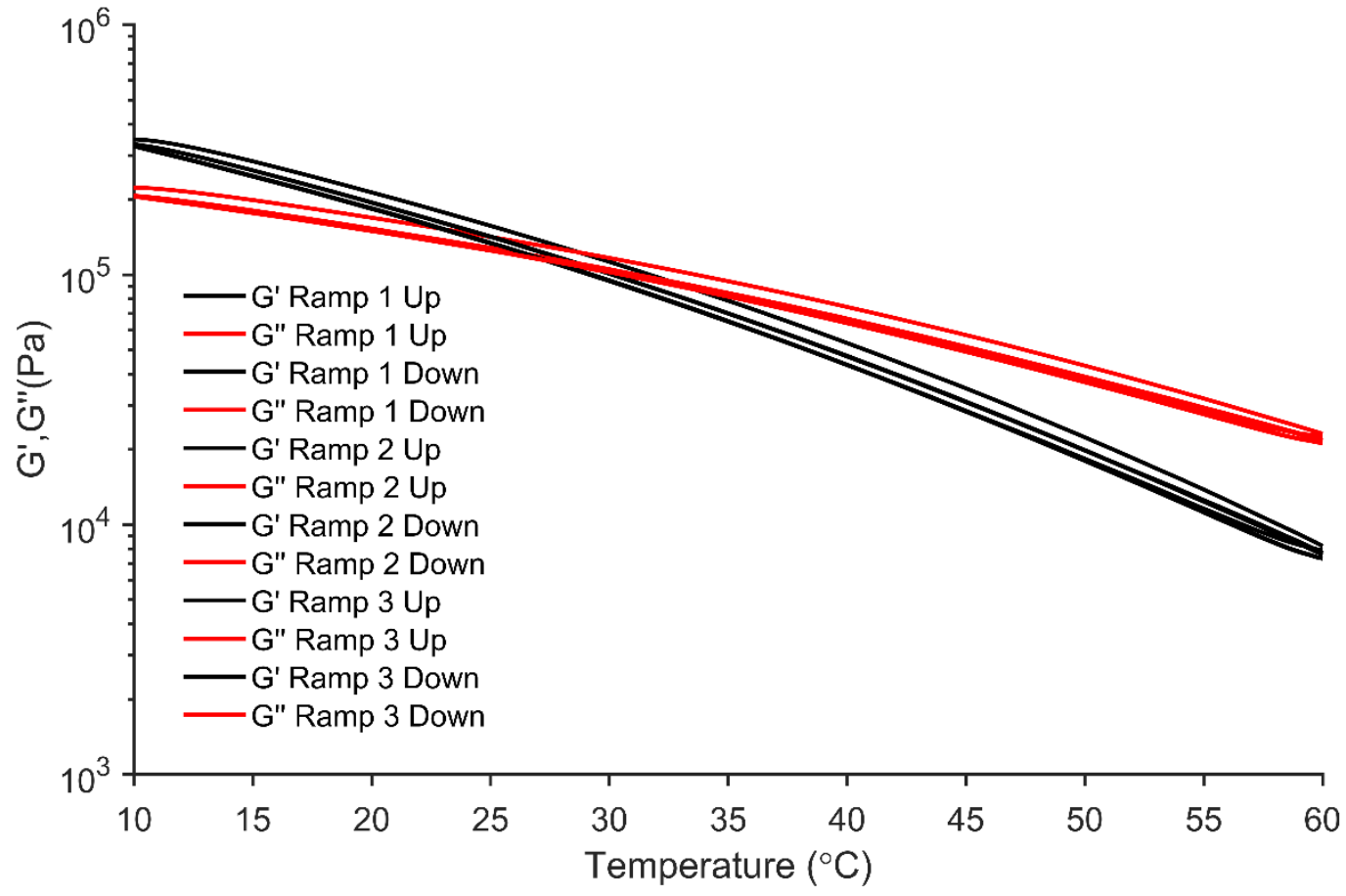

Fig. S12. Rheological Data from three heat-cool cycles for Polymer 10. 


\section{Polymer 11}

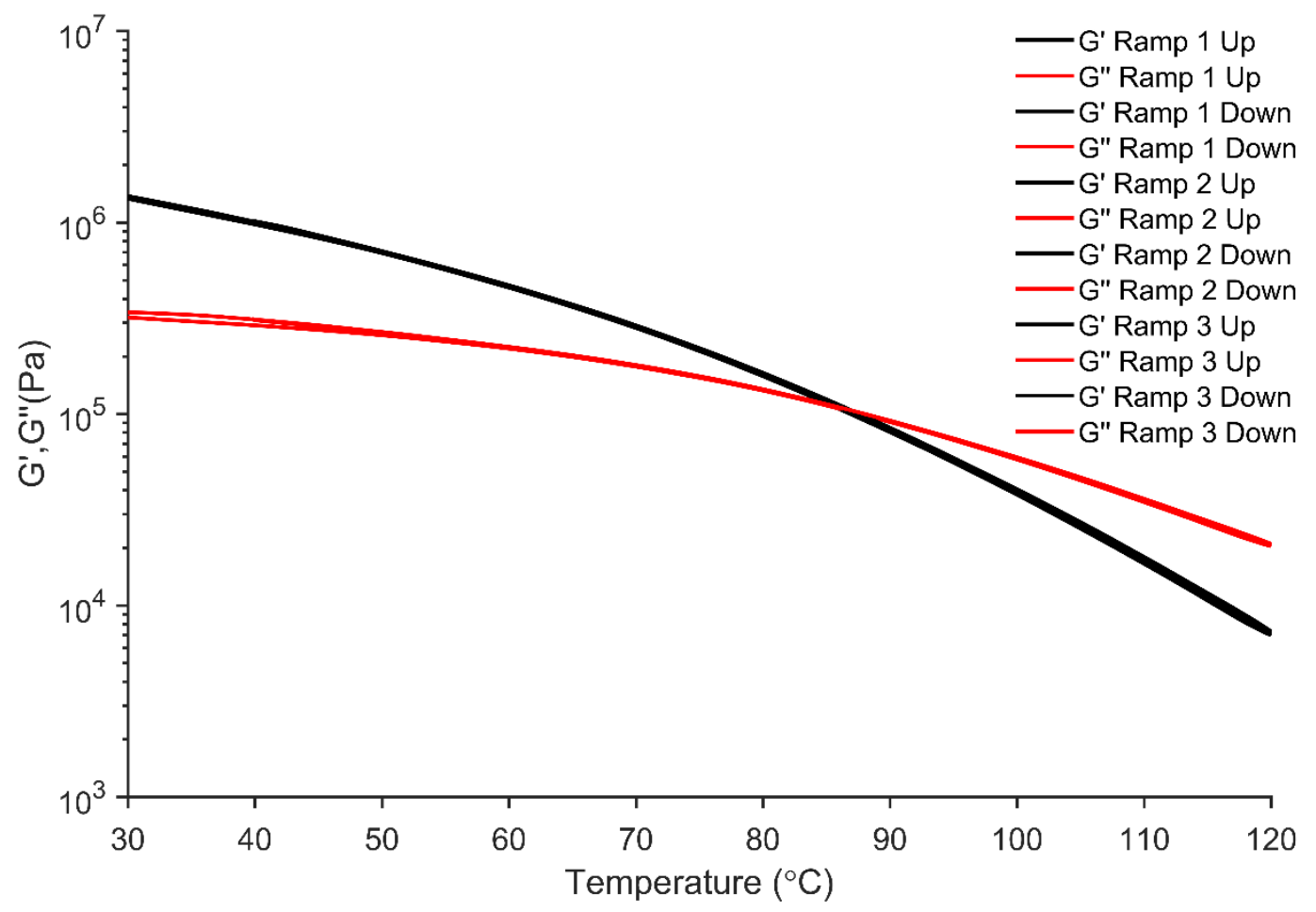

Fig. S13. Rheological Data from three heat-cool cycles for Polymer 11

\section{Polymer 12}

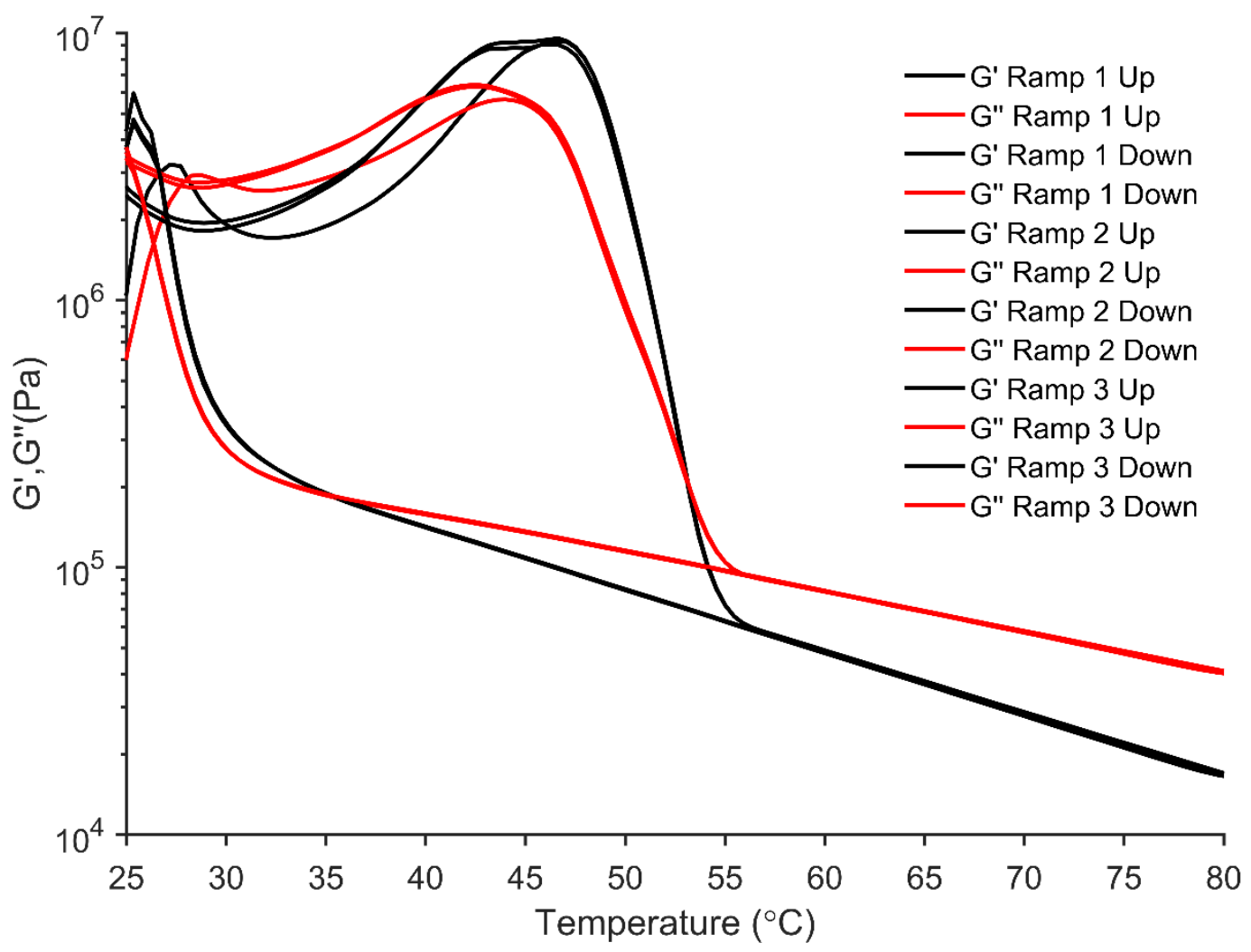

Fig. S14. Rheological Data from three heat-cool cycles for Polymer 12. 
- Polymer 8 - Polymer 9 - Polymer 10 - Polymer 11 - Polymer 12
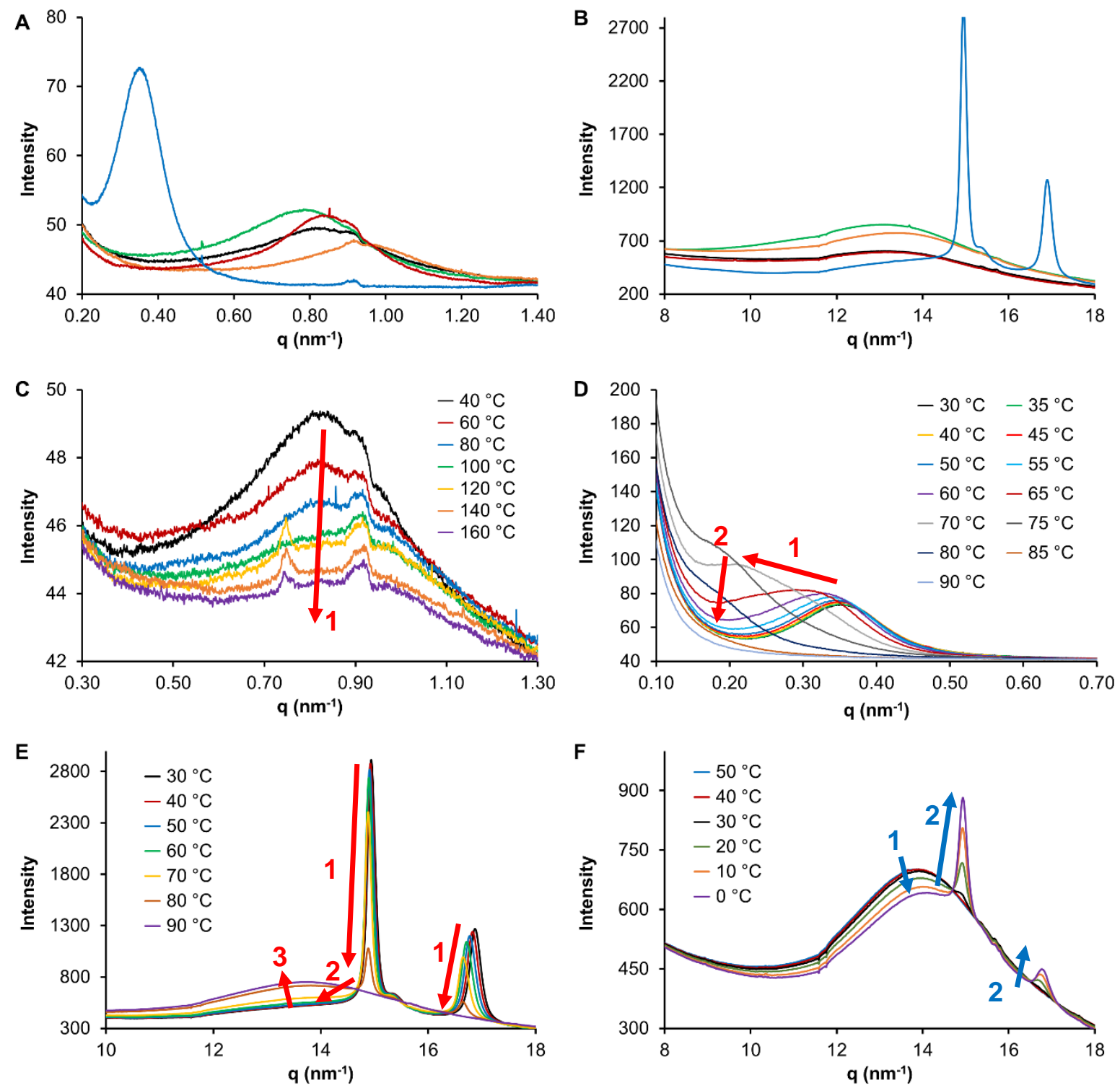

Fig. S15. (A) SAXS and (B) WAXS analysis of polymers 8 - 12; 2 D diffraction data of $(C)$ VT SAXS of polymer 8 during a heat ramp; (D) VT SAXS of polymer 12 during a heat ramp; VT WAXS of polymer 12 during $(E)$ heating ramp and $(F)$ cooling ramp. 


\section{Lap Shear Adhesion Measurements for Samples for Adhesive Series 1 with}

\section{Different Isocyanate linkers}

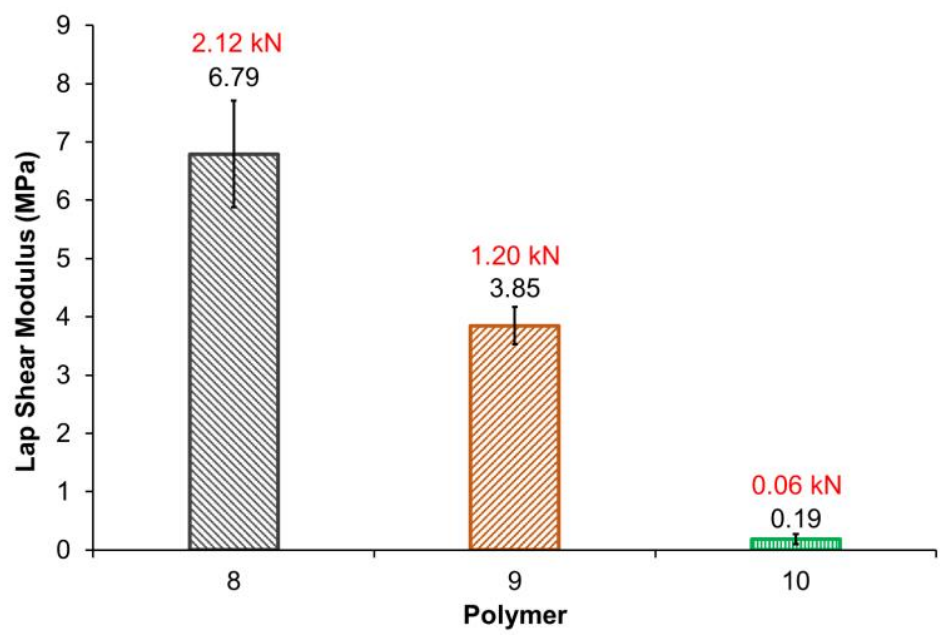

Fig. S16. The lap shear modulus taken from the lap shear adhesion samples of polymers 8, 9 and 10, adhered at $140{ }^{\circ} \mathrm{C}$. Values in red indicate the force at break recorded and used to calculate the lap shear modulus in respect to the surface area of adhesion. Errors were calculated from the standard deviation $(n=5)$.

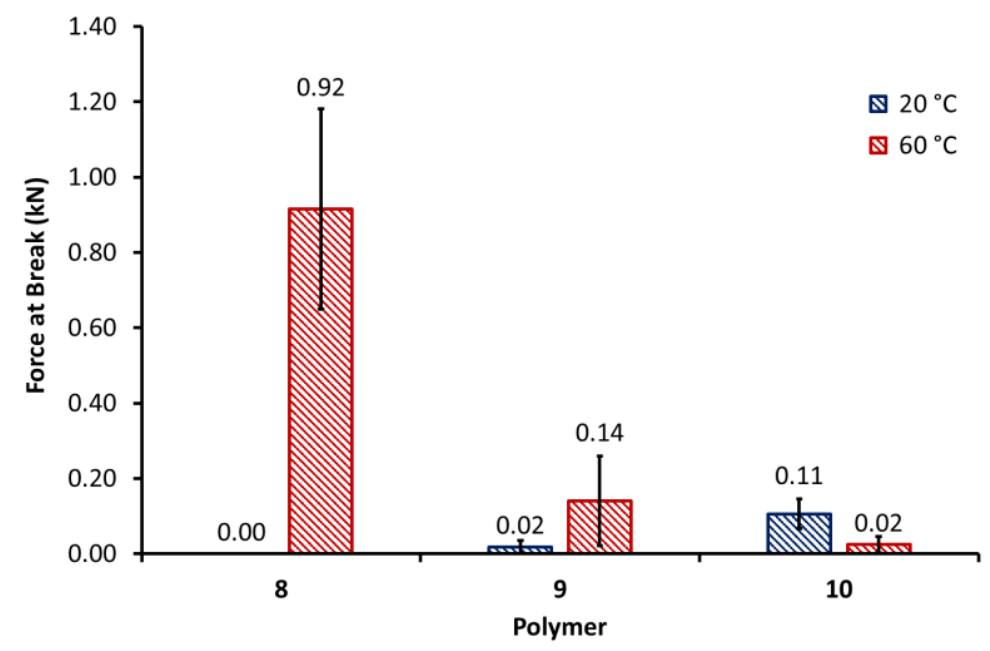

Fig. S17. The averaged force required to break the adhesive bond between two butt-tensile cylinders adhered at different temperatures for polymers 8, 9 and 10 containing different isocyanate linkers. Errors show the standard deviation for the average $(n=5)$. 


\section{Full DSC thermograms}

\section{Polymer 8}

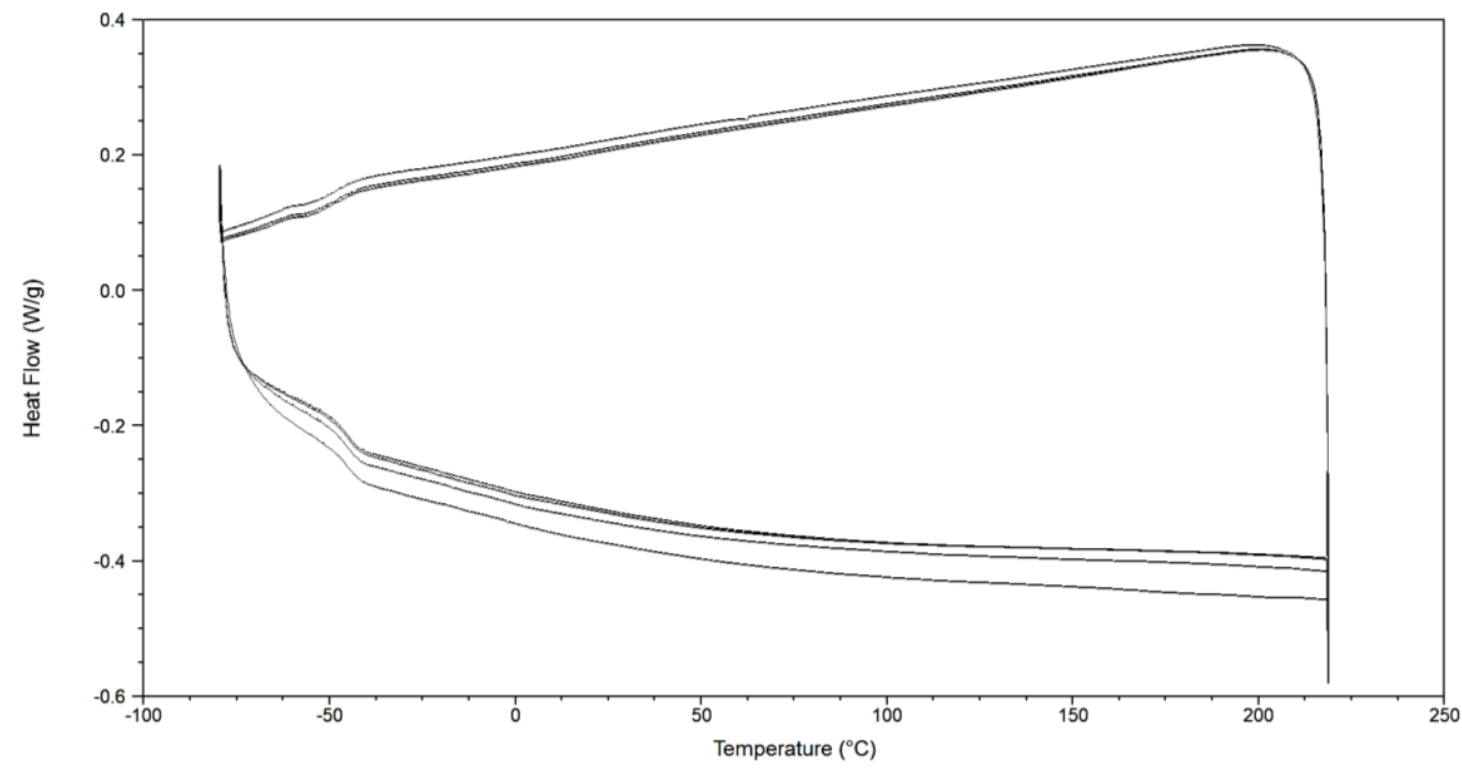

Fig. S18. DSC thermogram showing the three heat-cool cycles of polymer 8.

Polymer 9

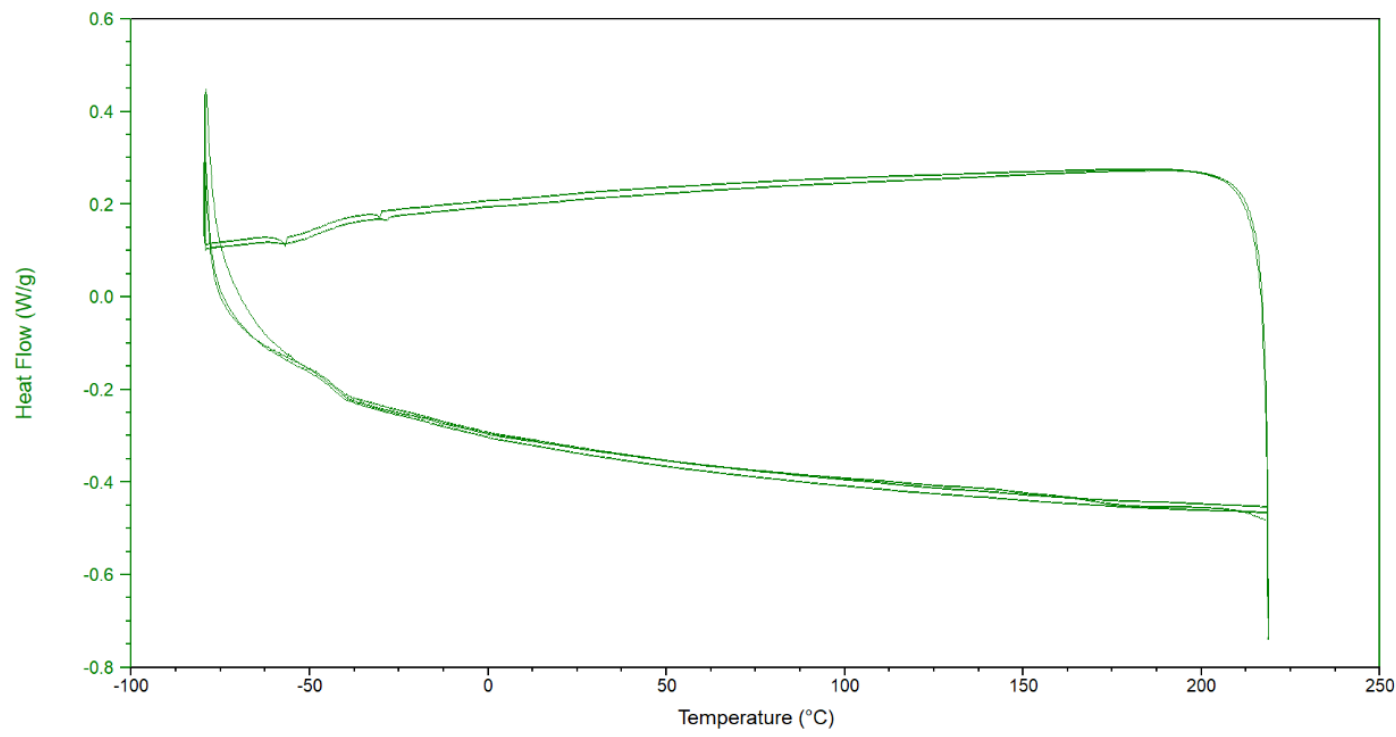

Fig. S19. DSC thermogram showing the three heat-cool cycles of polymer 9. 
Polymer 10

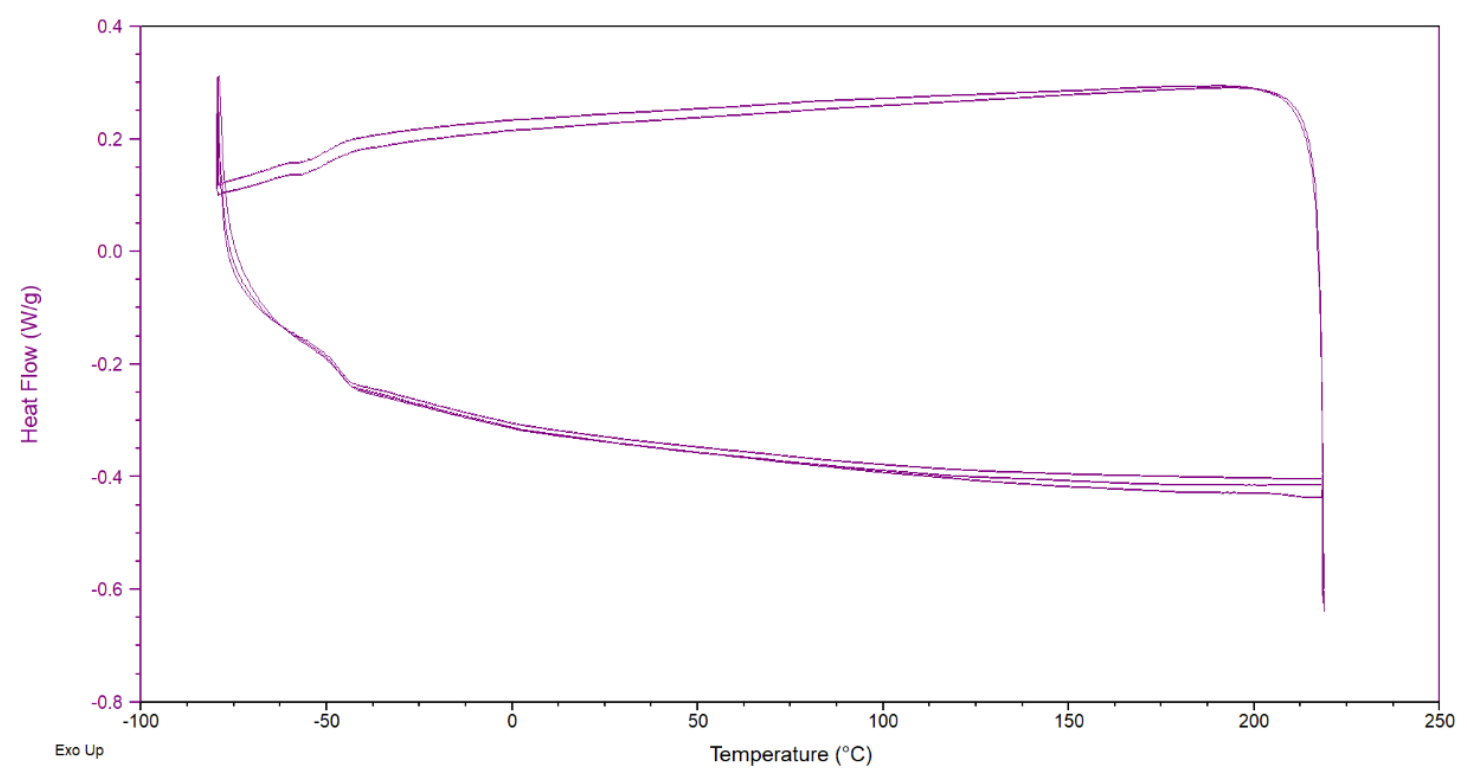

Fig. S20. DSC thermogram showing the three heat-cool cycles of polymer 10.

\section{Polymer 11}

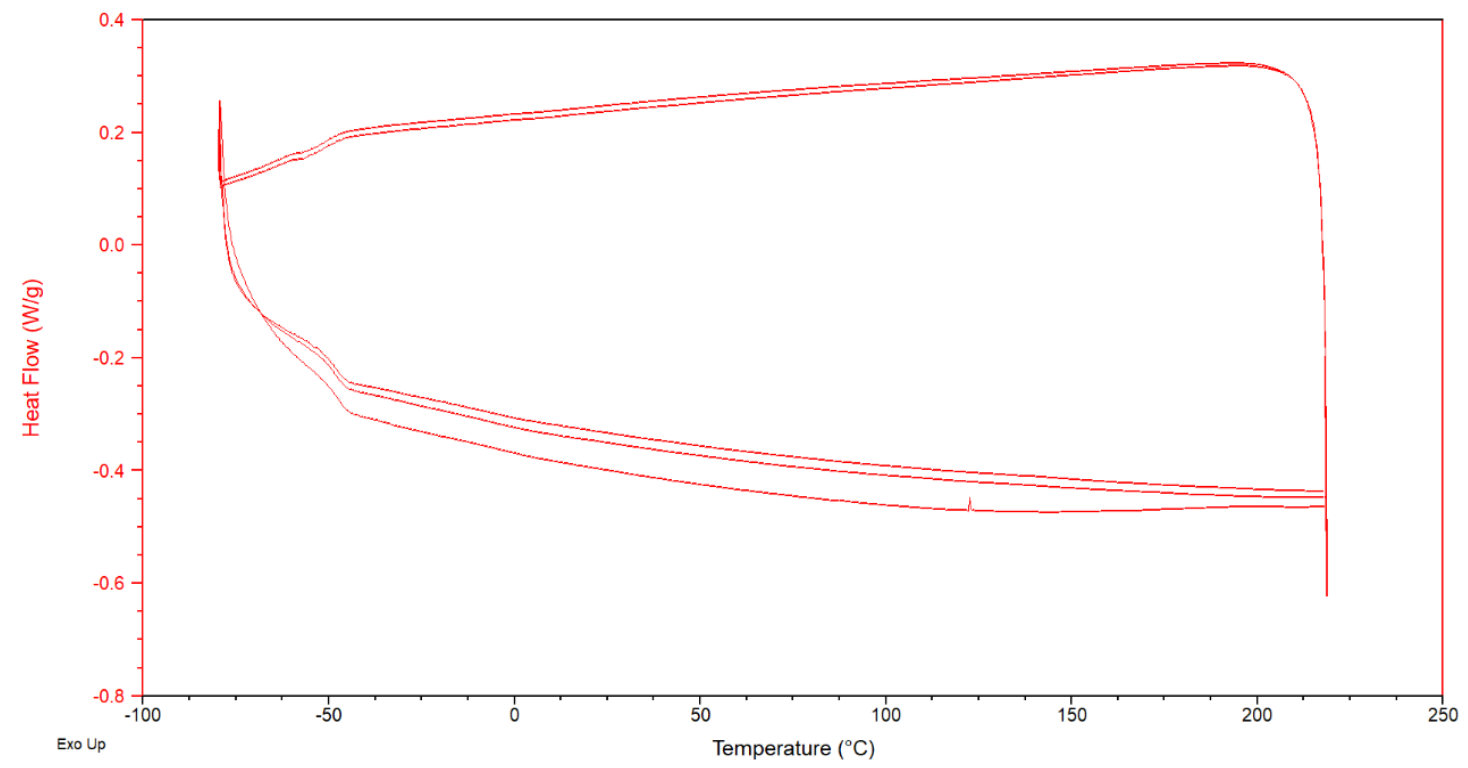

Fig. S21. DSC thermogram showing the three heat-cool cycles of polymer 11 


\section{Polymer 12}

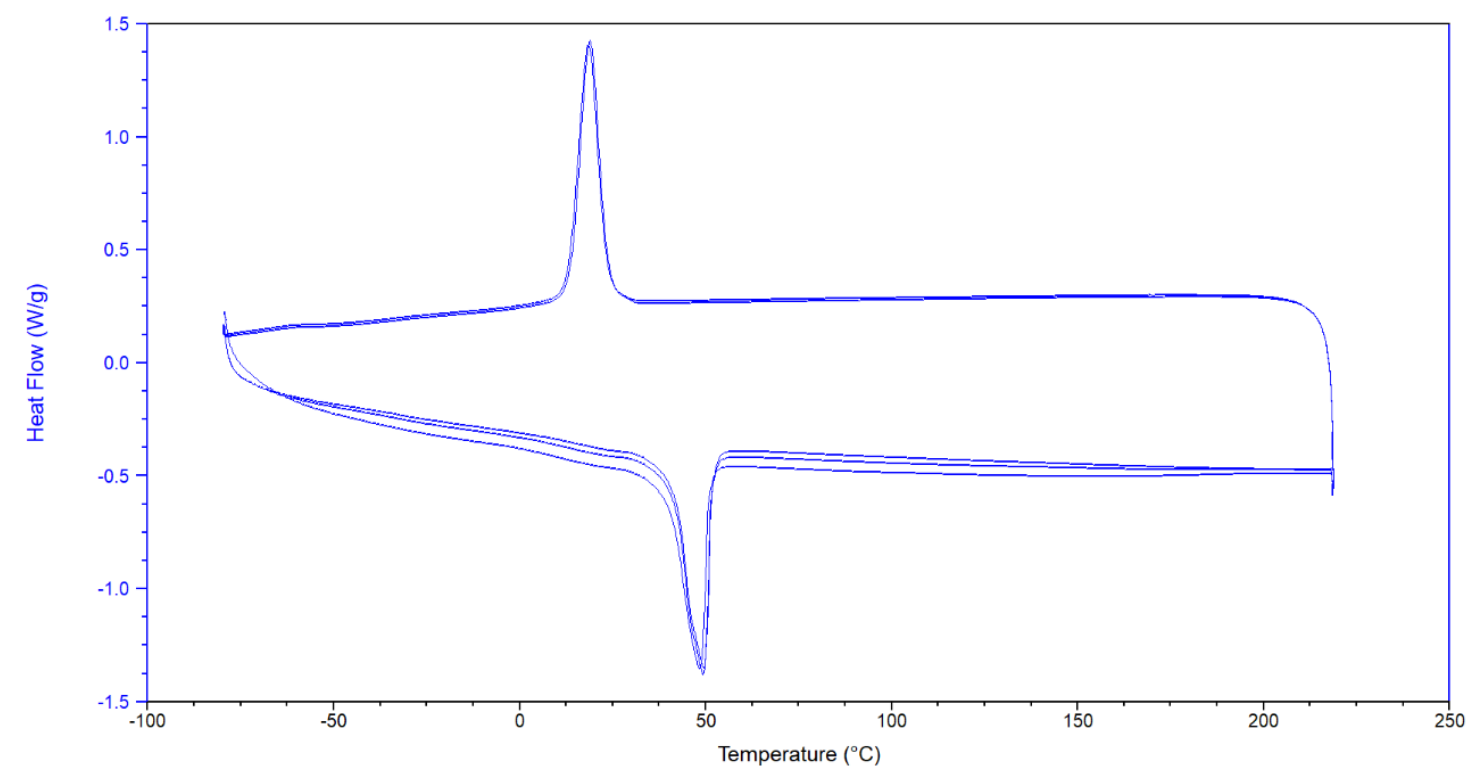

Fig. S22. DSC thermogram showing the three heat-cool cycles of polymer 12.
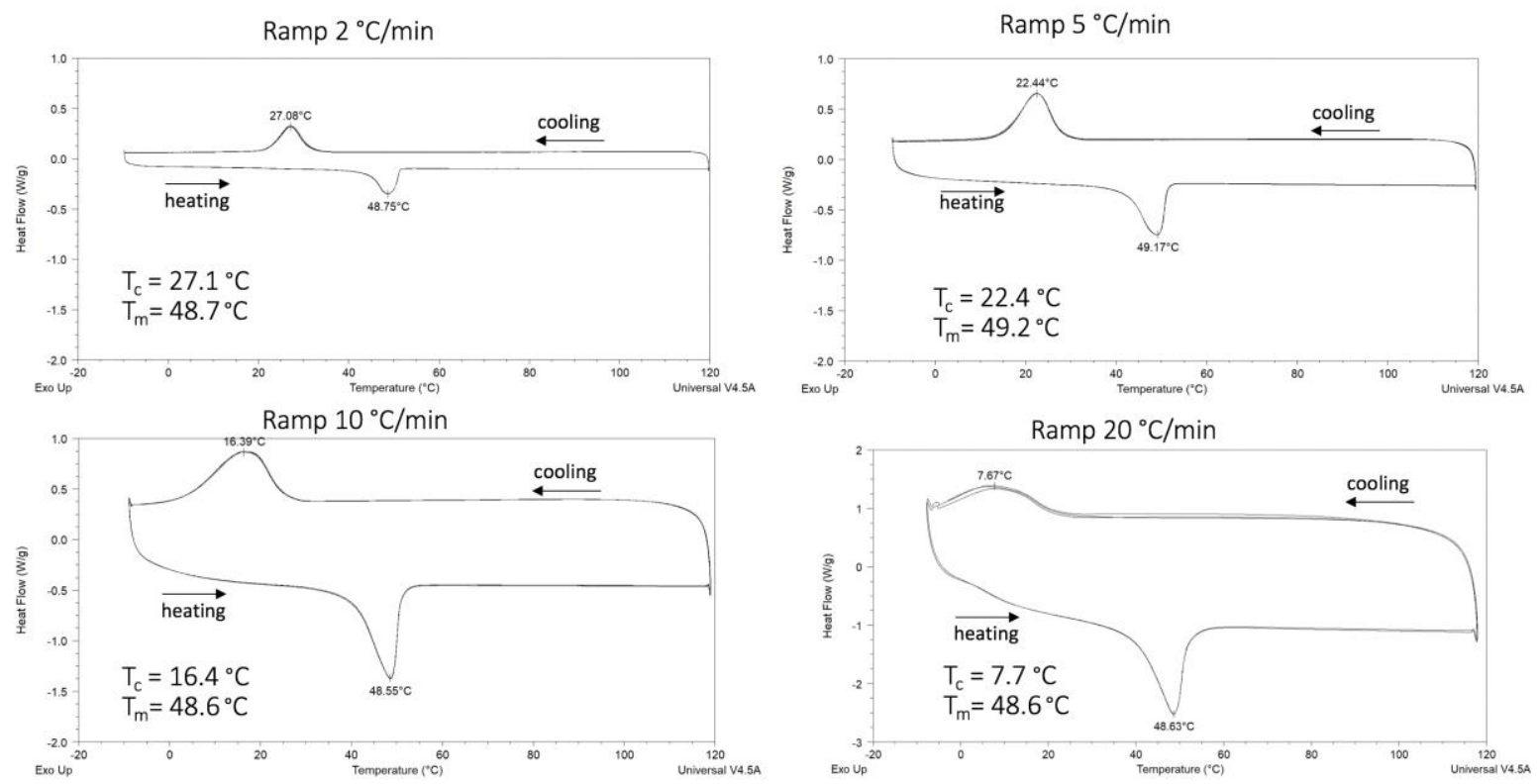

Fig. S23: DSC data for polymer 12 at varying heating/cooling rates. The $T_{c}$ decreases from 27.1 to $7.7{ }^{\circ} \mathrm{C}$ as the ramp rate increase from 2 to $20{ }^{\circ} \mathrm{C} / \mathrm{min}$. The $T_{m}$ is essentially constant $\left(49+/-0.5{ }^{\circ} \mathrm{C}\right)$ at all heating / cooling rates measured. 


\section{$\underline{\text { Stress Strain Curves }}$}

Polymer 8

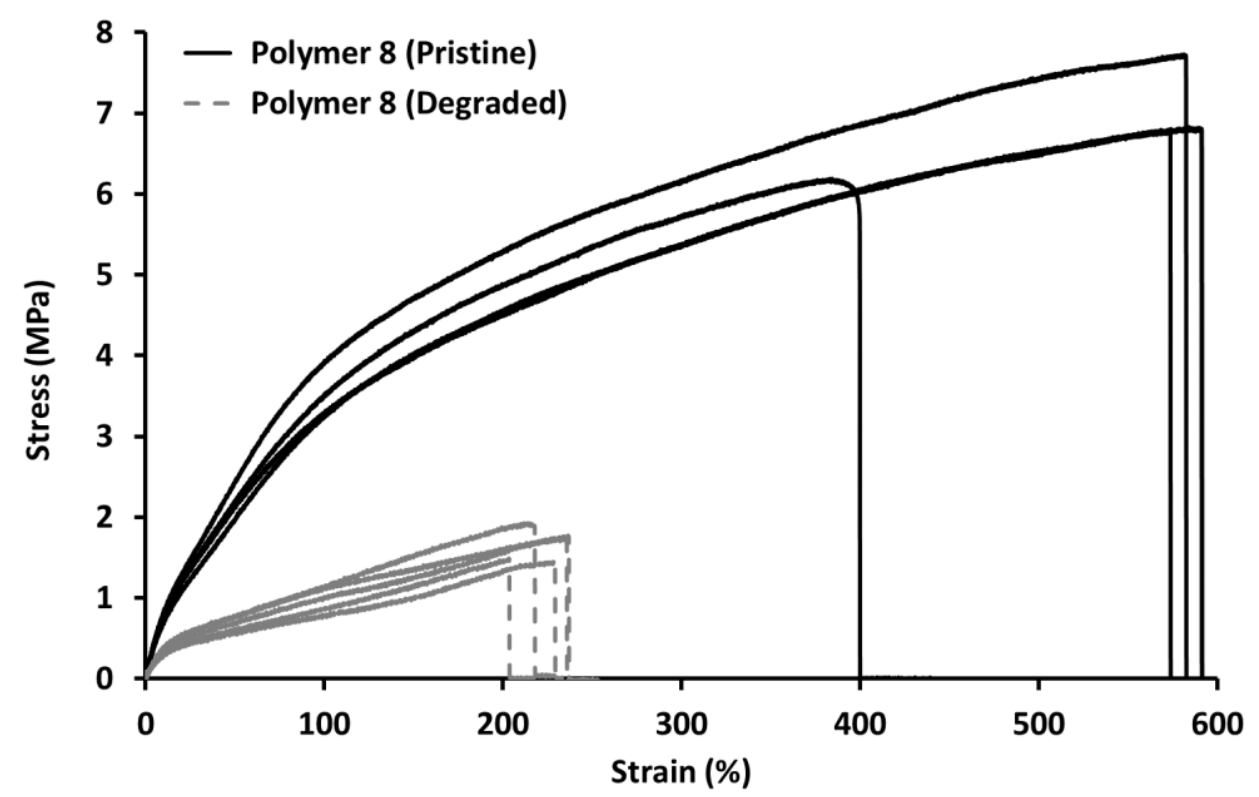

Fig. S23. Five Stress-Strain curves of polymer 8 before (solid) and after (dashed) degradation in $1 M$ TBAF/Acetone for 30 minutes.

Polymer 11

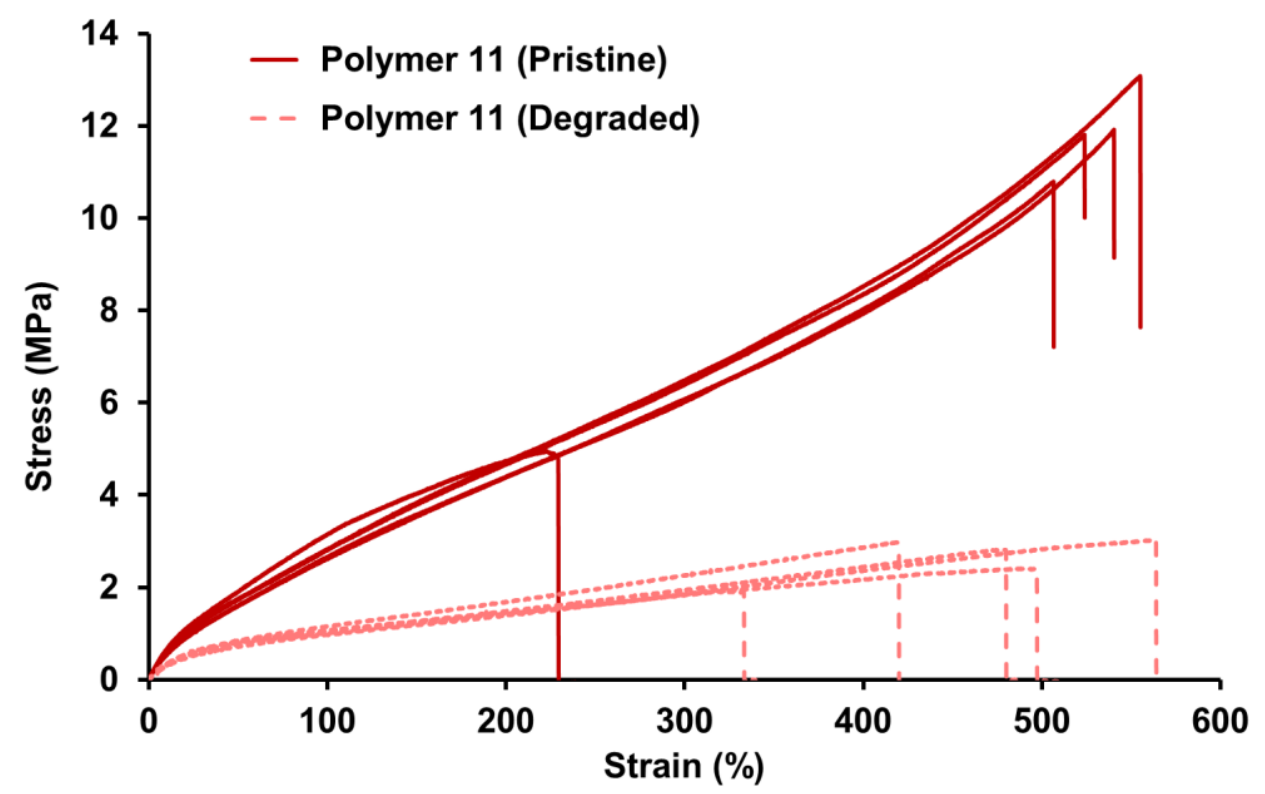

Fig. S24. Five Stress-Strain curves of polymer 11 before (solid) and after (dashed) degradation in $1 M$ TBAF/Acetone for 30 minutes. 
Polymer 12

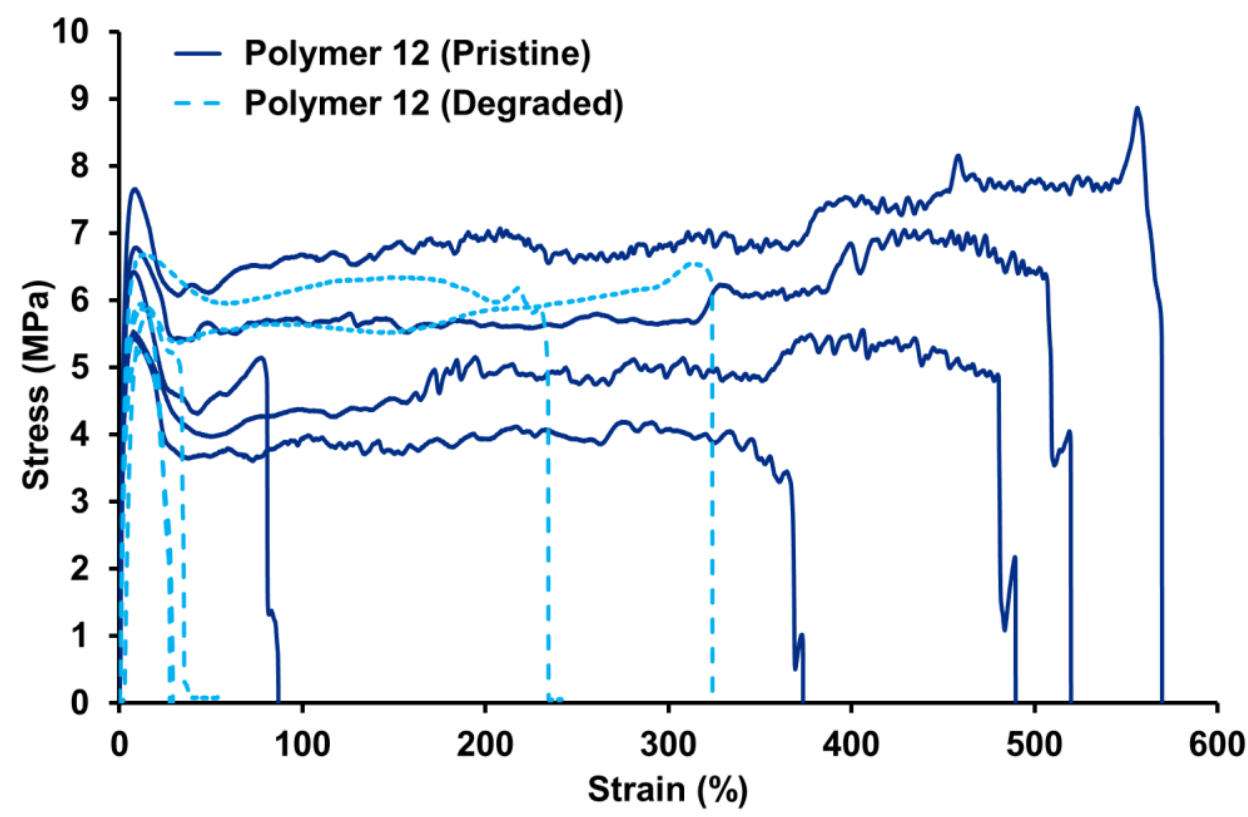

Fig. S25. Five Stress-Strain curves of polymer 12 before (solid) and after (dashed) degradation in $1 M$ TBAF/Acetonitrile for 30 minutes. 


\section{Butt-Tensile Adhesion Temperature Dependant Studies}

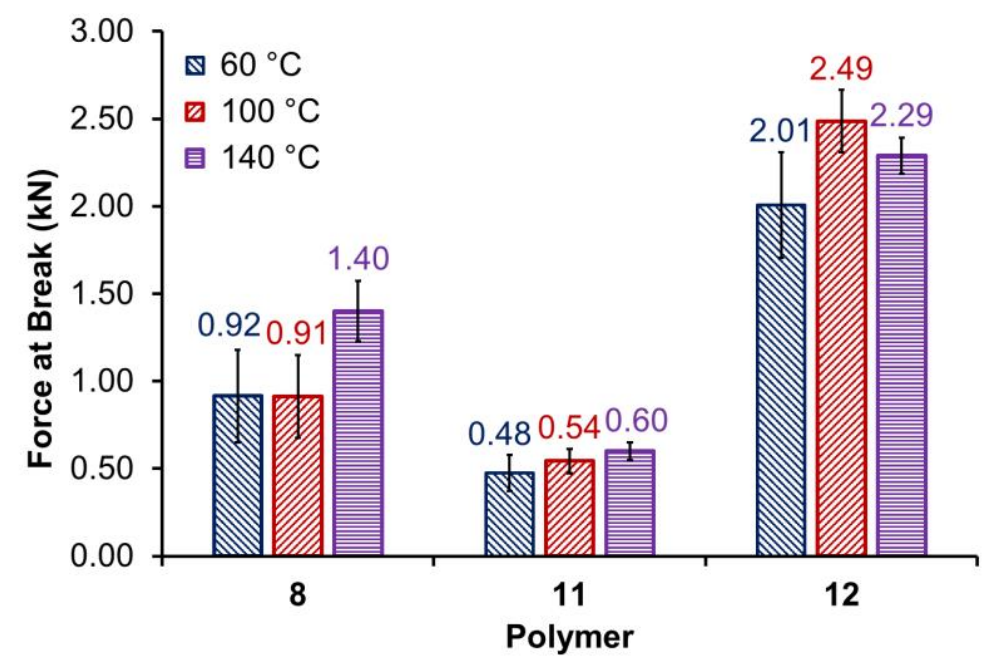

Fig. S26. Butt-Tensile adhesion studies for polymers 8,11 and 12 adhered at different temperatures for 18 hours to determine the optimal conditions for adhesion. Errors were calculated from the standard deviation $(n=4)$ 


\section{$\underline{{ }^{1} \mathrm{H} \text { and }{ }^{13} \mathrm{C} \text { NMR Spectroscopic Analysis: }}$}

\section{Polymer 8}

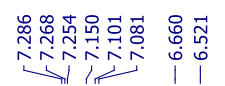

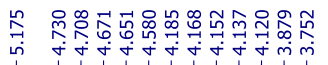

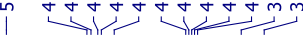

空

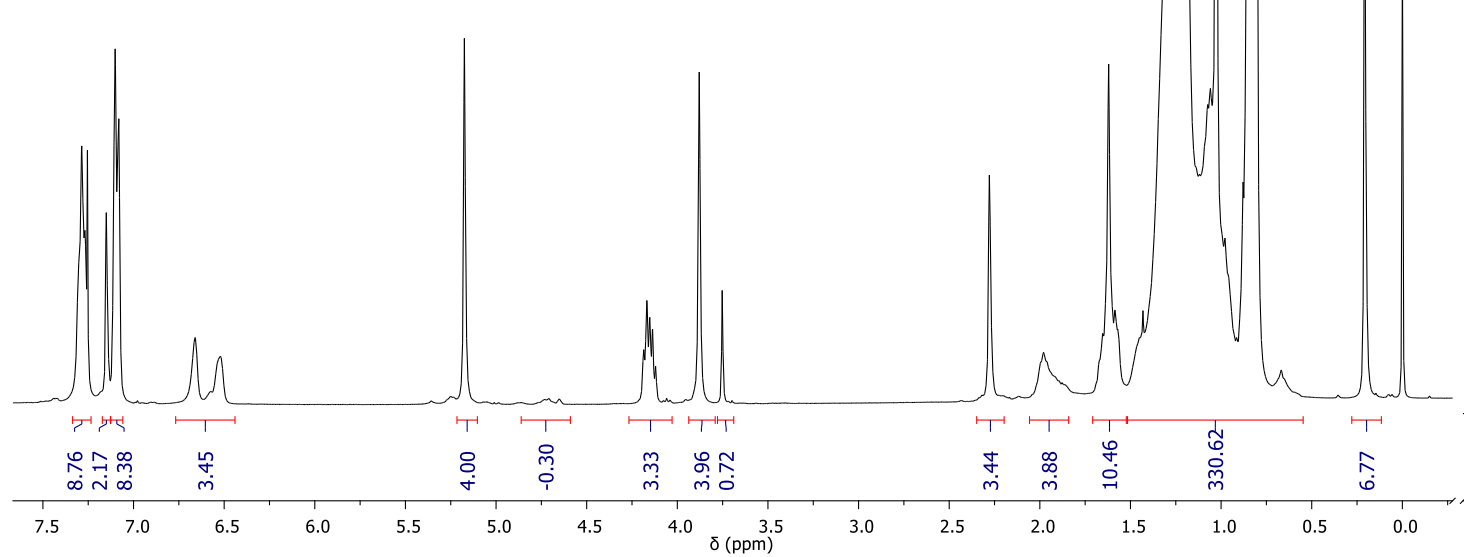

Fig. S27. ${ }^{1}$ H NMR spectroscopic characterisation of Polymer 8.

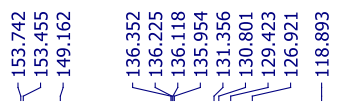

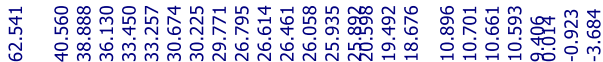

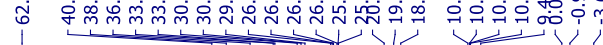

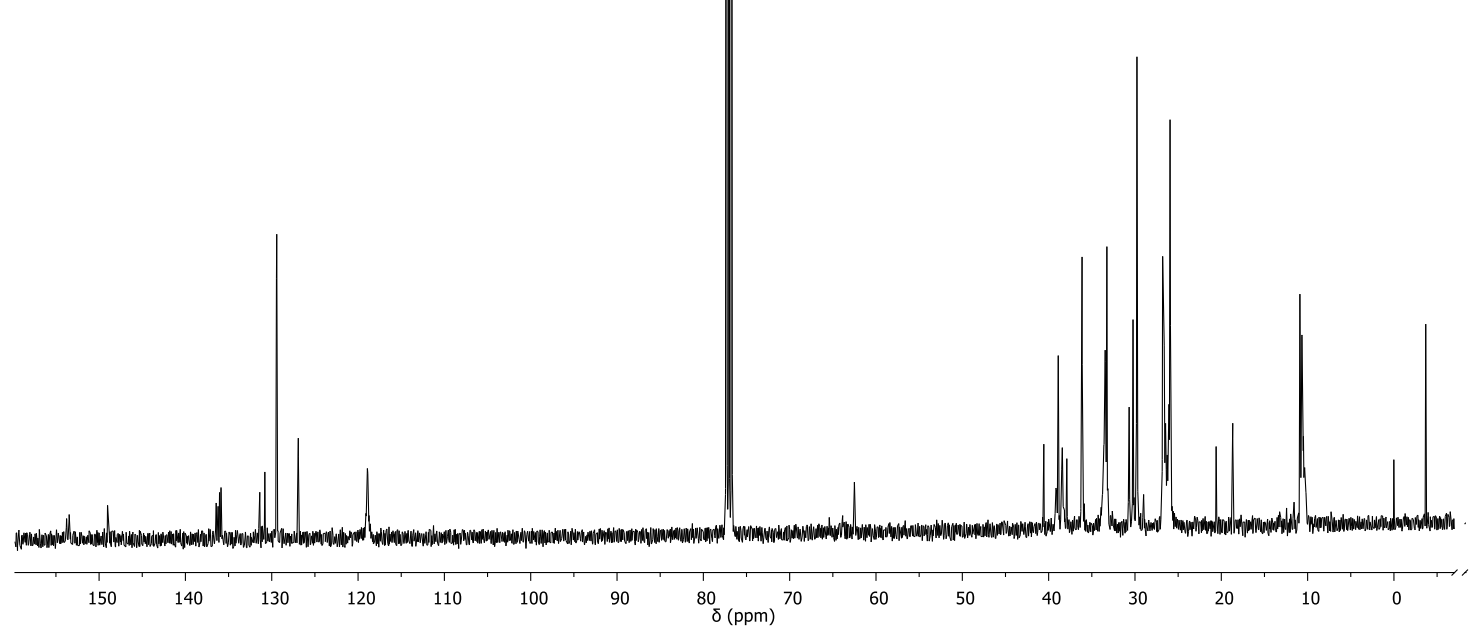

Fig. S28. ${ }^{13}$ C NMR spectroscopic characterisation of Polymer 8. 


\section{Polymer 9}

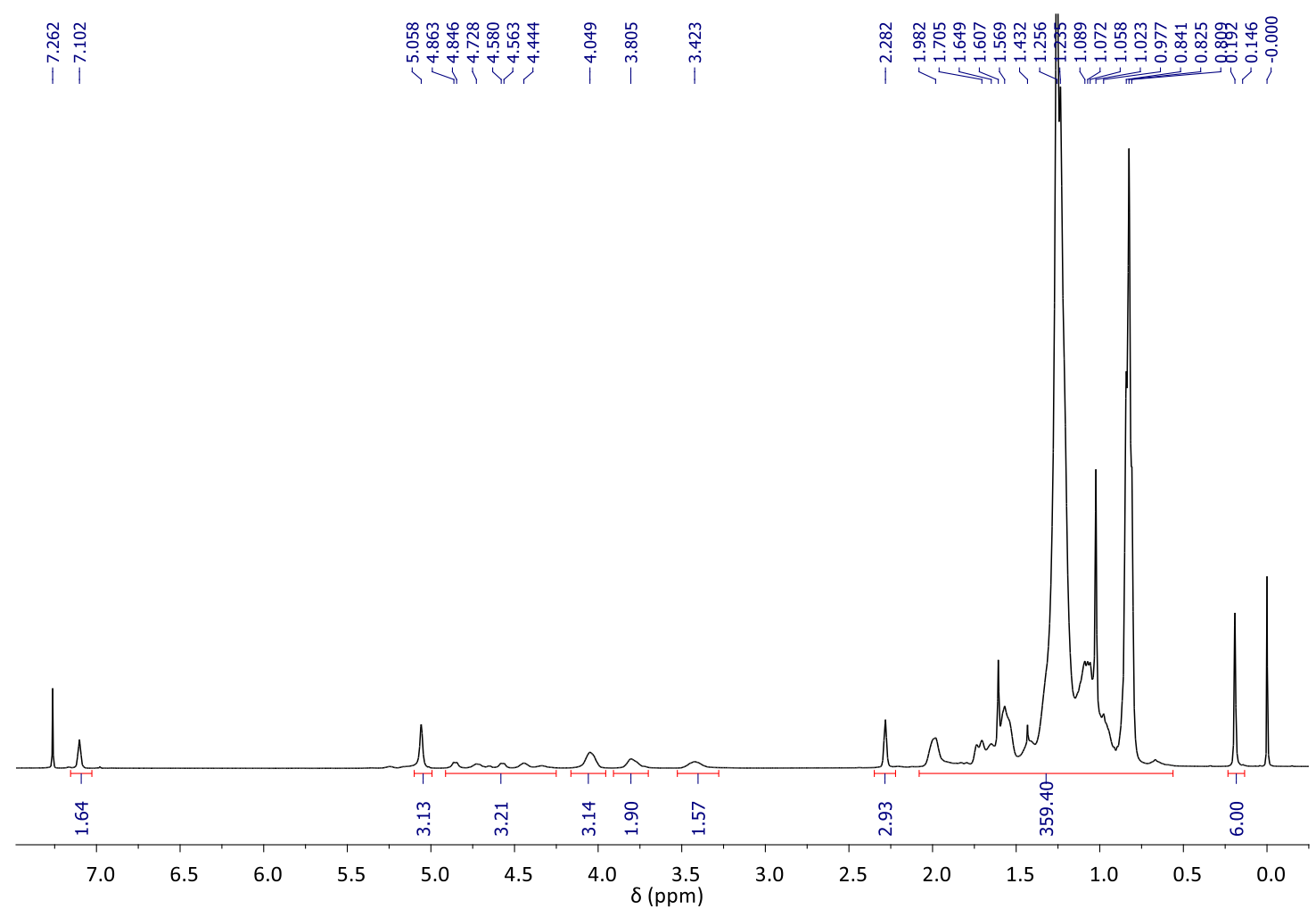

Fig. S30. ${ }^{1}$ H NMR spectroscopic characterisation of Polymer 9.

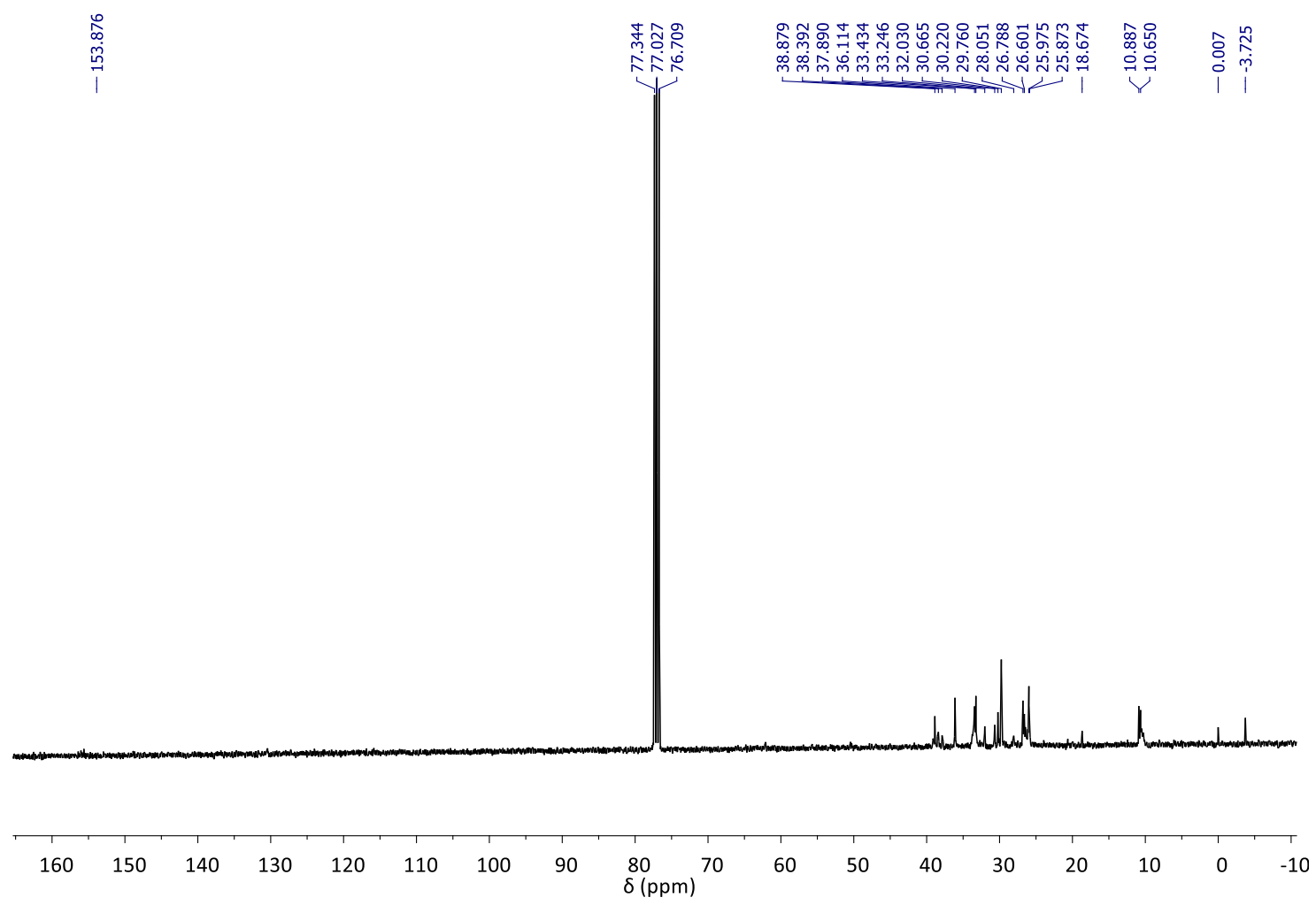

Fig. S29. ${ }^{13}$ C NMR spectroscopic characterisation of Polymer 9. 
Polymer 10

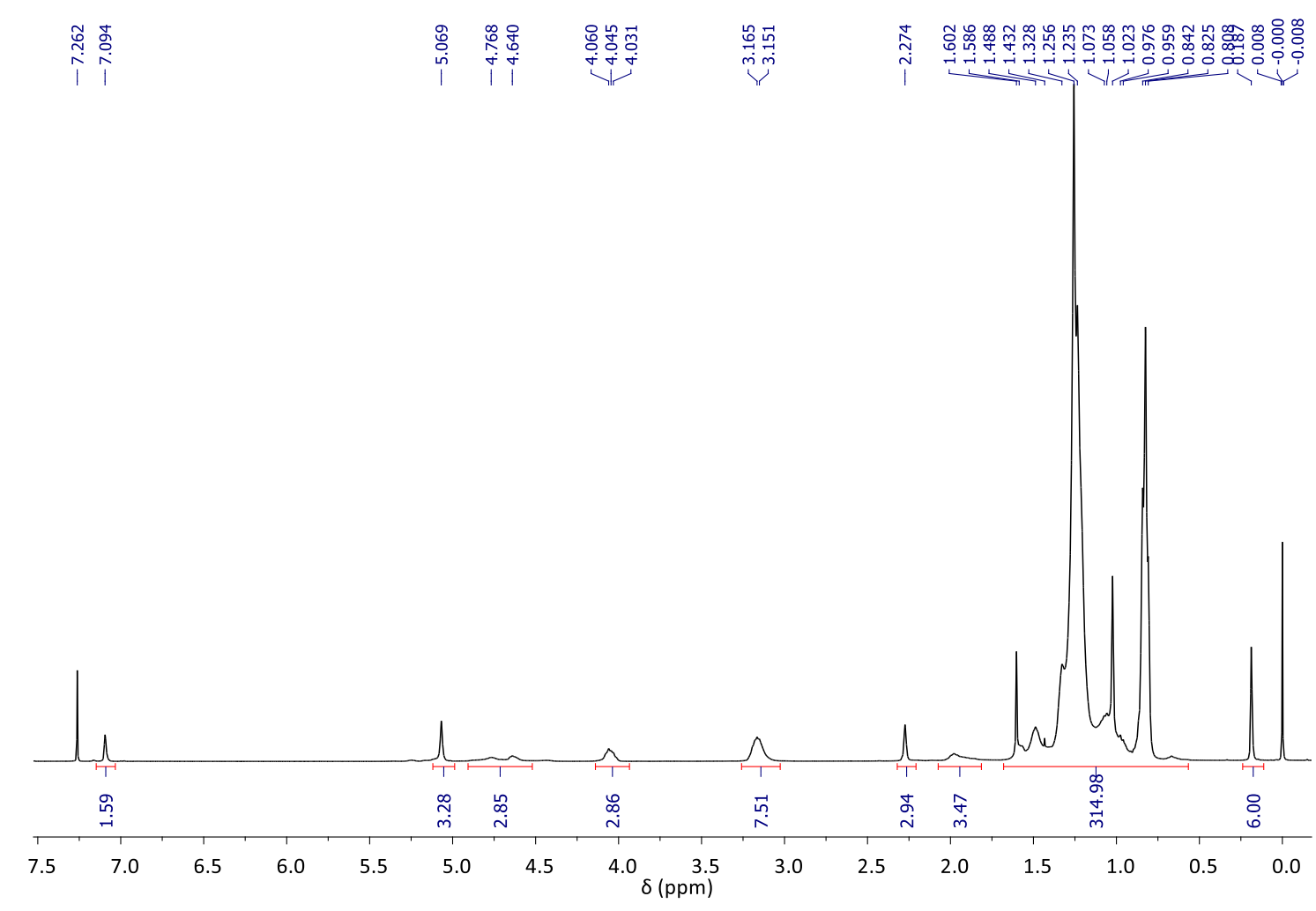

Fig. S30. ${ }^{1}$ H NMR spectroscopic characterisation of Polymer 10.

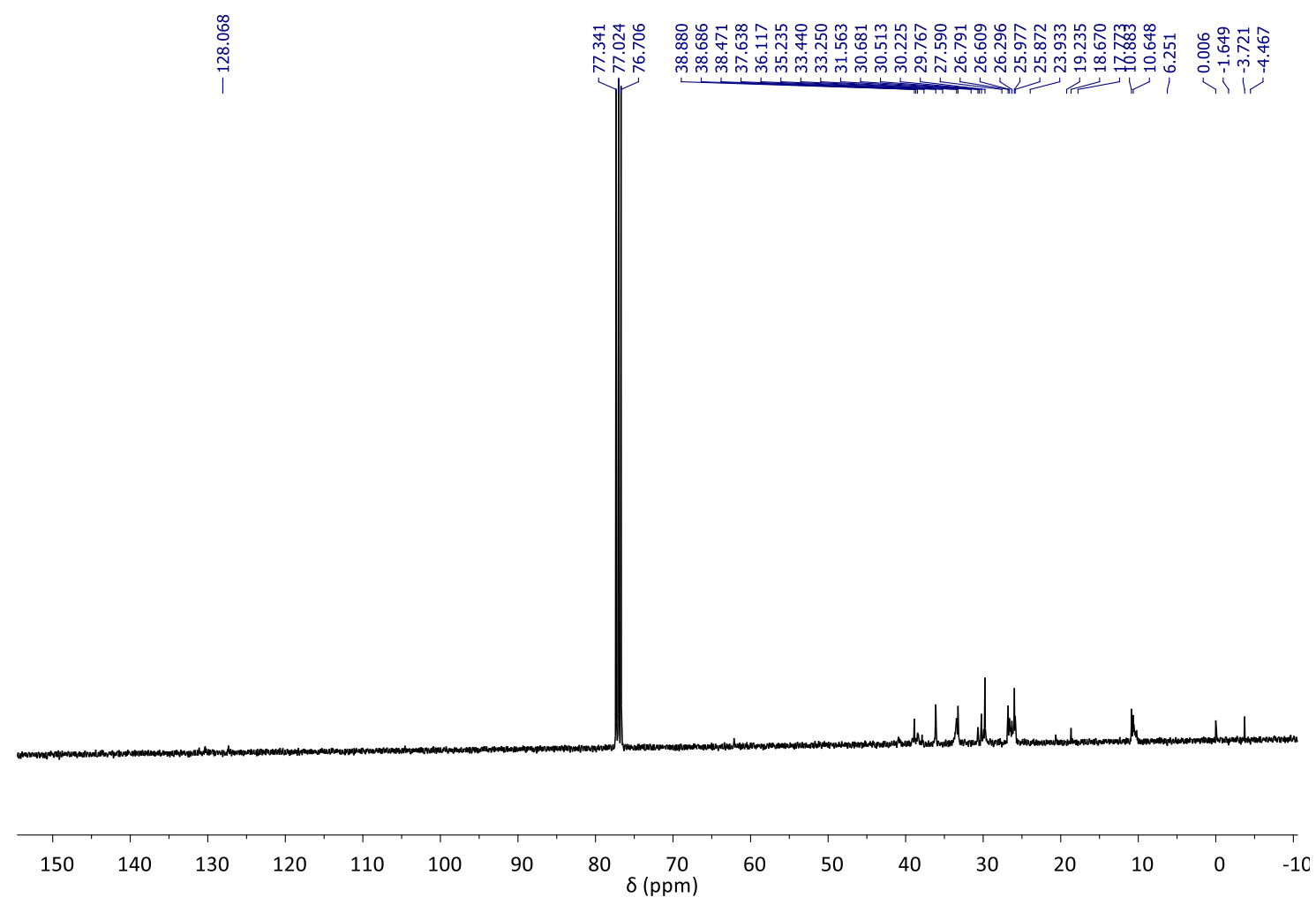

Fig. S31. ${ }^{13}$ C NMR spectroscopic characterisation of Polymer 10 


\section{Polymer 11}

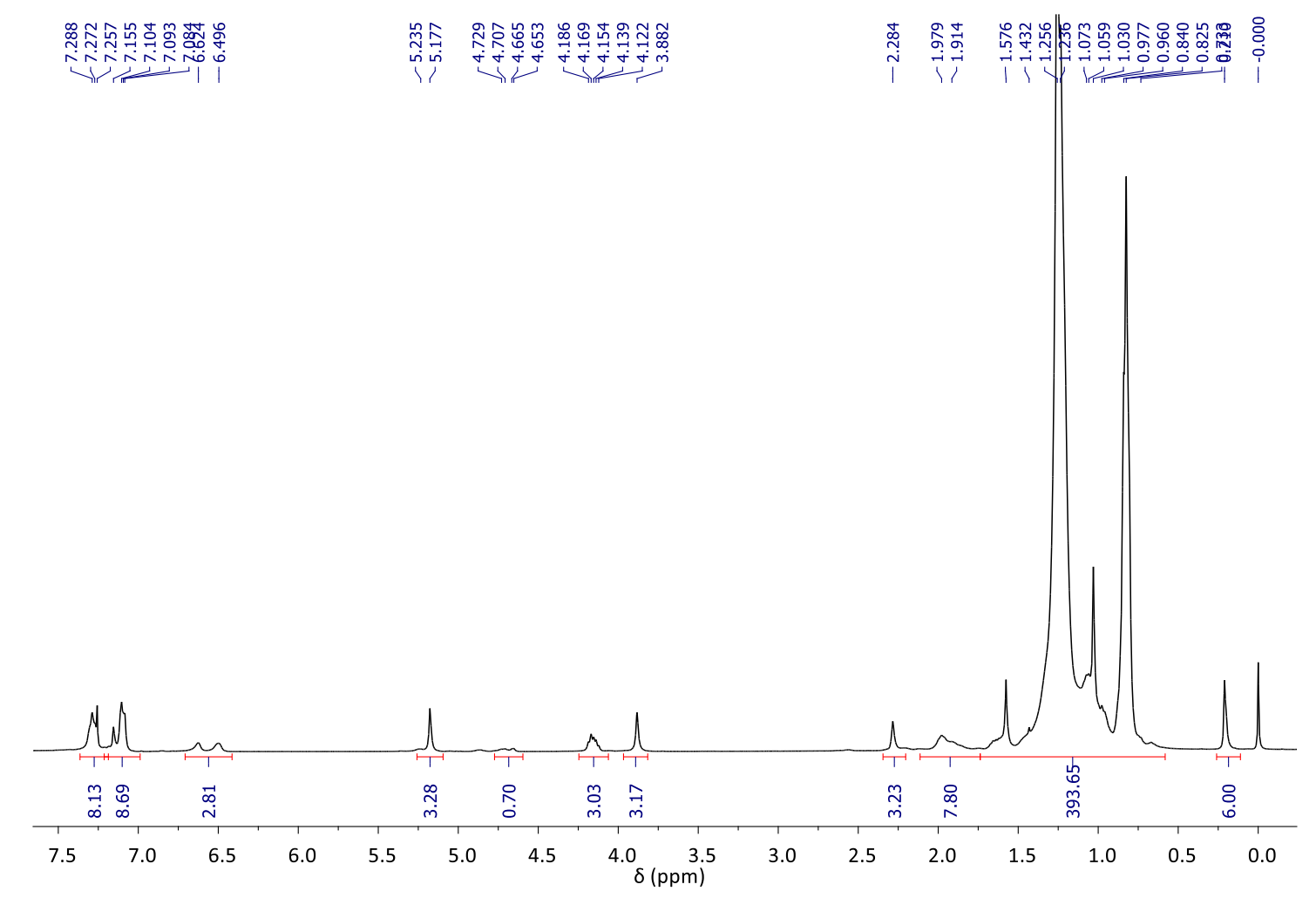

Fig. S32. ${ }^{1} H$ NMR spectroscopic characterisation of Polymer 11.

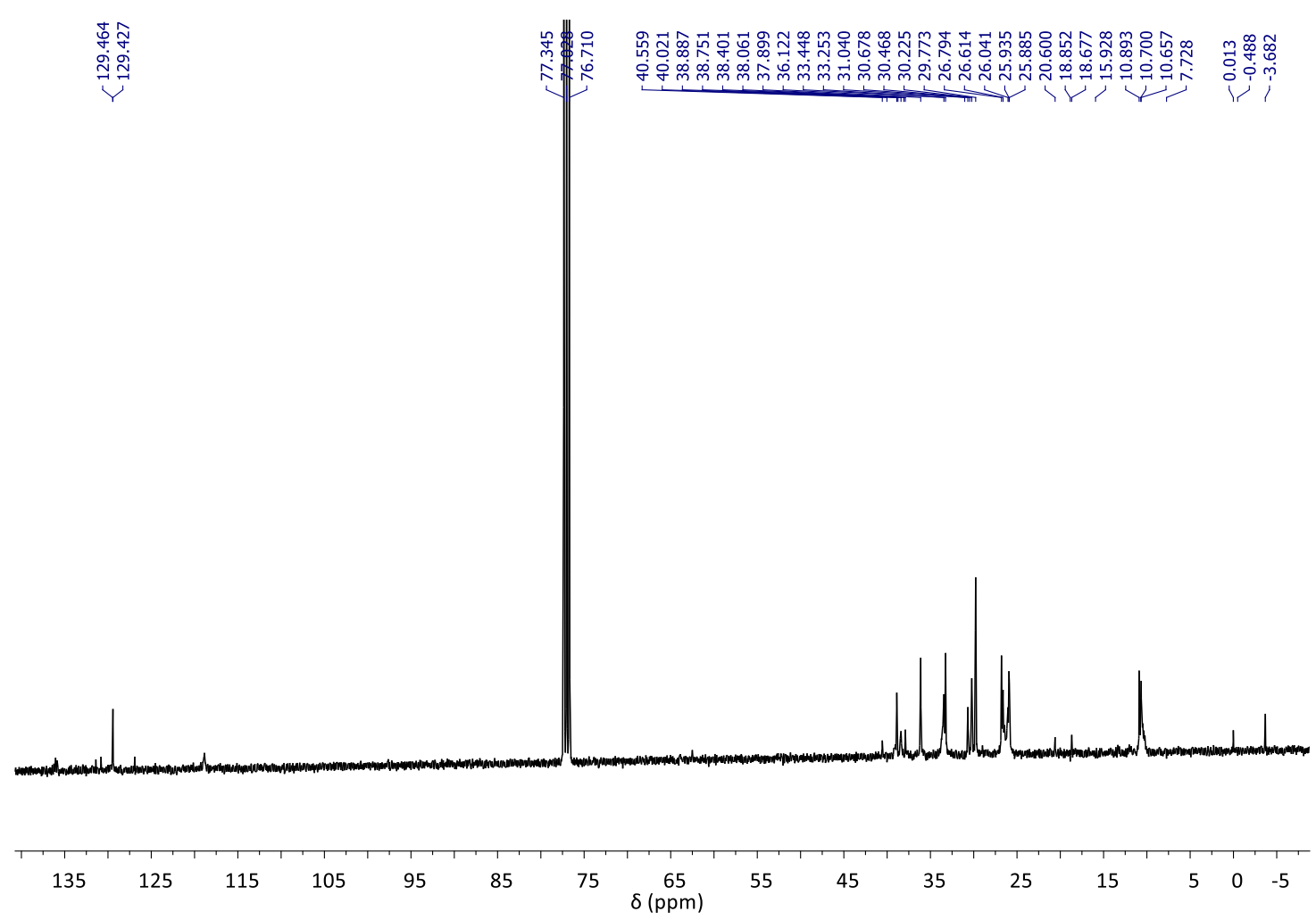

Fig. S33. ${ }^{13}$ C NMR spectroscopic characterisation of Polymer 11. 


\section{Polymer 12}

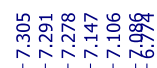

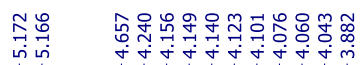

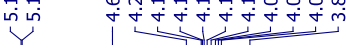

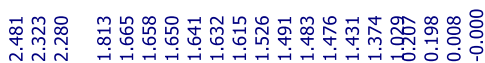

7ricio

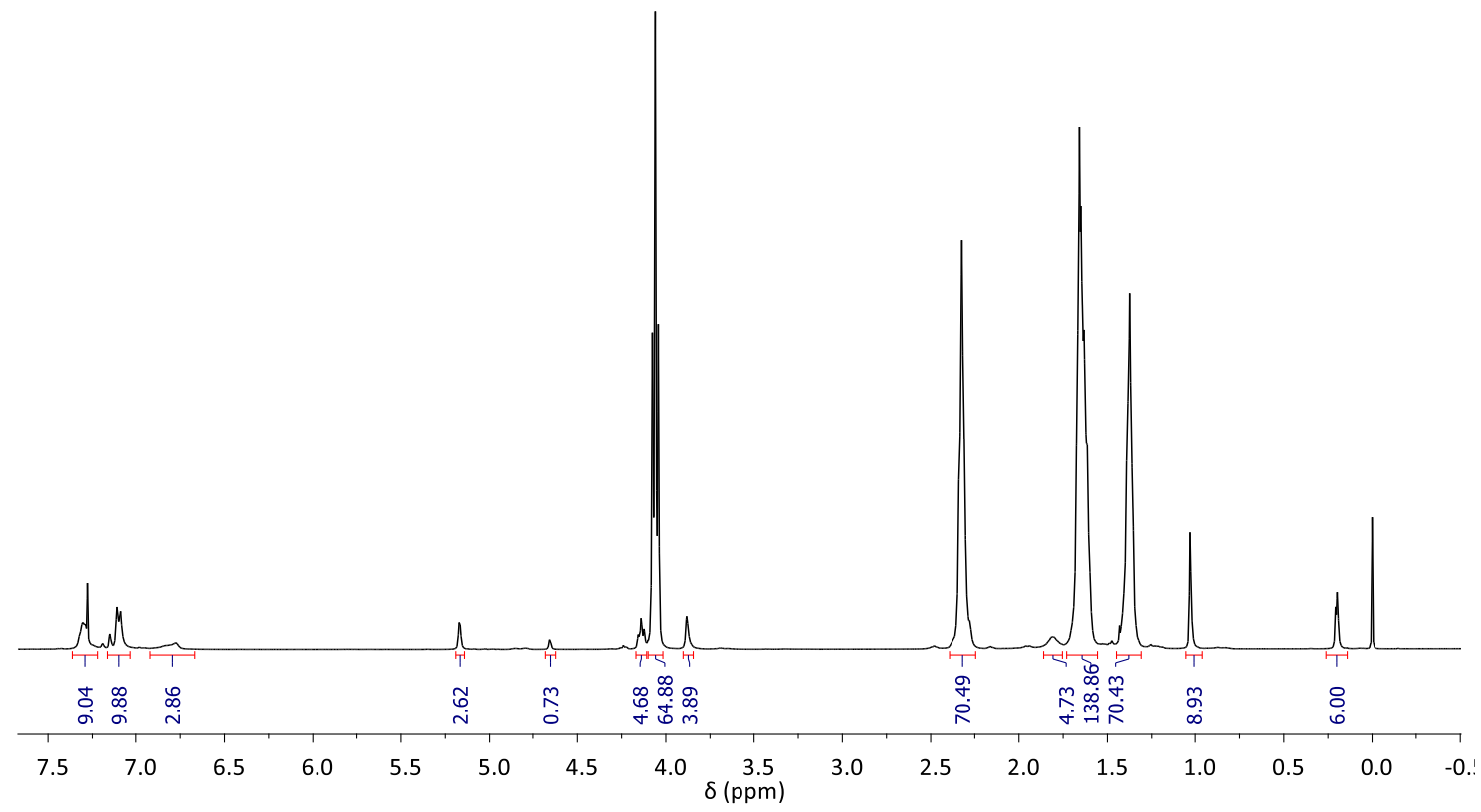

Fig. S34. ${ }^{1}$ H NMR spectroscopic characterisation of Polymer 12.

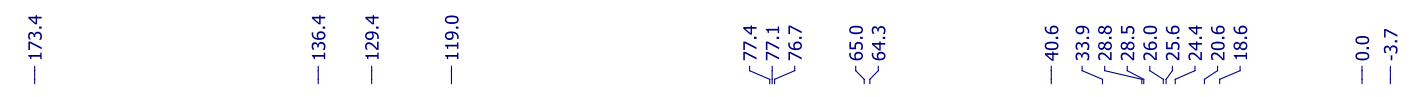

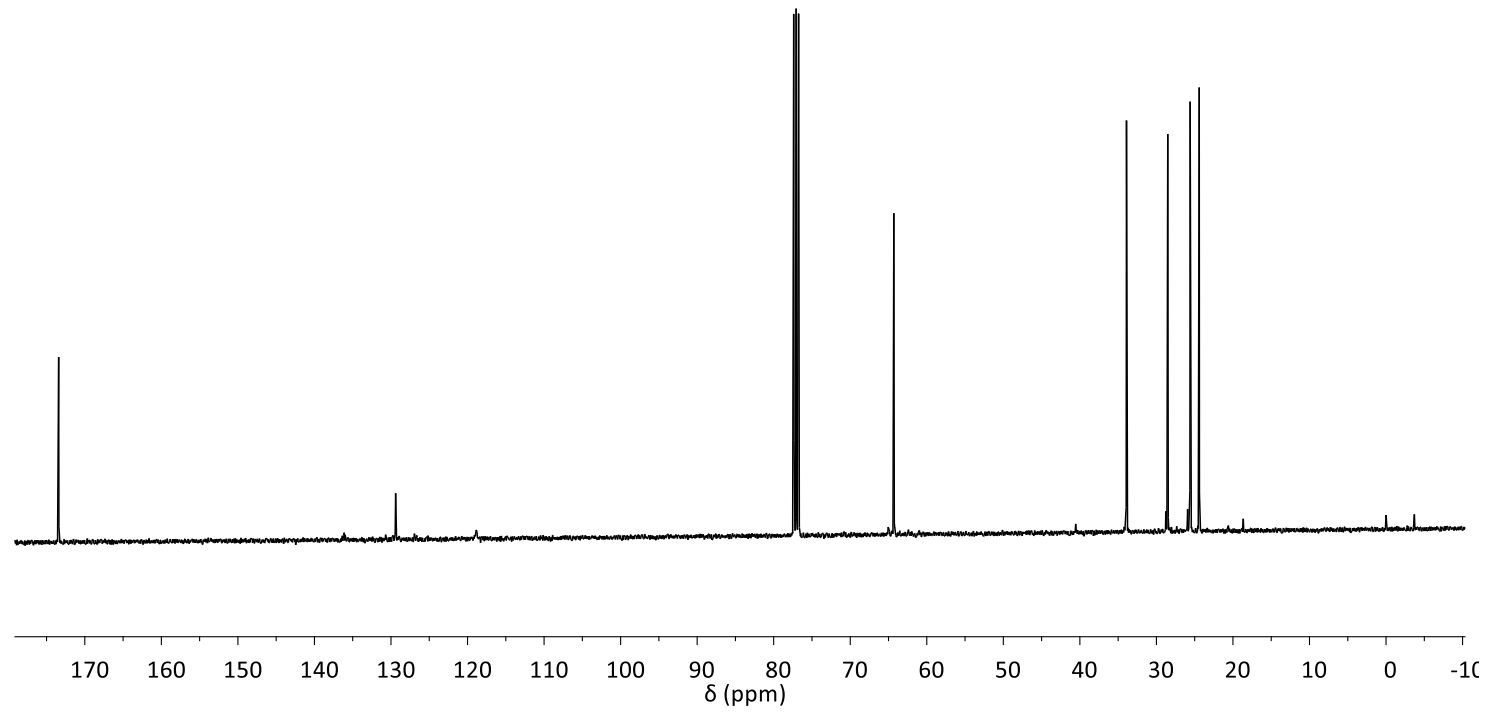

Fig. S35. ${ }^{13}$ C NMR spectroscopic characterisation of Polymer 12 
